NBER WORKING PAPER SERIES

\title{
SIGN RESTRICTIONS IN BAYESIAN FAVARS WITH AN APPLICATION TO MONETARY POLICY SHOCKS
}

\author{
Pooyan Amir Ahmadi \\ Harald Uhlig \\ Working Paper 21738 \\ http://www.nber.org/papers/w21738 \\ NATIONAL BUREAU OF ECONOMIC RESEARCH \\ 1050 Massachusetts Avenue \\ Cambridge, MA 02138 \\ November 2015
}

The authors would like to thank without implicating Albrecht Ritschl, Chris Sims, Mark Watson, and Bartosz Mackowiak, workshop participants at Princeton University, Humboldt University, Nottingham University, annual SED meetings in Prague as well as Cyprus, and the NBER summer Institute 2010. This research has been supported by the NSF grant SES-0922550. We are grateful to Paul Ho for research assistance. Part of this research was conducted while the first author was a visiting research scholar at the economics department at Princeton University, or while both were at Humboldt University and the SFB649: their support is gratefully acknowledged. Harald Uhlig has consulting relationships with the Bundesbank, the Federal Reserve Bank of Chicago and the ECB. The usual disclaimer applies. The views expressed herein are those of the authors and do not necessarily reflect the views of the National Bureau of Economic Research.

NBER working papers are circulated for discussion and comment purposes. They have not been peerreviewed or been subject to the review by the NBER Board of Directors that accompanies official NBER publications.

(C) 2015 by Pooyan Amir Ahmadi and Harald Uhlig. All rights reserved. Short sections of text, not to exceed two paragraphs, may be quoted without explicit permission provided that full credit, including (C) notice, is given to the source. 
Sign Restrictions in Bayesian FaVARs with an Application to Monetary Policy Shocks Pooyan Amir Ahmadi and Harald Uhlig

NBER Working Paper No. 21738

November 2015

JEL No. C22,E5

\begin{abstract}
$\underline{\text { ABSTRACT }}$
We propose a novel identification strategy of imposing sign restrictions directly on the impulse responses of a large set of variables in a Bayesian factor-augmented vector autoregression. We conceptualize and formalize conditions under which every additional sign restriction imposed can be qualified as either relevant or irrelevant for structural identification up to a limiting case of point identification. Deriving exact conditions we establish that, (i) in a two dimensional factor model only two out of potentially infinite sign restrictions are relevant and (ii) in contrast, in cases of higher dimension every additional sign restriction can be relevant improving structural identification. The latter result can render our approach a blessing in high dimensions. In an empirical application for the US economy we identify monetary policy shocks imposing conventional wisdom and find modest real effects avoiding various unreasonable responses specifically present and pronounced combining standard recursive identification with FAVARs.
\end{abstract}

Pooyan Amir Ahmadi

Goethe University Frankfurt

Department of Economics

House of Finance

Grüneburgplatz 1

60323 Frankfurt am Main, Germany

amir@econ.uni-frankfurt.de

Harald Uhlig

Dept. of Economics

University of Chicago

1126 E 59th Street

Chicago, IL 60637

and NBER

huhlig@uchicago.edu 


\title{
SIGN RESTRICTIONS IN BAYESIAN FAVARS WITH AN APPLICATION TO MONETARY POLICY SHOCKS ${ }^{1}$
}

\author{
Pooyan Amir-Ahmadi ${ }^{\mathrm{a}}$ AND Harald Uhlig ${ }^{\mathrm{b}}$
}

\begin{abstract}
We propose a novel identification strategy of imposing sign restrictions directly on the impulse responses of a large set of variables in a Bayesian factor-augmented vector autoregression. We conceptualize and formalize conditions under which every additional sign restriction imposed can be qualified as either relevant or irrelevant for structural identification up to a limiting case of point identification. Deriving exact conditions we establish that, (i) in a two dimensional factor model only two out of potentially infinite sign restrictions are relevant and (ii) in contrast, in cases of higher dimension every additional sign restriction can be relevant improving structural identification. The latter result can render our approach a blessing in high dimensions. In an empirical application for the US economy we identify monetary policy shocks imposing conventional wisdom and find modest real effects avoiding various unreasonable responses specifically present and pronounced combining standard recursive identification with FAVARs.
\end{abstract}

Keywords: Bayesian FAVAR, Dynamic Factor Models, Identification, Sign Restriction, Gibbs Sampling, Monetary Policy Shocks.

\section{INTRODUCTION}

What are the dynamic effects of monetary policy shocks on the economy? To answer these type of questions and generally policy analysis in time series settings we suggest combining two recent advances in empirical macroeconomics: factoraugmented VARs (FAVAR) and identification per sign restrictions. We propose and assess a novel identification strategy of imposing sign restrictions directly on the impulse responses of large set of variables to shocks in a Bayesian FAVAR. The novel feature and key strength of our approach is the additional "bite" due to the differences in factor loadings across sets of time series representing, say, "prices" or "output" resulting in a further minimized and refined identified set. As an important advantage, our procedure does not require a structural interpretation of the factors themselves or adding observables to the list of factors ${ }^{1}$. For the application to monetary policy shocks we impose the conventional wisdom regarding the responses of prices, monetary aggregates, spreads and interest rates.

\footnotetext{
${ }^{1}$ The authors would like to thank without implicating Albrecht Ritschl, Chris Sims, Mark Watson, and Bartosz Maćkowiak, workshop participants at Princeton University, Humboldt University, Nottingham University, annual SED meetings in Prague as well as Cyprus, and the NBER summer Institute 2010. This research has been supported by the NSF grant SES0922550. We are grateful to Paul Ho for research assistance. Part of this research was conducted while the first author was a visiting research scholar at the economics department at Princeton University, or while both were at Humboldt University and the SFB649: their support is gratefully acknowledged. The usual disclaimer applies.

${ }^{a}$ Goethe University Frankfurt,amir@econ.uni-frankfurt.de

${ }^{\mathrm{b}}$ The University of Chicago, NBER and CEPR,huhlig@uchicago.edu

${ }^{1}$ Hence our suggested approach works for the general class of dynamic factor models.
} 
We provide formal conditions to establish whether an additional sign restriction is relevantly binding and by that leading to an improved and refined identification further narrowing the bounds of the identified set towards exact point identification. This is generally feasible due to the inherent large dimensional nature of dynamic factor models and FAVARs. We demonstrate an important distinction in those conditions for case of two or higher factor dimensions. In the former case exactly two sign restriction are sufficient and we show what those conditions are. In the latter case, theoretically every additional sign restriction could potentially improve structural identification. In the limit of binding sign restrictions the it can lead to exact point identification.

Our approach avoids the price puzzle by construction, and remains usable for subsamples as well. We show this per applying our approach to a data set ending in June 2010, thus including the 2008 financial crisis episode and the ensuing quantitative easing policies of the Federal Reserve Bank, an episode that generates considerable challenges to any strategy of identifying monetary policy shocks: the results do not change much, even when we restrict the sample to include only the "post-Volcker" years from 1984 to 2010 or excluding the period in which quantitative easing was in place.

Following the lead of Sims [1972], Sims [1980] and Sims [1986], a large literature has developed, analyzing the effects of monetary policy shocks with the aid of vector autoregression (VAR). Most VAR studies consider a small number of variables in order to save degrees of freedom for keeping the model tractable ${ }^{2}$. The central bank is likely to take considerably more information into account when choosing its course of actions, however. As pointed out by Bernanke and Boivin [2003], monetary policy takes place in a "data-rich environment". Bernanke and Boivin [2003], Stock and Watson [2005] and Bernanke, Boivin and Eliasz [2005] therefore introduced factor vector autoregression (FAVAR) models, combining dynamic factor models with the VAR analysis.

Identifying assumptions are key. We propose to identify monetary policy shocks with the help of sign restrictions, introduced by Dywer [1997], Faust [1998], Canova and Pina [2005], Canova and De Nicoló [2002] and Uhlig [2005]. A survey and various extensions for structural VAR identified with sign restrictions are in Rubio-Ramirez, Waggoner and Zha [2010]. They also show how to efficiently draw from the Haar measure generating candidate rotation matrices. Mumtaz and Surico [2009] and Mumtaz, Zabczyk and Ellis [2014] impose standard contemporaneous sign restrictions either directly on structured factors in a FAVAR model or on the standard small set of variables respectively. Hamilton and Baumeiseter [2015] study among others the role of the prior in set identified structural VAR models potentially carrying over to the posterior with substantial weight. Arias, Waggoner and Rubio-Ramirez (2014) and Kilian and Murphy (2012) show how to employ a mixture of zero and sign restrictions. Employing sign restrictions, the response of key macroeconomic variables such as prices and

\footnotetext{
${ }^{2}$ On the larger side, Leeper, Sims and Zha [1996] employ a Bayesian VAR with 18 variables.
} 
interest rates to a monetary policy shock is restricted to accord with a priori theory, in order to achieve identification. Our key innovation compared to that literature is to use a FAVAR approach allowing us to impose restrictions on a comparatively large number of observable time series, potentially providing a more exact identification. For example, not one, but many price series can and will be restricted in their response: as each reacts somewhat differently to shocks, the range of potential candidates for monetary policy shocks is reduced. This is important, since sign restrictions offer weak or set identification, as opposed to point identification, see Canova [2007] for a discussion of the latter. Compared to other identification strategies in FAVARs as introduced as well as surveyed by Stock and Watson [2005] and Stock and Watson [2011], our approach avoids a structural interpretation of the factors themselves or adding observables to the list of factors. In fact, our approach can be applied and is appealing more broadly, when a substantial number of observable time series can potentially be restricted in their response to a shock, and thus can also be applied in dynamic factor models.

Sims and Zha [1998] review Bayesian methods for multivariate models and their advantages: our paper is in that tradition. For the estimation we choose a Bayesian likelihood-based estimation based on MCMC methods which is fully parametric. Thus we can explicitly exploit the factor structure of the data and the law of motion of the extracted factors. Our impulse response confidence bands are posterior probability statements rather than confidence sets, an issue raised and analyzed in Moon and Schorfheide [2012] and Granziera, Moon and Schorfheide [2013], and discussed from a Bayesian perspective in Rubio-RamírezWaggoner-Zha [2010]. Giacomini and Kitagawa (2015) propose general method for conducting inference in SVARs that are partially identified due to inequality restrictions. Their objective is to characterize the identified set using robust Bayesian methods. We use a set of monthly macroeconomic data from 1960:02 to 2010:06, building and extending a data set provided by Stock and Watson. We check for subsample stability. We compare the results from our approach to the Cholesky identification in FAVARs, as proposed by Bernanke, Boivin and Eliasz [2005]. We choose a benchmark specification in terms of the FAVAR as well as the restrictions imposed, but have studied a number of variations, documented in a technical appendix.

Compared to the VAR sign restriction literature, our confidence bands for the on-impact response is typically considerably more narrow. For the full sample as well as the post-Volcker sample, we find that a monetary policy shock one standard deviation in size raises the Federal Funds Rate by about 15 basis points, before eventually reverting course and an eventual decrease of 10 basis points. In response, we find that industrial production decreases, with a maximum impact of minus 0.2 percent at the median estimate after one year before reverting back. For the subsectors, we find the smallest or even a positive reaction for the industrial production in residential utilities as well as fuels, while industrial production of business equipment as well as durable materials falls somewhat 
more strongly and more persistently than total industrial production. The effect on real GDP is less pronounced. The posterior confidence bands includes zero or positive reactions, consistent with Uhlig [2005]. We find that the forecast-error revision variance of industrial production due to monetary policy shocks accounts for less than 10 percent at the median estimate, which is consistent with results in Sims and Zha [2006] and Uhlig [2005]. Similar results have been obtained for the period of the US Great Depression in Sims [1999] and Amir Ahmadi and Ritschl [2013]. Employment falls by 0.1 percent within two years, starting from an initial zero response. Total unemployment puzzlingly shows an initial fall of about 0.08 percentage points. The CPI falls by 0.1 percent on impact, and by half a percent eventually within four years, showing a persistent response. Yield spreads initially fall in response, and fall the more strongly, the longer the maturity. The spread between the 3-month TBill and the Federal Funds Rate falls by 5 basis points one month after the shock, whereas the spread between the 10 year Treasury Bond and the Federal Funds Rate falls by 15 basis points. The spread responses are rather tightly estimated.

For the Cholesky identification as proposed by Bernanke, Boivin and Eliasz [2005], we find substantial prize puzzles. For the post-1984 subsample, for example, the CPI response is rather tightly estimated to rise by 0.1 percent within a year. Even within four years, it remains considerably more likely that the CPI response stays positive rather than turning negative. The commodity prices increase on impact. We argue that these results render the Cholesky identification approach considerably less useful for the analysis of monetary policy shocks than ours. The Cholesky decomposition implies a persistent fall in industrial production, whereas our identification shows industrial production to return to a near-zero uncertainty band within two years. This matters in particular for the purpose of political debates regarding monetary policy choices, and provides all the more reason to adapt our identification rather than a Cholesky identification in a FAVAR.

\section{THE MODEL}

The idea of a factor vector autoregression or FAVAR, as introduced by Bernanke, Boivin and Eliasz [2005], is to summarize the key dynamics of a large set of time series by a small list, containing some common factors as well as some key variables. Time is indexed by $t=1, \ldots, T$. The small list of key variables is a $\left[n_{y} \times 1\right]$ vector $f_{t}^{y}$. The remaining time series are a $\left[n_{x} \times 1\right]$ vector $x_{t}$. Let $f_{t}$ denote the $\left[n_{f} \times 1\right]$ vector of unobservable common factors of $X_{t}^{c}$. The $\left[n_{x} \times 1\right]$ vector $e_{t}$ is a time- $t$ error term. The model is

$$
X_{t}^{c}=\lambda^{c} f_{t}^{c}+\lambda^{y} f_{t}^{y}+e_{t}, \text { with } e_{t} \sim N\left(0, R_{e}\right) \text { iid }
$$

Here $\lambda^{c}$ and $\lambda^{y}$ denote the matrix of factor loadings of the factors and the perfectly observable variables included as factors with dimension $\left[n_{x} \times n_{f}\right]$ and 
$\left[n_{x} \times n_{y}\right]$ respectively. The covariance matrix $R_{e}$ is assumed to be diagonal. Hence the error terms of the observable variables are assumed to be mutually uncorrelated. The FAVAR state equation represents the joint dynamics of factors and the key variables $f_{t}=\left(\left(f_{t}^{c}\right)^{\prime},\left(f_{t}^{y}\right)^{\prime}\right)^{\prime}$ following a $\operatorname{VAR}(\mathrm{P})$ process.

$$
\left[\begin{array}{l}
f_{t}^{c} \\
f_{t}^{y}
\end{array}\right]=\sum_{p=1}^{P} \phi_{p}\left[\begin{array}{l}
f_{t-p}^{c} \\
f_{t-p}^{y}
\end{array}\right]+u_{t}, \text { with } u_{t} \sim N\left(0, Q_{u}\right) \text { iid }
$$

where $u_{t}$ is the date- $t$ reduced form shock, $Q_{u}$ is the factor error covariance matrix and $\phi_{p}$ are the $p$-lag coefficient matrices. The dimensions are $[K \times 1]$, $[K \times 1]$ and $[K \times K]$ respectively, where the total number of factors is $K=n_{f}+n_{y}$. We assume that $Q_{u}$ is of full rank.

\section{IDENTIFICATION}

\subsection{Sign Restrictions in FAVARs and DFMs}

The major objective of this paper is to identify structural shocks in a FAVAR, per imposing sign restrictions on impulse responses as introduced by Uhlig [2005] for the VAR framework. The specific application is to the identification of a monetary policy shock.

The structural shocks $\nu_{t} \in \mathbf{R}^{K}$ are related to the reduced form shocks $u_{t}$ of the factor VAR (2.2) per

$$
u_{t}=A \nu_{t}
$$

where the matrix $A$ is an orthogonal invertible matrix of dimension $[K \times K]$, satisfying

$$
Q_{u}=A A^{\prime}
$$

arising from the assumption that the $\nu_{t}$ are uncorrelated and of unit variance,

$$
E\left[\nu_{t} \nu_{t}^{\prime}\right]=I_{K}
$$

The instantaneous response to any structural shock is an "impulse vector", as defined in Uhlig (2005):

Definition 1 The vector $a \in \mathbf{R}^{K}$ is called an impulse vector, iff there is some matrix $A$, so that $A A^{\prime}=Q_{u}$ and so that $a$ is a column of $A$.

Per proposition 1 of Uhlig [2005,pp. 18], any impulse vector can be characterized as follows. Let $\tilde{A} \tilde{A}^{\prime}=Q_{u}$ be the Cholesky decomposition. Then $a$ is an impulse vector if and only if there is some $K$-dimensional vector $\alpha$ of unit length so that

$$
a=\tilde{A} \alpha
$$


For estimation and further analysis, consider the companion form of (2.1) to $(2.2)$

$$
\begin{aligned}
F_{t} & =\Phi F_{t-1}+u_{t} \\
X_{t} & =\Lambda F_{t}+E_{t} .
\end{aligned}
$$

where $F_{t}, X_{t}, \Phi, E_{t}$ are defined in the appendix, equations (A.4) in the usual manner per stacking. Let $\mathbf{a}=\left[a^{\prime}, 0_{1, K(P-1)}\right]^{\prime}$. Compute

$$
r_{a}^{(f)}(s)=\Phi^{s} \mathbf{a}
$$

to obtain the vector of impulse responses of $f_{t}$ to an impulse in $a$ at horizon $s$. Compute

$$
r_{a}^{(X)}(s)=\Lambda r_{a}(s)
$$

to obtain the vector of impulse responses of $X_{t}$ to an impulse in $a$ at horizon $s$.

To impose sign restrictions means to pick a list $\mathbf{L} \subseteq\left\{1, \ldots, n_{f}+n_{y}+n_{x}\right\}$ of variables among $f_{t}$ and $X_{t}$ as well as a restriction horizon $H \geq 0$.

DEFINITION 2 The impulse vector a satisfies the sign restrictions $(\mathbf{L}, H)$, if $r_{a}^{(f)}(s)_{j} \geq 0$ for all $j \in \mathbf{L}, j \leq n_{f}+n_{y}$ and $r_{a}^{(X)}(s)_{j-n_{f}-n_{y}} \geq 0$ for all $j \in \mathbf{L}, j>$ $n_{f}+n_{y}$, for all $s \in\{0, \ldots, \bar{H}\}$.

For the ease of exposition, we have imposed that sign restrictions are always positive. If the sign restriction on the original variable is negative, this can be achieved by flipping the sign of the variable: in practice, one would simply distinguish between negative and positive restrictions, of course. Further, and for the ease of exposition, we have assumed that the restriction horizon is the same for all variables: this is rather trivial to generalize, at the expense of more cumbersome notation. Furthermore, one may wish to impose sign restrictions on several impulse vectors or impose additional exact identifying restrictions: we do not pursue these rather straightforward generalizations here, in the interest of space and for the ease of exposition.

\subsection{Many sign restrictions: when do they help?}

In contrast to a VAR in a few variables, a FAVAR offers the opportunity to impose sign restrictions on many variables in $X$. In particular, as the panel dimension of the FAVAR diverges to infinity, one may have the opportunity to impose ever more sign restrictions, in principle. While one can also contemplate ever more sign restrictions in the VAR case per increasing the restriction horizon, this is arguably far less sensible than, say, finding more price series or more asset price series to constrain monetary policy impulse vectors.

The question then arises, whether they help and when? We seek to offer some insights on this matter. To that end, we wish to express sign restrictions in terms of sets for the impulse vector a. That vector only has an interpretation, if the coefficient matrices $\Phi, \Lambda$ are known. These need to be estimated in practice. Further, the factors and thus $\Phi$ will generally only be exactly known asymptotically, 
as both the panel dimension and the time dimension approach infinity. From a Bayesian perspective, which we adopt here throughout, the posterior will provide candidate draws for $\Phi, \Lambda$, which one can condition on. All these issues are wellunderstood outside the particular focus on sign restrictions here. We therefore allow ourselves to assume $\Phi, \Lambda$ to be known, for the discussion here.

Given the sign restrictions $(\mathbf{L}, H)$, values for $\Phi, \Lambda$, enumerate the $m=(H-$ 1) $\times \sharp \mathbf{L}$ sign restrictions $i=1, \ldots, m$, i.e., every one of these $i$ corresponds one for one to some $j_{i} \in \mathbf{L}$ and $s_{i} \in\{0, \ldots, H\}$. For each $i$ construct a row vector $\mathbf{b}_{i}$ of length $n_{f}+n_{y}$ as follows. If $j_{i} \leq n_{f}+n_{y}$, let

$$
\mathbf{b}_{i}=\mathbf{e}^{\left(j_{i}\right)} \Phi^{s_{i}}
$$

where $\mathbf{e}^{\left(j_{i}\right)}$ is a row vector of length $n_{f}+n_{y}$, with only zero entries, except for $\left(\mathbf{e}^{\left(j_{i}\right)}\right)_{j_{i}}=1$. If $j_{i}>n_{f}+n_{y}$, let

$$
\mathbf{b}_{i}=\tilde{\mathbf{e}}^{\left(j_{i}-n_{f}-n_{y}\right)} \Lambda \Phi^{s_{i}}
$$

where $\tilde{\mathbf{e}}^{\left(j_{i}-n_{f}-n_{y}\right)}$ is a row vector of length $n_{x}$, with only zero entries, except for $\left(\tilde{\mathbf{e}}^{\left(j_{i}-n_{f}-n_{y}\right)}\right)_{j_{i}-n_{f}-n_{y}}=1$. We shall refer to the $\mathbf{b}_{i}$ as sign restriction vectors. Let

$$
B=\left[\begin{array}{c}
\mathbf{b}_{1} \\
\mathbf{b}_{2} \\
\vdots \\
\mathbf{b}_{m}
\end{array}\right]
$$

the matrix stacking all row vectors $\mathbf{b}_{1}, \ldots, \mathbf{b}_{m}$. Finally, define the set $\mathcal{B}=$ $\left\{\mathbf{b}_{1}^{\prime}, \ldots, \mathbf{b}_{m}^{\prime}\right\}$ of all sign restriction vectors. Generally, for any subset $\mathcal{C}$ of $\mathbf{R}^{n_{f}+n_{y}}$, define the dual cone $\mathcal{C}^{*}$ per

$$
\mathcal{C}^{*}=\left\{y \in \mathbf{R}^{n_{f}+n_{y}} \mid x^{\prime} y \geq 0 \text { for all } x \in \mathcal{C}\right\}
$$

The following property is well-known in convex analysis: for completeness, we provide a proof.

Proposition 1 For any subset $\mathcal{C}$ of $\mathbf{R}^{n_{f}+n_{y}}$, we have $\mathcal{C}^{*}=\mathcal{C}^{* * *}$

Proof: If $x \in \mathcal{C}$, then $x^{\prime} y \geq 0$ for all $y \in \mathcal{C}^{*}$ per definition of $\mathcal{C}^{*}$. Thus, $x \in \mathcal{C}^{* *}$. This implies that $\mathcal{C}^{* * *} \subseteq \mathcal{C}^{*}$. Conversely, let $y \in \mathcal{C}^{*}$. Then $x^{\prime} y \geq 0$ for all $x \in \mathcal{C}^{* *}$ per definition of $\mathcal{C}^{* *}$. Hence, $y \in \mathcal{C}^{* * *}$.

Q.E.D.

The following characterization is now immediate.

Proposition 2 Given $\Phi, \Lambda$, the following statements are equivalent:

1. The impulse vector a satisfies the sign restrictions $(\mathbf{L}, H)$.

2. $\mathbf{b}_{i} \mathbf{a} \geq 0$ for all sign restriction vectors $\mathbf{b}_{i}, i=1, \ldots, m$. 
3. $B \mathbf{a} \geq 0$.

4. $\mathbf{a} \in \mathcal{B}^{*}$

5. $\mathbf{a} \in \mathcal{B}^{* * *}$

Note that the sign restrictions only restrict the direction or cone for $\mathbf{a}$. The length restriction for a obtains from the requirement that $A A^{\prime}=Q_{u}$, see equation (3.1).

Equipped with these tools, we can characterize, when some additional sign restriction is useful or not.

Definition 3 Given the sign restrictions $(\mathbf{L}, H)$ and values for $\Phi, \Lambda$, an additional sign restriction $\mathbf{b a} \geq 0$, characterized by a sign restriction vector $\mathbf{b}^{\prime} \in$ $\mathbf{R}^{n_{f}+n_{y}}$, is called irrelevant, if all $\mathbf{a}$ satisfying the sign restrictions $(\mathbf{L}, H)$ also satisfy ba $\geq 0$.

With the insights above, we obtain

Proposition 3 An additional sign restriction $\mathbf{b a} \geq 0$ for some $\mathbf{b}^{\prime} \in \mathbf{R}^{n_{f}+n_{y}}$ is irrelevant, iff $\mathbf{b}^{\prime} \in \mathcal{B}^{* *}$.

Note that $\mathcal{B}^{* *}$ is the closure of the smallest convex cone containing $\mathcal{B}$.

Proof: Per proposition 2, a satisfies the sign restrictions $(\mathbf{L}, H)$, iff $\mathbf{a} \in \mathcal{B}^{* * *}$. Suppose it does. If $\mathbf{b}^{\prime} \in \mathcal{B}^{* *}$, we therefore have $\mathbf{b a} \geq 0$. Conversely, suppose that $\mathbf{b}^{\prime} \notin \mathcal{B}^{* *}$. Then $\mathbf{b a}<0$ for some $\mathbf{a} \in \mathcal{B}^{*}$, and thus for some a satisfying the sign restrictions $(\mathbf{L}, H)$, per proposition 2 .

A rather clean distinction can and should be made between the two-dimensional case and higher-dimensional cases ${ }^{3}$.

Proposition 4 Suppose there are only two factors, $n_{f}+n_{y}=2$. Suppose there are finitely many sign restrictions, $\sharp \mathcal{B}<\infty$ and that the sign restrictions are not impossible to satisfy, i.e. that $\mathcal{B}^{*} \neq\{0\}$. Then there are two sign restrictions $\hat{\mathbf{b}}$ and $\check{\mathbf{b}}$, such that $\mathcal{B}^{*}=\{\hat{\mathbf{b}}, \check{\mathbf{b}}\}^{*}$. The two sign restrictions solve

$$
\min _{\hat{\mathbf{b}}, \check{\mathbf{b}} \in \mathcal{B} /\{0\}} \frac{\hat{\mathbf{b}} \check{\mathbf{b}}^{\prime}}{\|\hat{\mathbf{b}}\|\|\check{\mathbf{b}}\|}
$$

In words, with these two sign restrictions $\hat{\mathbf{b}}$ and $\check{\mathbf{b}}$, which maximizes the angle between them, all others are irrelevant.

Proof: Geometrically, the proposition is equivalent to the statement that a closed cone in two dimensions is the area between two rays, which have the maximal angle between them of all rays in the cone. This latter statement is true by inspection.

Q.E.D.

\footnotetext{
${ }^{3}$ We leave out the trivial zero-dimensional and one-dimensional cases.
} 
It is worth emphasizing that this applies also to sign restrictions in twodimensional VARs: only two sign restrictions "matter".

In dimensions higher than three, it can happen that no sign restriction is irrelevant, i.e. no sign restriction is irrelevant, when added to the set of all other sign restrictions. It suffices to provide an example in $\mathbf{R}^{3}$ : it is then clear, that this example can be generalized to all higher dimensions. For $\mathbf{R}^{3}$, let the sign restrictions be characterized by $\mathbf{b}_{i}=\left[\cos \theta_{i}, \sin \theta_{i}, 1\right]$, where the $\theta_{i} \in[0, \pi)$ are all distinct. Examine one of these, say, $\mathbf{b}_{1}=\left[\cos \theta_{1}, \sin \theta_{1}, 1\right]$. Consider $\mathbf{a}_{\lambda}=$ $\left[-\cos \theta_{1},-\sin \theta_{1}, \lambda\right]$ for $\lambda \in[0,1]$. Note that

$$
\begin{aligned}
\mathbf{b}_{i} \mathbf{a}_{\lambda} & =-\cos \left(\theta_{i}-\theta_{1}\right)+\lambda \\
& >-1+\lambda \\
& =\mathbf{b}_{1} \mathbf{a}_{\lambda}
\end{aligned}
$$

We can therefore find $\lambda \in[0,1]$, so that $\mathbf{b}_{i} \mathbf{a}_{\lambda}>0$ for all $i \neq 1$, but $\mathbf{b}_{1} \mathbf{a}_{\lambda}<0$. This shows that $\mathbf{b}_{1}$ is not irrelevant, when added to all other sign restrictions.

Finally, we can examine what happens as the panel dimension $n=n_{x}$ of the FAVAR diverges to infinity. Suppose there are potentially infinitely many sign restrictions $\mathbf{L}_{\infty} \subseteq \mathbf{N}$, with the list $\mathbf{L}_{n}$ of sign restrictions for any given $n=n_{x}$ given by $\mathbf{L}_{\infty} \cap\left\{1, \ldots, n_{f}+n_{y}+n_{x}\right\}$. Does it help to impose ever more sign restrictions? The analysis above provides the answer, at least conceptually. Proposition 3 shows that if there is some $\bar{n}$ and associated set of sign restriction vectors $\mathcal{B}_{\bar{n}}$, so that all additional $\mathbf{b}$ arising for larger panels are contained in $\mathcal{B}_{\bar{n}}^{* *}$, i.e. the closure of the smallest cone containing $\mathcal{B}_{\bar{n}}$, then these new sign restrictions are irrelevant.

In the two-dimensional case, as proposition 4 and the geometric interpretation in the proof shows, this irrelevance arises, if all future b-rays are within the two boundary rays $\hat{\mathbf{b}}_{n}$ and $\check{\mathbf{b}}_{n}$ of the panel-dimension- $n$ FAVAR. On the other hand, suppose that

$$
\frac{\hat{\mathbf{b}}_{n} \check{\mathbf{b}}_{n}^{\prime}}{\left\|\hat{\mathbf{b}}_{n}\right\|\left\|\check{\mathbf{b}}_{n}\right\|} \rightarrow \kappa
$$

without reaching the limit at some $n$, where $\hat{\mathbf{b}}_{n}$ and $\check{\mathbf{b}}_{n}$ are the extreme rays of the panel-dimension- $n$ FAVAR, calculated in proposition 4 . Then there are always new sign restrictions coming up with increasing the panel dimension, which are not irrelevant. In the extreme case, where $\kappa=-1$, one obtains exact identification of $\mathbf{a}$, as $n \rightarrow \infty$. It may not be particularly reasonable to hope for such a tightening of sign restrictions, as the panel dimension diverges to infinity, but such a hope might have a better foundation in any empirical application than the hope that one can obtain exact identification in the sign-restricted VAR case, with an ever increasing horizon.

In higher-dimensional cases, it may be that all new sign restrictions are relevant as in example constructed above for $\mathbf{R}^{3}$ : one can certainly construct a sequence of $\theta_{i} \in[0, \pi)$, which are all distinct, $i=1,2, \ldots$ One can also construct cases, 
where one gets exact identification of $\mathbf{a}$, as $n \rightarrow \infty$ : this happens, if the cone $\mathcal{B}^{* *}$, which is an intersection of half-spaces, converges ${ }^{4}$ to a ray.

\subsection{Sign restrictions for monetary policy shocks}

We proceed by imposing sign restrictions derived from "conventional wisdom": after a monetary policy contraction, the federal funds rate should increase, prices should not increase and nonborrowed reserves as well as M1 should decrease. The precise list is stated in section 4 .

Assumption 1 A (contractionary) monetary policy impulse vector is an impulse vector a so that the individual impulse response functions to a of prices, nonborrowed reserves and M1 are not positive and the impulse responses short term interest rate is positive, for a specified horizons $s=0, \ldots, S$.

Note that our strategy can be implemented, even if $n_{y}=0$, i.e., even if the model is a dynamic factor model rather than a FAVAR.

\subsection{Cholesky decomposition and monetary policy shocks in FAVARs}

For comparison we also employ the Cholesky Identification following Bernanke, Boivin and Eliasz [2005] who impose a recursive structure. We impose that $f_{t}^{y}=$ $\left[C P I_{t}, F F R_{t}\right]^{\prime}$, i.e., we use the CPI and the Federal Funds Rate as the key macroeconomic variables in the overall list of factors $f_{t}$. Let

$$
\begin{aligned}
u_{t} & =\tilde{A} \nu_{t} \\
\tilde{A} \tilde{A}^{\prime} & =Q_{u}
\end{aligned}
$$

where $\tilde{A}$ is lower triangular Cholesky factor of the covariance matrix $Q_{u}$ of the reduced form shocks $u_{t}$ and where the Federal Funds Rate as policy instrument is ordered last in the FAVAR equation. A detailed description and defense of the identification assumptions can be found in Bernanke et. al. [2005]. A survey and discussion of alternatives identification schemes is provided in Stock and Watson [2005], Stock and Watson [2011] and Stock and Watson [2015]. Note that this strategy can only be implemented, when the policy instrument is part of the list of factors, and therefore cannot be implemented in a dynamic factor model as opposed to a FAVAR. Note that this strategy can only be implemented, when the policy instrument (or a subeset of observable data) is part of the list of factors, and therefore cannot be implemented in a dynamic factor model as opposed to a FAVAR.

\footnotetext{
${ }^{4}$ We use the word "converge" in this sentence somewhat loosely, but it can be given a precise mathematical definition
} 


\subsection{Misspecification}

Bernanke, Boivin and Eliasz [2005] add the Federal Funds Rate as the key policy variable to a list of factors. The following considerations show, that one ought to also include those variables, for which the "noise" component in the factor representation is relevant for the monetary authority, when choosing its monetary policy instrument. If the true underlying monetary policy rule involves a variable not spanned by factors then the corresponding monetary policy shock is not spanned by factors. This leads to misspecifications and the identification of the monetary policy shock is incorrect.

While this may sound reasonably obvious in this rather general form, it may be less obvious why it is useful to also include the CPI in the list of factors. It turns out that the FAVAR specification can be misspecified, if the monetary authority reacts to the "noise" component in the CPI and the CPI is not included in the list of factors. Therefore, we include the CPI as well as the FFR in the specification of our benchmark sign-restricted FAVAR model. These considerations may also show, why prices might respond positively to a monetary policy shock identified in a FAVAR, when the CPI is not included in the core VAR. This insight may help to understand the puzzling results for the CPI index in figures IV and V of Bernanke, Boivin and Eliasz [2005].

To provide a simple example, suppose that an inflation component $\pi_{t}$ and an interest rate component $r_{t}$ follow the data generating process

$$
\begin{aligned}
\pi_{t} & =-\alpha r_{t-1}+\gamma \pi_{t-1}+\epsilon_{\pi, t} \\
r_{t} & =\phi \pi_{t}+\epsilon_{m, t}
\end{aligned}
$$

where $\alpha, \gamma, \phi$ are positive coefficients, where $\epsilon_{\pi, t}$ and where $\epsilon_{m, t}$ are shocks to inflation and to monetary policy respectively, assumed to be independent with each other and across time as well as normally distributed with variances $\sigma_{\epsilon, \pi}^{2}$ and $\sigma_{\epsilon, m}^{2}$.

It is best to think about the components $\pi_{t}$ and $r_{t}$ as the noise components in a factor structure. The model above thus makes the extreme assumption, that the monetary policy shock is entirely contained in the "noise" component of the interest rates. There are also more general versions. For example, the structure above is relevant if the monetary policy shock does not affect inflation via the other factors, but solely through the direct effect of interest rates on the "noise component" of inflation. It is also relevant, if part of the monetary policy shock component in a FAVAR without inflation included in the core VAR can actually be explained by movements in inflation, and it is the part of interest rates driven by that component, which affects inflation.

Note that the model implies

$$
\pi_{t}=(\gamma-\alpha \phi) \pi_{t-1}+\epsilon_{\pi, t}-\alpha \epsilon_{m, t-1}
$$


Assume that $0 \leq \gamma-\alpha \phi<1$, and one can see that a positive monetary policy shock $\epsilon_{m, t}$ will affect inflation negatively with a one period delay, and with inflation gradually climbing back up to zero.

The empirical issue is now to correctly identify the monetary policy shock $\epsilon_{m, t}$. The approach in Bernanke, Boivin and Eliasz [2005] recommends to add the federal funds rate to the available factors. Since there are no factors in the model above (or since they have already been subtracted out), this amounts to estimating the model

$$
\begin{aligned}
& r_{t}=\beta r_{t-1}+u_{t} \\
& \pi_{t}=\lambda r_{t}+\nu_{t}
\end{aligned}
$$

where the first equation represents the factor model (with zero factors aside from the interest rate), the second equation is the factor representation of inflation with a factor loading $\lambda$ on the interest rate component as the only available factor. Usually, $u_{t}$ would be interpreted as the monetary policy shock. Given the assumptions above, the coefficients can easily be calculated.

Proposition 5 Assume $0 \leq \gamma-\alpha \phi<1$.

1. The variance of the inflation component is given by

$$
E[\pi \pi]=\frac{\sigma_{\epsilon, \pi}^{2}+\alpha^{2} \sigma_{\epsilon, m}^{2}}{1-(\gamma-\alpha \phi)^{2}}
$$

The variance of the interest rate component is given by

$$
E[r r]=\phi^{2} E[p p]+\sigma_{m}^{2}
$$

2. For large samples, the estimates for $\beta$ and $\lambda$ converge to

$$
\begin{aligned}
& \beta \rightarrow \gamma-\alpha \phi-\gamma \frac{\sigma_{m}^{2}}{E[r r]} \\
& \lambda \rightarrow \frac{1}{\phi}\left(1-\frac{\sigma_{m}^{2}}{E[r r]}\right)
\end{aligned}
$$

3. If $\phi>0$, then $\lambda>0$. If $\phi=0$, then $\beta=0$ and $\lambda=0$.

Proof: These results follow from straightforward calculations:

1. The equation for $E[\pi \pi]$ follows directly from (3.5). For $E[r r]$, use (3.4) to write $E[r r]=E\left[\left(\phi \pi+\epsilon_{m}\right)\left(\phi \pi+\epsilon_{m}\right)\right]$ and exploit $E\left[\pi \epsilon_{m}\right]=0$.

2. For the covariance $E\left[r_{t} \pi_{t}\right]$ of $r_{t}$ with $\pi_{t}$ or the autocovariance $E\left[r_{t} r_{t-1}\right]$, note $E\left[r_{t} \pi_{t}\right]=E\left[\left(\phi \pi_{t}+\epsilon_{m, t}\right) \pi_{t}\right]=\phi E[\pi \pi]$ as well as

$$
E\left[r_{t} r_{t-1}\right]=E\left[\phi\left(-\alpha \phi r_{t-1}+\gamma \pi_{t-1}+\epsilon_{\pi, t}\right) r_{t-1}\right]=-\alpha \phi E[r r]+\gamma \phi E\left[r_{t} \pi_{t}\right]
$$

Now, calculate $\beta \rightarrow E\left[r_{t} r_{t-1}\right] / E[r r]$ and $\lambda \rightarrow E\left[r_{t} \pi_{t}\right] / E[r r]$.

3. Direct.

Q.E.D. 
Note now, that the impulse response of the inflation component to $u_{t}$, the "identified" monetary policy shock, is simply $\lambda$ times the impulse response of $r_{t}$ to a monetary policy shock. Since $\lambda>0$ for $\phi>0$, there will be a price puzzle on impact. If furthermore $\beta>0$, a condition which is easily met, inflation appears to react positively to a monetary policy shock throughout. Put differently, if the "noise" inflation component matters to monetary policy in setting interest rates, and if the researcher fails to include inflation in the "core" VAR, one easily obtains a price puzzle.

On the other hand, note the shocks could be correctly identified from a VAR in $\left(r_{t}, \pi_{t}\right)$ with one lag and a Cholesky-decomposition. Thus adding both, the interest rate as well as inflation, to the factor specification, would resolve this problem and result in correct identification of the monetary policy shock.

\section{EMPIRICAL APPLICATION}

\subsection{Data, Model Specification and Identification}

We follow the empirical approach of Bernanke, Boivin and Eliasz [2005]. They use the data set of Stock and Watson [1998,1999] which consists of a panel of 120 macroeconomic variables in monthly frequency transformed to induce stationarity. For our analysis we have updated the data set documented in Stock and Watson [2005] with observations from 1960:02-2003:12 to 1960:02-2010:06, slightly changing the set of variables ${ }^{5}$. The data set is listed in Appendix B.1. To check on subsample stability, we also use 1960:02-1979:09 ("Pre-Volcker") as well 1984:02-2010:06 ("Post-Volcker").

We use a total of $K=6$ factors $f_{t}$. We use $n_{y}=2$ key variables, the CPI and the Federal Funds Rate, for reasons described in appendix 3.5, and $n_{f}=4$ general factors, which are "extracted" and sampled from the remaining time series in the estimation phase. We used $P=12$ lags in the factor VAR. The horizon for the sign restriction to hold is set to $H=6$ which is based on Uhlig (2005). In our baseline specification, the impulse responses of the following variables have been sign-restricted, in order to achieve identification of the monetary policy shock, where numbers refer to table I in appendix B.1:

1. prices: 104 to $111,113,114,116$ to 118 .

2. monetary aggregates: M1 (69) and nonborrowed reserves (73).

3. interest rates: Federal Funds Rate (82).

We also examined a minimal restriction specification, where we have restricted the following variables:

1. prices: commodity price index (108) and CPI (109).

2. monetary aggregates: M1 (69) and nonborrowed reserves (73).

\footnotetext{
${ }^{5}$ We thank Mark Watson for making his data and computer codes available on his webpage http://www.princeton.edu/ mwatson/wp.html. Our updated data set is available on our web pages and in companion material for this paper.
} 
3. interest rates: Federal Funds Rate (82).

The results are very similar to our benchmark identification, and we thus refrain from reporting the results here: they are available in a technical appendix.

Alternatively, we examine an output-restricted specification where, in addition to the full set of restrictions in our benchmark model, total industrial production (17) as well as real GDP (18) is restricted to fall. This specification is useful for economists, who believe that output surely falls after a monetary contraction, and are interested in the shapes of the impulse responses and their quantitative magnitudes, given these additional identifying assumption. This turns out to result in more tightly estimated responses and (unsurprisingly) rather clearly negative responses for output. The results, in form of a comparison to our benchmark specification, is available in a technical appendix to this paper.

As a robustness check, we employed several variants of our strategy. The details are available as a technical appendix. We considered changing the set of sign-restricted variables as well as the set of key variables $f_{t}^{y}$ included as factors. Leaving out the CPI altered the results, which we suspect is due to the misspecification discussed in 3.5. We experimented with changing the number of general factors extracted from the data. We found that little information was added by increasing the dimension of the system, per analyzing the marginal contribution of further factors for the explanation of the variation in the data based on $R^{2}$. We tried several versions with different lag length, but the results compared to the ones reported here do not differ much. We found a tendency that the impact and intensity of the responses of restricted variables increases with the horizon $H$. For additional subsample checks, we used the data sets 1984:02-2002:12 as well as 1981:09-2002:12, to vary the begin of the "post-Volcker" episode and to exclude the financial crisis of 2008.

\subsection{Estimation}

For the estimation, we rely on now standard techniques. A detailed survey with several identification schemes in the classical estimation approach can be found in Stock and Watson [2005]. Bernanke, Boivin and Eliasz [2005] present two competing approaches. The second estimation approach described in their paper is the one that we employ in this paper because the likelihood based one-step estimation approach employing MCMC methods explicitly exploits the factor structure. We employ a Bayesian approach. We estimate the model with a multi-move Gibbs sampler for which we have to cast the model into its state space representation. Details matter: they are described in appendix A. All our results are based on 50000 simulation draws of the Gibbs sampler of which the first 40000 were discarded as a burn-in, keeping only the last 10000, in order to avoid an initial transient of the starting values that initiated the simulation. For each of these draws, 100 impulse vectors are drawn and checked for consistency with the sign restrictions: we keep the once that do to calculate the posterior distributions. 
In order to assure that the results are based on converged simulations, that represent the respective target distribution completely and e.g. not only some local mode, we apply a number of standard convergence diagnostics for the simulated parameters. We checked the ineffciency factors in figure (14). In figure (15)-(19) we plotted the first half of the kept draws against the second to check whether the sampler is still "moving" towards the target distribution or whether the whole density of the distribution is represented. Details are reported in a technical appendix.

We check the fit of our model. To this end, we estimated the $R^{2}$ s from regressing the respective series onto the four factors. Results are listed in table (II) in appendix B.2. These results provide a report to what extend the individual series are driven by common components: those with a low $R^{2}$ are driven by idiosyncratic forces rather than the common factors. We find that the model fits well overall. We also estimated the respective marginal contribution of each factor, not reported here, for the explanatory part in the variation of the data. We provide plots of the extracted factors in a technical appendix.

\subsection{Impulse Response Analysis}

The key statistics suited to answer the question at hand are impulse response functions. Figure (1) shows some of the results for our benchmark specification. A monetary policy shock one standard deviation in size raises the Federal Funds Rate by about 15 basis points, before eventually reverting course and an eventual decrease of 10 basis points. This may reflect either an attempt of the Federal Reserve Bank to reverse an earlier mistake or reflect the increase in the implied real rate, due to the fallen inflation rate. In response, we find that industrial production decreases, with a maximum impact of minus 0.2 percent at the median estimate after one year before reverting back. The 80 percent posterior confidence set two years after the shock ranges from a decline of 0.4 percent to an increase of 0.5 percent. The CPI falls 0.1 percent on impact and nearly half a percent eventually, showing a persistent response. By contrast the commodity price index decreases less strong with a maximum impact after about a year (aside from the initial reaction) before reverting back to the pre shock level a year later. Compared to CPI this may not be surprising as the commodity price index reflects measures traded on the market with presumably more flexible prices.

The rather clearly negative and hump-shaped response of industrial production in (1) may appear to be in contrast to the more neutral finding regarding real GDP reported in Uhlig [2005], when applying sign restrictions in a smallscale VAR. The resolution is partly the distinction between these two variables: as figure (2) shows, the posterior confidence band for the response of real GDP is rather symmetric around zero for the first 12 months following the shock, consistent with Uhlig [2005]. Figure (2) shows that employment falls by 0.1 per- 
Figure 1.- Selected Impulse Responses for the Baseline Model.
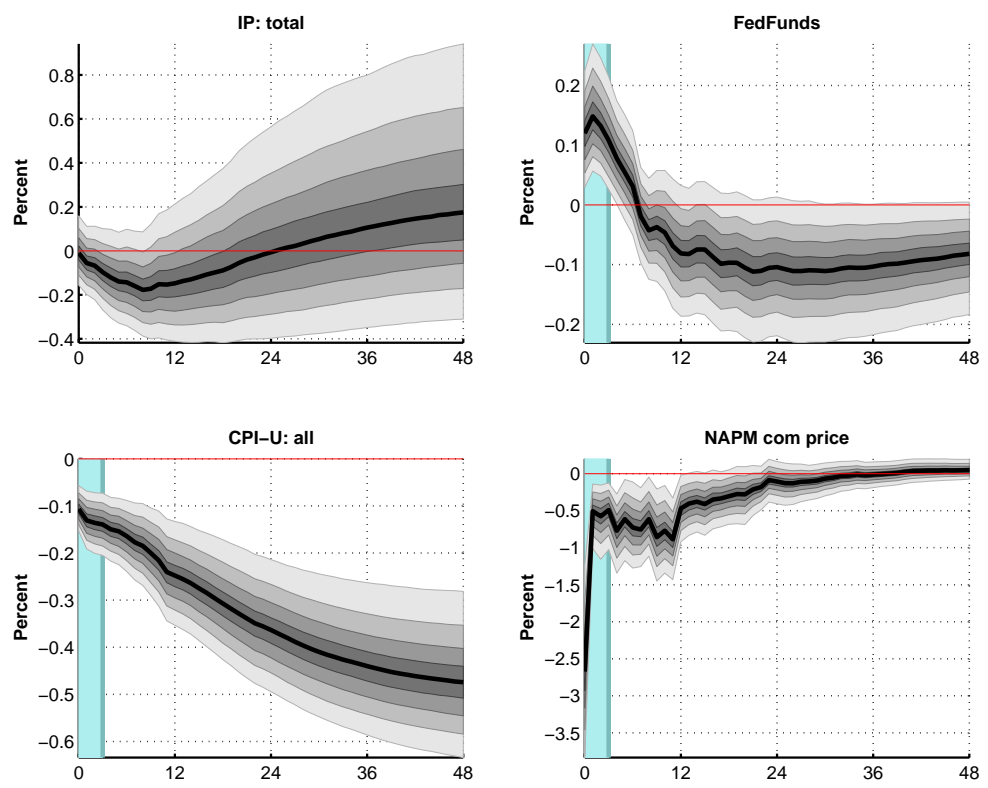

Results identified with sign restriction with the grey shaded area covering the 8 deciles ( $80 \%$ posterior probability bands).

cent within the first year, starting from an initial zero or modestly negative response. Somewhat puzzlingly, unemployment shows an initial fall of 0.08 percentage points, but rises subsequently from that point during the first two years. We speculate that this is either due to a discouragement effect of fewer displaced workers re-entering the labor force and searching for employment, following a contractionary monetary policy shock, or due to monetary policy misinterpreting a fall in unemployment as a rationale for raising interest rates. For more disaggregated unemployment series, we essentially find only increases, however, see figure (59) in the appendix.

Different sectors are affected differently. Figure (57) in the appendix shows the impulse responses for the industrial production for a variety of sectors. We find the smallest or even a positive reaction for the industrial production in residential utilities as well as fuels, while industrial production of business equipment as well as durable materials falls somewhat more strongly and more persistently than total industrial production. Figure (58) in the appendix shows the reaction of the different price indices. The producer price indices generally fall a bit more 


\section{Figure 2.- Selected Impulse Responses for the Baseline Model.}
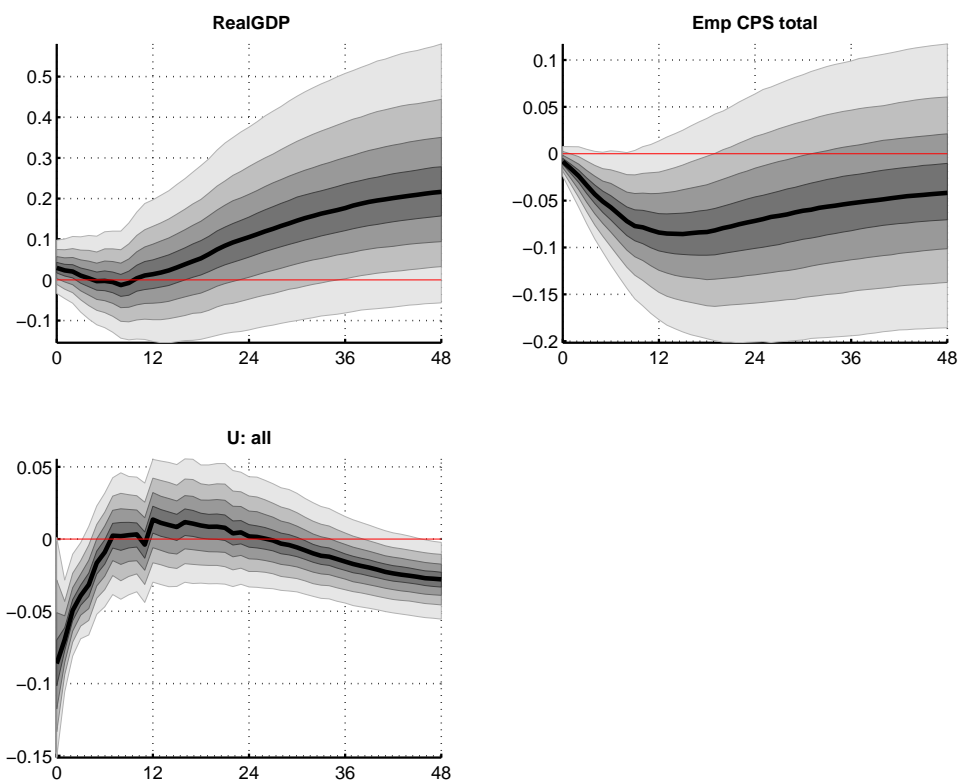

Results identified with sign restriction with the grey shaded area covering the 8 deciles $(80 \%$ posterior probability bands).

than the consumer price indices. Note that we did not restrict the price indices for medical care, or the implicit price deflators. This can serve as a cross-check on our identification: indeed, they all react negatively, except for a very modest price puzzle for the price index for medical services.

Yield spreads initially fall in response. Figure (3) shows the responses of the spreads to the Federal Funds Rate one month after the shock, as a function of maturity: the spread response is the larger, the longer the maturity of the bonds. While the 3-mo-FF spread falls by 5 basis points, the 10-year bond falls by 12 basis points, at the median estimate and at the one-month horizon. Figure (62) in the appendix shows the impulse response for each spread: the responses tend to be stronger for longer maturities. These responses are rather tightly estimated.

Figures (4) and (5) show the impulse responses of figure (1), but for the two subsamples 1960:02-1979:09 ("Pre-Volcker") as well 1984:02-2010:06 ("PostVolcker"). The results for these variables as well as for most other variables in the VAR remain reasonably robust during the first year or two after the shock, though differences arise. In particular, there appears to be a continu- 
Figure 3.- Impulse Responses after 1 month for the treasury spreads at different maturities vs. the federal funds rate in the baseline model.

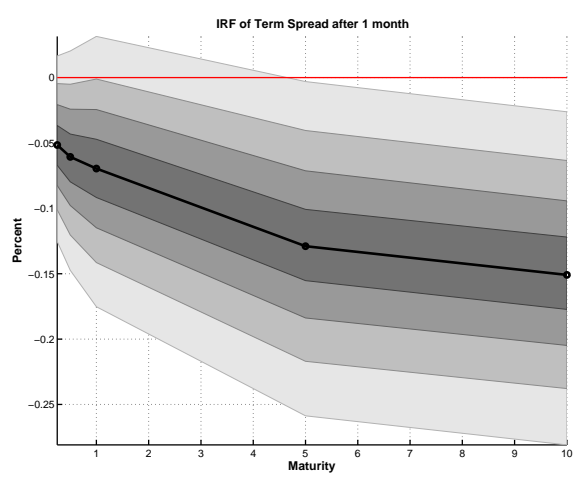

Results identified with sign restriction with the grey shaded area covering the 8 deciles $(80 \%$ posterior probability bands).

ous sequence of reversals in the Federal Funds Rate in the pre-Volcker episode than in the post-Volcker episode. One possible explanation may be that these shocks in the pre-Volcker episode were mistakes that the Federal Reserve subsequently tried to undo, but overshooting a bit in doing so, and so forth. More importantly, the results for the post-Volcker episode look reasonable and plausible, and more consistent with the results for the total sample, including the response for the Federal Funds Rate. We find these results encouraging, as the post-Volcker subsample includes the financial crisis of 2008 and the subsequent quantitative easing episode, generating substantial challenges for any empirical exercise aimed at identifying monetary policy shocks.

Surely, these results should be taken with a grain of salt. It is plausible, that monetary policy has changed both in terms of its reactions to economic news, as well as in its constraints (such as the zero lower bound) and tools. It would be fascinating to extend the methods here to allow for smooth time variation as analyzed e.g. in Primiceri [2005], Cogley-Sargent [2005] and Sargent-WilliamsZha [2006] or for Markov regime shifts as analyzed in Sims-Zha [2006], SimsWaggoner-Zha [2008] and Auerbach-Gorodnichenko [2012] or to extend the methods to allow for nonlinearities and the peculiarities of the zero lower bound. This is beyond the scope of this paper. We rather wish to emphasize that reasonable progress can already be made with the method at hand, that ours provides an important benchmark. However, note that the extension of our suggested approach extends to the case of FAVARs with either time varying or Markov-Switching parameters. Extensions of this method with these additional tools should provide 
Figure 4.- Selected Impulse Responses for the pre-Volcker period.
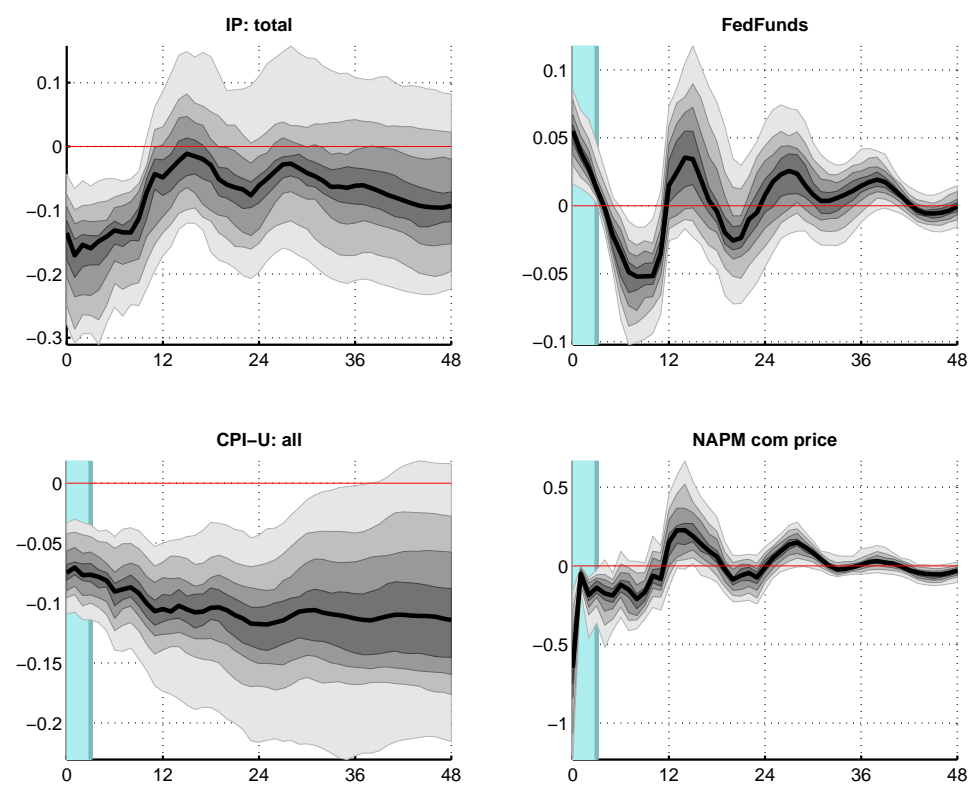

Results identified with sign restriction with the grey shaded area covering the 8 deciles $(80 \%$ posterior probability bands).

a promising avenue for future research.

Figure (6) shows the forecast error variance decompositions for our four key variables, in the benchmark specification. Monetary policy shocks account for less than $10 \%$ of the variation in industrial production and the Federal Funds Rate, consistent with the view that the central bank typically does not role dice, but do explain around 30 percent of the variation in the CPI. These results are amongst others consistent with Sims [1999], Sims and Zha [2006], Uhlig [2005] and Amir-Ahmadi and Ritschl [2008].

Figure (7) shows the impulse response functions for the post-Volcker sample and a FAVAR-Cholesky identification of the monetary policy shock one standard deviation in size as the last shock in the Cholesky decomposition of the factors, where the federal funds rate is ordered last. The results for the entire sample are very similar and available in a technical appendix. The most striking difference is the unreasonable high and long lasting "price puzzle". The CPI response is rather tightly estimated to rise by 0.1 percent within a year. Even within four years, it remains considerably more likely that the CPI response stays positive 
FIGURE 5.- Selected Impulse Responses for the post-Volcker period.
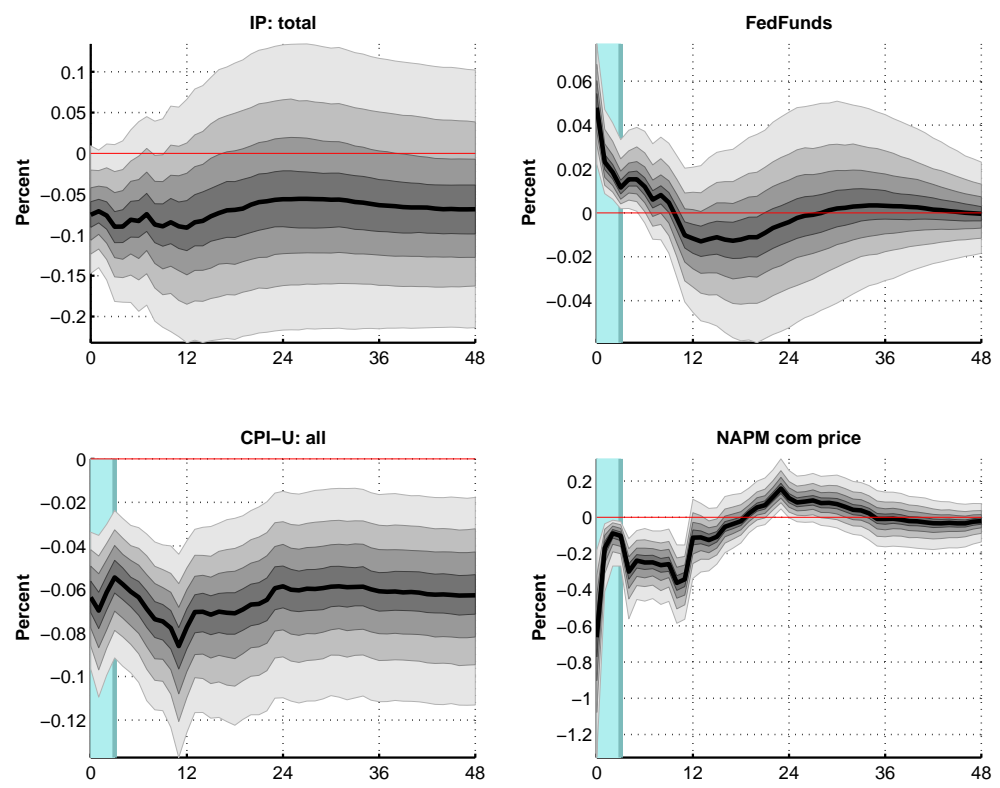

Results identified with sign restriction with the grey shaded area covering the 8 deciles $(80 \%$ posterior probability bands). The time span for the estimation covers $1984: 02-2006: 12$.

rather than turning negative. The commodity prices increase on impact. Another anomaly is the increasing reaction (not shown) of nonborrowed reserves which lasts for the whole horizon considered. We argue that these results render the Cholesky identification approach considerably less useful for the analysis of monetary policy shocks than ours. While the Cholesky decomposition implies that industrial production falls by nearly 0.4 percent within a year, and then stays there, our post-Volcker response shown in (5) implies a modest fall by 0.2 percent within a year, with subsequent reversal to an uncertainty band around a zero response within two years. While the difference in the size of the response may entirely be due to the initial difference of the movement in the Federal Reserve Rate ( 30 basis points for the Cholesky decomposition versus 15 basis points for our identification), the differences in the results regarding the persistence matters in particular for the purpose of political debates regarding monetary policy choices, and provides all the more reason to adapt our identification rather than a Cholesky identification in a FAVAR. 


\section{Figure 6.- Selected FEVD for the Baseline Model.}
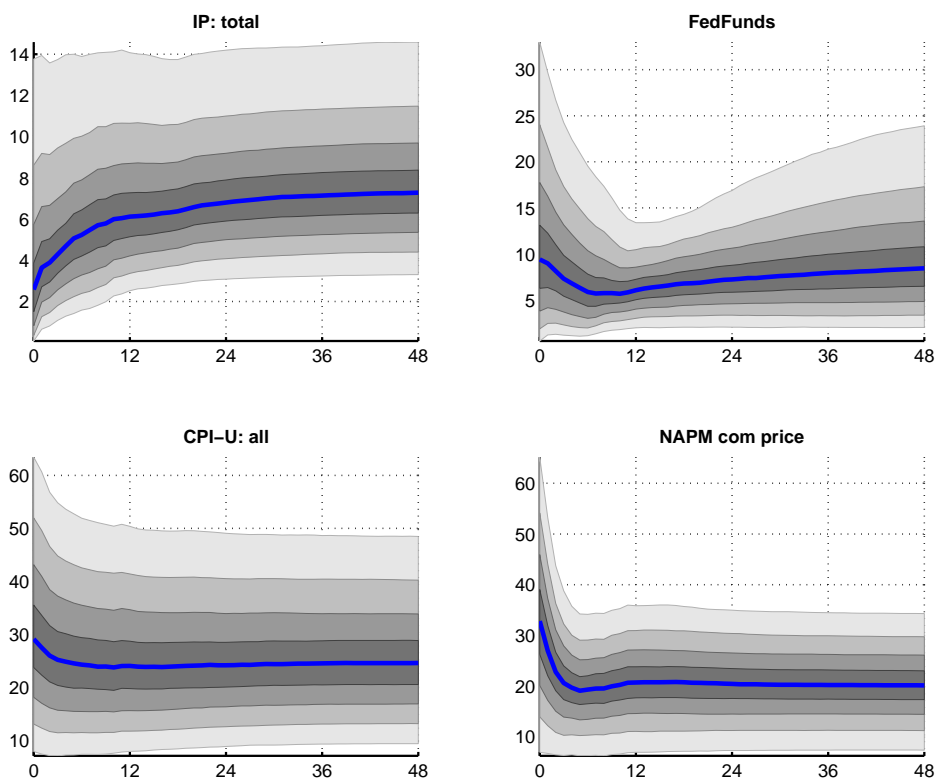

Forecast error variance decomposition for the baseline model identified with sign restriction.

The grey shaded area cover the 9 deciles of the posterior distribution.

\section{CONCLUSION}

In this paper we propose to conduct structural identification combining Bayesian FAVARs with sign restrictions. We show and discuss exact conditions under which many sign restrictions improve structural identification up to the limiting case of point identification. Furthermore we discuss the implication of misspecification and how they can lead to the "price puzzle". In our empirical application we estimate the model from a Bayesian perspective relying on MCMC methods. To infer the effects of a contractionary shock to monetary policy we impose sign restriction on the impulses responses on many prices, monetary aggregates and short term interest rates. FAVAR models as well as dynamic factor models offer the opportunity to impose a larger set of reasonable sign restrictions, leading to sharper identification and results. Sign restrictions in FAVARs offer the advantage of avoiding a structural interpretation of the factors themselves or adding observables to the list of factors. Our approach should therefore prove to be appealing in many applications beyond the one studied here. Our results 


\section{Figure 7.- Recursive Cholesky identification: post-Volcker Period}
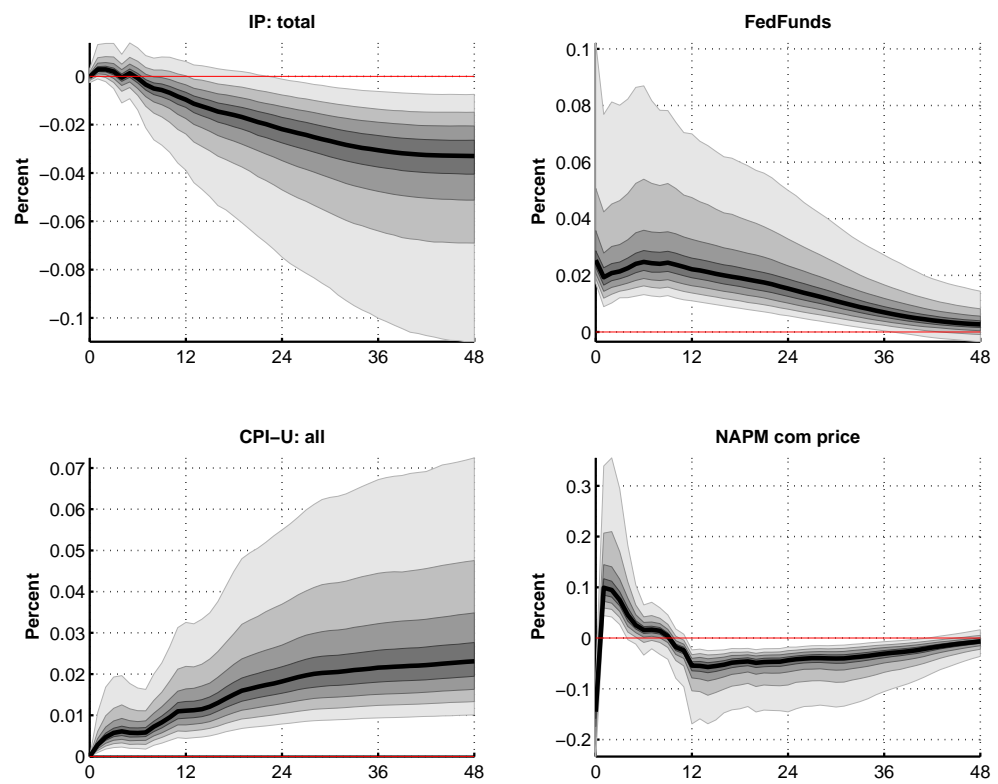

Results based on a recursive Cholesky identification with the grey shaded area covering the 8 deciles $(80 \%$ posterior probability bands). The time span for the estimation covers $1984: 02-2006: 12$.

are reasonable, even with the inclusion of the post-2008 financial-crisis data and remain fairly robust across subsamples, while a more conventional Cholesky identification leads to unreasonably large price puzzles. Compared to the VAR sign restriction literature, our confidence bands for the on-impact response is typically considerably more narrow. We find that after a contractionary monetary policy shock a negative response of output but modest in size. We find that industrial production decreases after a monetary contraction one standard deviation in size, with a maximum impact of minus 0.2 percent at the median estimate after one year, before returning to an uncertainty band around zero within two years. The effect on real GDP is less pronounced and includes zero within the posterior confidence band throughout. Monetary policy shocks account for less than 10 percent of the variation in industrial production and the Federal Funds Rate. The CPI falls by 0.1 percent initially and by half a percent eventually, showing a persistent response. Yield spreads initially fall in response, with the fall ranging from 5 basis points for the 3-month to Federal Funds Rate spread to 25 basis 
points for ten-year bonds.

\section{APPENDIX A: ESTIMATION AND INFERENCE}

For the estimation of FAVAR models Bernanke, Boivin and Eliasz [2005] present two competing approaches. The first one, which they prefer due to their results and the computational simplicity is the two-step estimation based on a dynamic principal component approach. This classical approach goes back to Stock and Watson [2003]. A detailed survey with several identification schemes in the classical estimation approach can be found in Stock and Watson [2005]. The second estimation approach described in their paper is the one that we employ in this paper because the likelihood based one-step estimation approach employing MCMC methods explicitly exploits the factor structure. We pursue the multi-move Gibbs sampler for which we have to cast the model into the state space representation. Let (2.2) be extended by $f_{t}^{y}$ which results in

$$
\left[\begin{array}{c}
X_{t}^{c} \\
f_{t}^{y}
\end{array}\right]=\left[\begin{array}{cc}
\lambda^{c} & \lambda^{y} \\
0 & I_{N_{y}}
\end{array}\right]\left[\begin{array}{c}
f_{t}^{c} \\
f_{t}^{y}
\end{array}\right]+\left[\begin{array}{c}
e_{t} \\
0
\end{array}\right]
$$

Let $X_{t} \equiv\left(X_{t}^{c \prime}, f_{t}^{y^{\prime}}\right)^{\prime}, E_{t} \equiv\left(e_{t}{ }^{\prime}, 0_{\left[N_{y} \times 1\right]^{\prime}}\right)^{\prime}$ and $f_{t} \equiv\left(f_{t}^{c \prime}, f_{t}^{y^{\prime}}\right)^{\prime}$, then the model can be rewritten as

$$
\begin{aligned}
X_{t} & =\lambda f_{t}+E_{t} \\
f_{t} & =\sum_{p=1}^{P} \phi_{p} f_{t-p}+u_{t}
\end{aligned}
$$

where $X_{t}$ has dimension $[N \times 1]$ with $N=N_{c}+K_{y}$. In most empirical applications and also in our specification the lag order $P$ exceeds one hence we have to rewrite the state space in a stacked first order Markov process. This requires the following straight forward definitions for the companion form of the model:

$$
\begin{aligned}
\lambda & \equiv\left[\begin{array}{cc}
\lambda^{c} & \lambda^{y} \\
0_{N_{y} \times K_{c}} & I_{N_{y}}
\end{array}\right] \\
\phi & \equiv\left[\phi_{1}, \phi_{2}, \ldots, \phi_{P}\right]^{\prime} \\
F_{t} & \equiv\left(f_{t}, f_{t-1}, \ldots, f_{t-p+1}\right) \\
U_{t} & \equiv\left(u_{t}, 0, \ldots, 0\right)^{\prime}
\end{aligned}
$$

The lag polynomial of the FAVAR equation in the first-order representation changes to:

$$
\Phi=\left[\begin{array}{ccc}
\phi_{1} & \cdots & \phi_{P} \\
I_{K(P-1)} & & 0_{K(P-1) \times K}
\end{array}\right] .
$$

Now we have to transform the VCV of the FAVAR disturbances with 0's in a straightforward way to adjust the dimensions of the state equation which results in the following matrix:

$$
Q=\left[\begin{array}{cc}
Q_{u} & 0 \\
0 & 0
\end{array}\right]
$$

where $Q$ is of dimension $[P K \times P K]$ extended by zero matrices to match the companion form. We define $\Lambda \equiv\left[\begin{array}{llll}\lambda & 0 & \cdots & 0\end{array}\right]$. Then

(A.5) $\quad F_{t}=\Phi F_{t-1}+U_{t}$

(A.6) $\quad X_{t}=\Lambda F_{t}+E_{t}$

(A.7) $\quad U_{t} \sim \mathcal{N}(0, Q)$

(A.8) $\quad E_{t} \sim \mathcal{N}(0, R)$

is the final state-space representation prepared to fit the estimation procedure. Note again that $R$ is diagonal and that $e_{t}$ and $u_{t}$ are mutually independent.

\section{A.1. Factor Identification}

The factors are only identified up to an invertible rotation. Any rotation of the factors results in the same likelihood for the factors though the models are different. Identifying restrictions 
have to be set, in order to distinguish the idiosyncratic from the common component. Additionally one can set further identifying assumptions in order to identify the factors and the loadings, separately. We follow the standard identification restrictions either on the factor loading matrix employed by Bernanke, Boivin and Eliasz [2005] for unique identification against rotational indeterminacy. Since factors are estimated up to a rotation, the normalization should not affect the space spanned by the estimated factors. In the joint estimation case the specified identification against rotation requires that the factors are uniquely identified in the following form

(A.9) $\quad f_{t}^{*}=A f_{t}^{c}-B f_{t}^{y}$

where $A$ and $B$ are nonsingular. Restrictions are only imposed on the observation equation. Here we substitute $F_{t}^{*}$ into (2.1) due to the fact that restrictions should not be imposed on the VAR dynamics we obtain

(A.10) $\quad X_{t}^{c}=\lambda^{c} A^{-1} f_{t}^{*}+\left(\lambda^{y}+\lambda^{c} A^{-1} B\right) f_{t}^{y}+e_{t}$.

For unique identification of the factors and the loadings it is required that $\lambda^{c} A^{-1}=\lambda^{c}$ and $\lambda^{y}+\lambda^{c} A^{-1} B=\lambda^{y}$. As discussed in Bernanke, Boivin and Eliasz [2005] sufficient conditions are to set the upper $K_{c} \times K_{c}$ block of $\lambda^{c}$ to identity and the upper $K_{c} \times N_{y}$ block of $\lambda^{y}$ to a zero matrix ${ }^{6}$.

\section{A.2. Inference}

Bayesian analysis treats the parameters of the model as random variables. We are interested in inference on the parameter space $\theta=\left(\lambda^{f}, \lambda^{y}, R_{e}, \phi, Q_{u}\right)$ and the factors $\left\{f_{t}\right\}_{t=1}^{T}$. Multi move Gibbs Sampling alternately samples the parameters $\theta$ and the factors $f_{t}$, given the data. We use the multi move version of the Gibbs sampler because this approach allows us, as a first step, to estimate the unobserved common components, namely the factors via the Kalman filtering technique conditional on the given hyperparameters and data, and as a second step calculate the hyperparameters of the model given the factors and data via the Gibbs sampler in the respective blocking. Let $X^{T}=\left(X_{t}, \ldots, X_{T}\right)$ and $F^{T}=\left(F_{1}, \ldots, F_{T}\right)$ define the respective histories. For the estimation of the model we want to derive the posterior densities which requires to empirically approximating the marginal posterior densities of $F^{T}$ and $\theta$ :

where

$$
\begin{aligned}
p\left(F^{T}\right) & =\int p\left(F^{T}, \theta\right) d \theta \\
p(\theta) & =\int p\left(F^{T}, \theta\right) d F^{T}
\end{aligned}
$$

$$
p\left(F^{T}, \theta\right)
$$

is the joint posterior density and the integrals are taken with respect to the supports of $\theta$ and $F^{T}$ respectively. The procedure applied to obtain the empirical approximation of the posterior distribution is the previously mentioned multi move version of the Gibbs sampling technique by Carter and Kohn [1994] and Frühwirth-Schnatter [1994] ${ }^{7}$.

\section{A.3. Choosing the Starting Values}

In general one can start the iteration cycle with any arbitrary randomly drawn set of parameters, as the joint and marginal empirical distributions of the generated parameters will converge at an exponential rate to its joint and marginal target distributions as $S \rightarrow \infty$. This has been shown by Geman and Geman [1984]. Since Gelman and Rubin [1992] have shown that a single chain of the Gibbs sampler might give a "false sense of security ", it has become

\footnotetext{
${ }^{6}$ Note that this identification strategy is over-identified. However, for comparison purposes we follow closely the approach of Bernanke, Boivin and Eliasz [2005].

${ }^{7}$ For a survey and more details see Kim and Nelson [1999], Eliasz [2005] and Bernanke, Boivin and Eliasz [2005]
} 
common practice to try out different starting values. We check our results based on four different strategies regarding the set of starting values. One out of many convergence diagnostics involves testing the fragility of the results with respect to the starting values. For the results to be reliable, estimates based on different stating values should not differ. Strictly speaking, the different chains should represent the same target distribution. In order to verify we resestimated our model initialzing our Gibbs sampler in the following different ways

(i) Randomly draw $\theta_{0}$ from (over)dispersed distribution

(ii) Set $\theta_{0}$ to rather "agnostic values" which involves setting 0's for coefficients and 1's for variances $^{8}$

(iii) Set $\theta_{0}$ to results from principal component analysis. ${ }^{9}$ In such a way the number of draws required for convergence can be reduced considerably.

(iv) Set $\theta_{0}$ to parameters of the last iteration of the previous run.

Results are robust to the various initialization strategies.

\section{A.4. Conditional density of the factors $F^{T}$ given $X^{T}$ and $\theta$}

In this subsection we want to sample from $p\left(F^{T} \mid X^{T}, \theta\right)$ assuming that the data and the hyperparameters of the parameter space $\theta$ are given, hence we describe Bayesian inference on the dynamic evolution of the factors $f_{t}$ conditional on $X_{t}^{c}$ for $t=1, \ldots, T$ and conditional on $\theta$. The transformations that are required to draw the factors have been done in the previous section. The conditional distribution, from which the state vector is generated, can be expressed as the product of conditional distributions by exploiting the Markov property of state space models in the following way

$$
p\left(F^{T} \mid X^{T}, \theta\right)=p\left(F_{T} \mid X^{T}, \theta\right) \prod_{t=1}^{T-1} p\left(F_{t} \mid F_{t+1}, X^{T}, \theta\right)
$$

The state space model is linear and Gaussian, hence we have:

$$
\begin{aligned}
F_{T} \mid X^{T}, \theta & \sim N\left(F_{T \mid T}, P_{T \mid T}\right) \\
F_{t \mid T} \mid F_{t+1 \mid T}, X^{T}, \theta & \sim N\left(F_{t \mid t, F_{t+1 \mid T}}, P_{t \mid t, F_{t+1 \mid T}}\right) \\
F_{T \mid T} & =E\left(F_{T} \mid X^{T}, \theta\right) \\
P_{T \mid T} & =\operatorname{Cov}\left(f_{T} \mid X^{T}, \theta\right) \\
F_{t \mid t, F_{t+1 \mid T}} & =E\left(F_{t} \mid F_{t \mid t}, F_{t+1}, \theta\right) \\
P_{t \mid t, F_{t+1 \mid T}} & =\operatorname{Cov}\left(F_{t} \mid F_{t \mid t}, F_{t+1}, \theta\right) .
\end{aligned}
$$

We first run the Kalman filter generating $F_{t \mid t}$ and $P_{t \mid}$ for $t=1, \ldots, T$. For the initialization we set $F_{1 \mid 0}=0_{K P \times 1}$ and $P_{1 \mid 0}=I_{K P}$ and iterate through the Kalman filter according to

$$
\begin{aligned}
& F_{t \mid t}=F_{t \mid t-1}+P_{t \mid t-1} \Lambda^{\prime} H^{-1} \eta_{t \mid t-1} \\
& P_{t \mid t}=P_{t \mid t-1}-P_{t \mid t-1} \Lambda^{\prime} H^{-1} \Lambda P_{t \mid t-1}
\end{aligned}
$$

where $\eta_{t \mid t-1}=\left(X_{t}-\Lambda F_{t \mid t-1}\right)$ is the conditional forecast error and its covariance is denoted by $H_{t \mid t-1}=\left(\Lambda P_{t \mid t-1} \Lambda^{\prime}+R_{e}\right)$. Furthermore let

(A.19) $\quad F_{t \mid t-1}=\Phi F_{t-1 \mid t-1}$

(A.20) $\quad P_{t \mid t-1}=\Phi P_{t-1 \mid t-1} \Phi^{\prime}+Q_{u}$.

The last iteration of the Kalman filter yields $F_{T \mid T}$ and $P_{T \mid T}$ required for (A.11) to draw the last observation and start the Kalman smoother according to (A.12) going backwards through

\footnotetext{
${ }^{8}$ This strategy has been applied by Belviso and Milani [2007].

${ }^{9}$ This strategy is particularly suited for large models as the ones studied here and has been proposed by Eliasz [2005].
} 
the sample for $F_{t}, t=T-2, T-3, \ldots, 1$ updating the filtered estimates with the sampled factors one period up subject to

(A.21) $\quad F_{t \mid t, F_{t+1 \mid T}}^{*}=F_{t \mid t}+P_{t \mid t} \Phi^{* \prime} J_{t+1 \mid t}^{-1} \xi_{t+1 \mid t}$

(A.22) $\quad P_{t \mid t, F_{t+1 \mid T}}^{*}=P_{t \mid t}-P_{t \mid t} \Phi^{* \prime} J_{t+1 \mid t}^{-1} \Phi^{*} P_{t \mid t}$.

where $\xi_{t+1 \mid t}=F_{t+1}^{*}-\Phi^{*} F_{t \mid t}$ and $J_{t+1 \mid t}=\Phi^{*} P_{t \mid t} \Phi^{*}+Q^{*}$. Note that $Q^{*}$ refers to the upper $K \times K$ block of $Q$ and $\Phi^{*}$ and $F_{t}^{*}$ denote the first $K$ rows of $\Phi$ and $F_{t}$ respectively. This is required when $Q$ is singular which is the case for the companion form when there is more than one lag in (A.3). Here we closely follow Kim and Nelson [1999] where a detailed explanation and derivation can be found.

\section{A.5. Conditional density of the parameters $\theta$ given $X^{T}$ and $F^{T}$}

Sampling from the conditional distribution of the parameters $p\left(\theta \mid X^{T}, F^{T}\right)$ requires the blocking of the parameters into the two parts that refer to the observation equation and to the state equation respectively. The blocks can be sampled independently from each other conditional on the extracted factors and the data.

\section{A.5.1. Conditional density of $\Lambda$ and $R_{e}$}

This part refers to observation equation of the state space model which, conditional on the estimated factors and the data, specifies the distribution of $\Lambda$ and $R_{e}$. The errors of the observation equation are mutually orthogonal with diagonal $R_{e}$. Hence we can apply equation by equation OLS in order to obtain the ols estimates $\hat{\Lambda}_{n}$ and $\hat{e}^{c}$ as the observation equation amounts to a set of independent regressions. Note that the subscript $n$ refers to the $n$-th equation and all hat variables refer to the respective ols estimates. We assume conjugate priors $p\left(R_{n n}\right)=\mathcal{I} \mathcal{G}\left(\delta_{0} / 2, \eta_{0} / 2\right)$

$$
p\left(\Lambda_{n} \mid R_{n n}\right)=\mathcal{N}\left(\Lambda_{n 0}, R_{n n} M_{n 0}^{-1}\right)
$$

which according to Bayesian results ${ }^{10}$ conform to the following conditional posterior distribution

with

$$
\begin{aligned}
p\left(R_{n n} \mid \tilde{X}_{T}, \tilde{F}_{T}\right) & =\mathcal{I} \mathcal{G}\left(\delta_{i} / 2, \eta_{i} / 2\right) \\
p\left(\bar{\Lambda}_{n n} \mid \tilde{X}_{T}, \tilde{F}_{T}, R_{n n}\right) & =\mathcal{N}\left(\bar{\Lambda}_{n}, R_{n n} M_{n}^{-1}\right) .
\end{aligned}
$$

$$
\begin{aligned}
\eta_{n} & =\eta_{0}+T \\
\delta_{n} & =\delta_{0}+\left(\hat{e}_{n}^{c}\right)^{\prime}\left(\hat{e}_{n}^{c}\right)+\left(\hat{\Lambda}_{n}-\Lambda_{n 0}\right)^{\prime}\left[M_{n 0}^{-1}+\left(F_{T}^{n \prime} F_{T}^{n}\right)^{-1}\right]^{-1}\left(\hat{\Lambda}_{n}-\Lambda_{n 0}\right) \\
\bar{M}_{n} & =M_{n 0}+\left(F_{T}^{n \prime} F_{T}^{n}\right) \\
\Lambda_{n} & =\bar{M}_{n}\left(M_{n 0}^{-1} \Lambda_{n 0}+\left(F_{T}^{n \prime} F_{T}^{n}\right) \hat{\Lambda}_{n}\right)
\end{aligned}
$$

where we set the same prior specification $\left(\delta_{0}=6, \eta_{0}=10^{-3}, M_{n 0}=I_{K_{c}}, \Lambda_{n 0}=0_{K_{c} \times 1}\right)$ as in Bernanke, Boivin and Eliasz [2005] in order to allow an adequate comparison. $M_{0}$ denotes the matrix in the prior on the coefficients of the $n$-th equation of $\Lambda_{n}$. The factor normalization discussed earlier requires to set $M_{0}=I$. The regressors of the $n$-th equation are represented by $F_{T}^{n}$ and the fitted errors of the $n$-th equation are represented by $\hat{e_{t n}^{c}}$.

\section{A.5.2. Conditional density of $\operatorname{vec}(\phi)$ and $Q_{u}$}

The next Gibbs block requires to draw $\operatorname{vec}(\phi)$ and $Q_{u}$ conditional on the most current draws of the factors and the data. We employ the Normal-Inverse Wishart prior according to Uhlig [1994]

$$
\begin{aligned}
p\left(Q_{u}\right) & =\mathcal{I} \mathcal{W}\left(S_{0}, \nu_{0}\right) \\
p\left(\operatorname{vec}(\phi) \mid Q_{u}\right) & =\mathcal{N}\left(\bar{\phi}_{0}, Q_{u} \otimes N_{0}^{-1}\right)
\end{aligned}
$$

\footnotetext{
${ }^{10}$ For a derivation see Gelman, Carlin, Stern and Rubin [1995],
} 
which results in the following posterior:

with

$$
\begin{aligned}
p\left(Q_{u} \mid X^{T}, F^{T}\right) & =\mathcal{I} \mathcal{W}\left(S_{T}, \nu_{T}\right) \\
P\left(\operatorname{vec}(\phi) \mid X^{T}, F^{T}, Q_{u}\right) & =\mathcal{N}\left(\operatorname{vec}\left(\bar{\phi}_{T}\right), Q_{u} \otimes N_{T}^{-1}\right)
\end{aligned}
$$

$$
\begin{aligned}
\nu_{T} & =T+\nu_{0} \\
N_{T} & =N_{0}+\left(F_{T-1}^{\prime} F_{T-1}\right) \\
\bar{\phi}_{T} & =N_{T}^{-1}\left(N_{0} \bar{\phi}_{0}+F_{T-1}^{\prime} F_{T-1} \hat{\phi}\right) \\
S_{T} & =\frac{\nu_{0}}{\nu_{T}} S_{0}+\frac{T}{\nu_{T}} \hat{Q_{u}}+\frac{1}{\nu_{T}}\left(\hat{\phi}-\bar{\phi}_{0}\right)^{\prime} N_{0}\left(N_{T}\right)^{-1}\left(F_{T-1}^{\prime} F_{T-1}\right)\left(\hat{\phi}-\bar{\phi}_{0}\right)
\end{aligned}
$$

This prior and has the following specification

$$
\begin{aligned}
\nu_{0} & =0 \\
N_{0} & =0_{K \times K}
\end{aligned}
$$

where the choice of $S_{0}$ and $\bar{\phi}_{0}$ are arbitrary as they cancel out in the posterior. We alternatively also implemented the Normal-Wishart prior for according to Kadiyala and Karlsson [1997] where the diagonal elements of $Q_{0}$ are set to the corresponding $p$-lag univariate autoregressions, $\sigma_{i}^{2}$. The diagonal elements of $\Omega_{0}$ are constructed such that the prior variances of the parameter of the $k$ lagged $j$ 'th variable in the $i$ 'th equation equals $\sigma_{i}^{2} / k \sigma_{j}^{2}$. Hence $S_{0}=Q_{0}$ and $\bar{\phi}_{0}=\mathbf{0}$. Results were virtually the same. To ensure stationarity, we truncate the draws by discarding

\begin{tabular}{|c|c|c|c|}
\hline Pos: & Shortname & Mnemonics & Description \\
\hline 1 & PI & $\mathrm{a} 0 \mathrm{~m} 052$ & Personal income (AR, bil. chain $2005 \$)$ \\
\hline 2 & $\begin{array}{l}\text { PI less trans- } \\
\text { fers }\end{array}$ & A0M051 & Personal income less transfer payments (AR, bil. chain $2005 \$$ ) \\
\hline 3 & M\&T sales & A0M057 & Manufacturing and trade sales (mil. Chain $1996 \$$ ) \\
\hline 4 & Retail sales & A0M059 & Sales of retail stores (mil. Chain $2000 \$$ ) \\
\hline 5 & IP: products & IPS11 & INDUSTRIAL PRODUCTION INDEX - PRODUCTS, TOTAL \\
\hline 6 & IP: final prod & IPS299 & INDUSTRIAL PRODUCTION INDEX - FINAL PRODUCTS \\
\hline 7 & IP: cons gds & IPS12 & INDUSTRIAL PRODUCTION INDEX - CONSUMER GOODS \\
\hline 8 & IP: cons dble & IPS 13 & $\begin{array}{l}\text { INDUSTRIAL PRODUCTION INDEX - DURABLE CONSUMER } \\
\text { GOODS }\end{array}$ \\
\hline 9 & $\begin{array}{l}\text { iIP:cons nond- } \\
\text { ble }\end{array}$ & IPS 18 & $\begin{array}{l}\text { INDUSTRIAL PRODUCTION INDEX - NONDURABLE CONSUMER } \\
\text { GOODS }\end{array}$ \\
\hline 10 & IP:bus eqpt & IPS25 & INDUSTRIAL PRODUCTION INDEX - BUSINESS EQUIPMENT \\
\hline 11 & IP : matls & IPS32 & INDUSTRIAL PRODUCTION INDEX - MATERIALS \\
\hline 12 & IP: dble mats & IPS34 & $\begin{array}{l}\text { INDUSTRIAL PRODUCTION INDEX - DURABLE GOODS MATERI- } \\
\text { ALS }\end{array}$ \\
\hline 13 & $\begin{array}{l}\text { IP:nondble } \\
\text { mats }\end{array}$ & IPS38 & $\begin{array}{l}\text { INDUSTRIAL PRODUCTION INDEX - NONDURABLE GOODS MA- } \\
\text { TERIALS }\end{array}$ \\
\hline 14 & IP : $\mathrm{mfg}$ & & INDUSTRIAL PRODUCTION INDEX - MANUFACTURING (SIC) \\
\hline 15 & util & & INDUSTRIAL PRODUCTION INDEX - RESIDENTIAL UTILITIES \\
\hline 16 & IP : $f$ & & INDUSTRIAL PRODUCTION INDEX - FUELS \\
\hline 17 & & & INDUSTRIAL PRODUCTION INDEX - TOTAL INDEX \\
\hline 18 & Real & $\mathrm{DP}$ & RealGDP \\
\hline 19 & PCE Def & PCEPI & $\begin{array}{l}\text { Personal Consumption Expenditures: Chain-type Price Index (Keep } \\
\text { used as defator in progam) }\end{array}$ \\
\hline 20 & PCED lfe & PCEPILFE & $\begin{array}{l}\text { Personal Consumption Expenditures: Chain-Type Price Index Less Food } \\
\text { and Energy (Keep used as defator in progam) }\end{array}$ \\
\hline 21 & NAPM prodn & & NAPM PRODUCTION INDEX (PERCENT) \\
\hline 22 & & & Capacity Utilization (Mfg) \\
\hline 23 & Emp CPS total & & CIVILIAN LABOR FORCE: EMPLOYED, TOTAL (THOUS.,SA) \\
\hline 24 & $\begin{array}{ll}\text { Emp } & \text { CPS } \\
\text { nonag }\end{array}$ & LHNAG & $\begin{array}{l}\text { CIVILIAN LABOR FORCE: EMPLOYED, NONAGRIC.INDUSTRIES } \\
\text { (THOUS.,SA) }\end{array}$ \\
\hline 25 & & LHUR & $\begin{array}{l}\text { UNEMPLOYMENT RATE: ALL WORKERS, } 16 \text { YEARS \& OVER } \\
(\%, S A)\end{array}$ \\
\hline
\end{tabular}
the draws of $\phi$ with the larges eigenvalue greater than 1 in absolute value.

\section{APPENDIX B: TABLES AND FIGURES}

\section{B.1. Data}

Table (I) contains our set of monthly macroeonomic data from 1960 : 02 to 2010 : 06, building and extending a data set provided by Stock and Watson [2005] and lists the short name of each series, its mnemonic (the series label used in the source database) and a brief data description. 


\begin{tabular}{|c|c|c|c|}
\hline Pos| & Shortname & Mnemonics & Description \\
\hline 26 & $\begin{array}{l}\text { U: mean dura- } \\
\text { tion }\end{array}$ & LHU680 & $\begin{array}{lll}\text { UNEMPLOY.BY DURATION: } & \text { AVERAGE(MEAN)DURATION } & \text { IN } \\
\text { WEEKS (SA) } & & \end{array}$ \\
\hline 27 & $\mathrm{U}<5$ wks & LHU5 & $\begin{array}{l}\text { UNEMPLOY.BY DURATION: PERSONS UNEMPL.LESS THAN } 5 \text { WKS } \\
\text { (THOUS.,SA) }\end{array}$ \\
\hline 28 & U 5-14 wks & LHU 14 & $\begin{array}{l}\text { UNEMPLOY.BY DURATION: PERSONS UNEMPL.5 TO } 14 \text { WKS } \\
\text { (THOUS.,SA) }\end{array}$ \\
\hline 29 & U $15+$ wks & LHU 15 & $\begin{array}{l}\text { UNEMPLOY.BY DURATION: } \\
\text { (THOUS.,SA) }\end{array}$ \\
\hline 30 & U $15-26$ wks & LHU 26 & $\begin{array}{l}\text { UNEMPLOY.BY DURATION: PERSONS UNEMPL.15 TO } 26 \text { WKS } \\
\text { (THOUS.,SA) }\end{array}$ \\
\hline 31 & U $27+$ wks & LHU 27 & $\begin{array}{l}\text { UNEMPLOY.BY DURATION: } \\
\text { (THOUS,SA) }\end{array}$ \\
\hline 32 & UI claims & A0M005 & Average weekly initial claims, unemploy. insurance (thous.) \\
\hline 33 & Emp: total & CESO02 & EMPLOYEES ON NONFARM PAYROLLS - TOTAL PRIVATE \\
\hline 34 & Emp: gds prod & CESO03 & EMPLOYEES ON NONFARM PAYROLLS - GOODS-PRODUCING \\
\hline 35 & Emp: mining & CES006 & EMPLOYEES ON NONFARM PAYROLLS - MINING \\
\hline 36 & Emp: const & CES011 & EMPLOYEES ON NONFARM PAYROLLS - CONSTRUCTION \\
\hline 37 & Emp: $\mathrm{mfg}$ & CES015 & EMPLOYEES ON NONFARM PAYROLLS - MANUFACTURING \\
\hline 38 & Emp: dble gds & CES017 & EMPLOYEES ON NONFARM PAYROLLS - DURABLE GOODS \\
\hline 39 & Emp: nondbles & CESO33 & EMPLOYEES ON NONFARM PAYROLLS - NONDURABLE GOODS \\
\hline 40 & Emp: services & CESO46 & EMPLOYEES ON NONFARM PAYROLLS - SERVICE-PROVIDING \\
\hline 41 & Emp: TTU & CES048 & $\begin{array}{l}\text { EMPLOYEES ON NONFARM PAYROLLS - TRADE, TRANSPORTA- } \\
\text { TION, AND UTILITIES }\end{array}$ \\
\hline 42 & $\begin{array}{l}\text { Emp: whole- } \\
\text { sale }\end{array}$ & CES049 & EMPLOYEES ON NONFARM PAYROLLS - WHOLESALE TRADE \\
\hline 43 & Emp: retail & CESO53 & EMPLOYEES ON NONFARM PAYROLLS - RETAIL TRADE \\
\hline 44 & Emp: FIRE & CES088 & EMPLOYEES ON NONFARM PAYROLLS - FINANCIAL ACTIVITIES \\
\hline 45 & Emp: Govt & CES140 & EMPLOYEES ON NONFARM PAYROLLS - GOVERNMENT \\
\hline 46 & Avg hrs & CES151 & $\begin{array}{l}\text { AVERAGE WEEKLY HOURS OF PRODUCTION OR NONSUPERVI- } \\
\text { SORY WORKERS ON PRIVATE NONFAR }\end{array}$ \\
\hline 47 & Overtime: $\mathrm{mfg}$ & CES155 & $\begin{array}{l}\text { AVERAGE WEEKLY HOURS OF PRODUCTION OR NONSUPERVI- } \\
\text { SORY WORKERS ON PRIVATE NONFAR }\end{array}$ \\
\hline 48 & Avg hrs: $\mathrm{mfg}$ & aom001 & Average weekly hours, mfg. (hours) \\
\hline 49 & NAPM empl & PMEMP & NAPM EMPLOYMENT INDEX (PERCENT) \\
\hline 50 & HStarts: Total & HSFR & $\begin{array}{l}\text { STARTS:NONFARM(1947-58);TOTAL } \\
\text { FARM\&NONFARM(1959-)(THOUS.,SA }\end{array}$ \\
\hline 51 & HStarts: NE & HSNE & HOUSING STARTS:NORTHEAST (THOUS.U.)S.A. \\
\hline 52 & HStarts: MW & HSMW & HOUSING STARTS:MIDWEST(THOUS.U.)S.A. \\
\hline 53 & HStarts: South & HSSOU & HOUSING STARTS:SOUTH (THOUS.U.)S.A. \\
\hline 54 & HStarts: West & HSWST & HOUSING STARTS:WEST (THOUS.U.)S.A. \\
\hline 55 & BP: total & HSBR & $\begin{array}{l}\text { HOUSING AUTHORIZED: TOTAL NEW PRIV HOUSING UNITS } \\
\text { (THOUS.,SAAR) }\end{array}$ \\
\hline 56 & BP: NE & HSBNE & 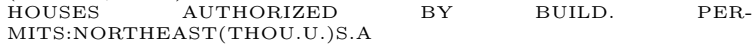 \\
\hline 57 & BP: MW & HSBMW & $\begin{array}{lcccc}\text { HOUSES AUTHORIZED } & \text { BY } & \text { BUILD. } & \text { PER- } \\
\text { MITS:MIDWEST(THOU.U.)S.A. } & & & \end{array}$ \\
\hline 58 & BP: South & HSBSOU & HOUSES AUTHORIZED BY BUILD. PERMITS:SOUTH(THOU.U.)S.A. \\
\hline 59 & BP: West & HSBWST & HOUSES AUTHORIZED BY BUILD. PERMITS:WEST(THOU.U.)S.A. \\
\hline 60 & PMI & PMI & PURCHASING MANAGERS' INDEX (SA) \\
\hline 61 & $\begin{array}{l}\text { NAPM new or- } \\
\text { drs }\end{array}$ & PMNO & NAPM NEW ORDERS INDEX (PERCENT) \\
\hline 62 & $\begin{array}{l}\text { NAPM vendor } \\
\text { del }\end{array}$ & PMDEL & NAPM VENDOR DELIVERIES INDEX (PERCENT) \\
\hline 63 & $\begin{array}{l}\text { NAPM Inven- } \\
\text { tories }\end{array}$ & PMNV & NAPM INVENTORIES INDEX (PERCENT) \\
\hline 64 & $\begin{array}{l}\text { Orders: cons } \\
\text { gds }\end{array}$ & A0M008 & Mfrs' new orders, consumer goods and materials (bil. chain $1982 \$$ ) \\
\hline 65 & $\begin{array}{l}\text { Orders: dble } \\
\text { gds }\end{array}$ & A0M007 & Mfrs' new orders, durable goods industries (bil. chain $2000 \$$ ) \\
\hline 66 & $\begin{array}{l}\text { Orders: cap } \\
\text { gds }\end{array}$ & $\mathrm{A} 0 \mathrm{M} 027$ & Mfrs' new orders, nondefense capital goods (mil. chain $1982 \$$ ) \\
\hline 67 & $\begin{array}{l}\text { Unf } \\
\text { dble }\end{array}$ & A1M092 & Mfrs' unfilled orders, durable goods indus. (bil. chain $2000 \$$ ) \\
\hline 68 & M\&T invent & A0M070 & Manufacturing and trade inventories (bil. Chain 2005 \$) \\
\hline 69 & & FM1 & $\begin{array}{l}\text { MONEY STOCK: M1(CURR,TRAV.CKS,DEM DEP,OTHER CK'ABLE } \\
\text { DEP)(BIL\$,SA) }\end{array}$ \\
\hline 70 & M2 & FM2 & $\begin{array}{l}\text { MONEY STOCK:M2(M1+O'NITE } \\
\text { MMMFS\&SAV\&SM TIME DEP(BIL } \$ \text {, }\end{array}$ \\
\hline 71 & MB & FMFBA & $\begin{array}{l}\text { MONETARY BASE, ADJ FOR RESERVE } \\
\text { CHANGES(BIL } \$ \text {,SA) }\end{array}$ \\
\hline 72 & Reserves tot & FMRRA & $\begin{array}{l}\text { DEPOSITORY INST RESERVES:TOTAL,ADJ FOR RESERVE REQ } \\
\text { CHGS(BIL } \$, S A)\end{array}$ \\
\hline 73 & $\begin{array}{l}\text { Reserves non- } \\
\text { bor }\end{array}$ & FMRNBA & $\begin{array}{l}\text { DEPOSITORY INST RESERVES:NONBORROWED,ADJ RES REQ } \\
\text { CHGS(BIL } \$, S A)\end{array}$ \\
\hline 74 & LoansRealEst & LoansRealEst & Real Estate Loans at All Commercial Banks \\
\hline 75 & C\&I loans & FCLNQ & $\begin{array}{l}\text { Commercial and Industrial Loans at All Commercial Banks (BUS- } \\
\text { LOANS), bil } \$ \text { (SA) }\end{array}$ \\
\hline 76 & Cons credit & CCINRV & CONSUMER CREDIT OUTSTANDING - NONREVOLVING(G19) \\
\hline 77 & Inst cred/PI & A0M095 & Ratio, consumer installment credit to personal income (pct.) \\
\hline 78 & S\&P 500 & FSPCOM & S\&P'S COMMON STOCK PRICE INDEX: COMPOSITE $(1941-43=10)$ \\
\hline 79 & DJIA & FSDJ & COMMON STOCK PRICES: DOW JONES INDUSTRIAL AVERAGE \\
\hline 80 & S\&P div yield & FSDXP & $\begin{array}{l}\text { S\&P'S COMPOSITE COMMON STOCK: DIVIDEND YIELD (\% PER } \\
\text { ANNUM) }\end{array}$ \\
\hline 81 & S\&P PE ratio & FSPXE & $\begin{array}{l}\text { S\&P'S COMPOSITE COMMON STOCK: PRICE-EARNINGS RATIO } \\
(\%, \text { Cyclically Adjusted) }\end{array}$ \\
\hline
\end{tabular}




\begin{tabular}{|c|c|c|c|}
\hline Pos| & Shortname & Mnemonics & Description \\
\hline 82 & FedFunds & FYFF & $\begin{array}{l}\text { INTEREST RATE: FEDERAL FUNDS (EFFECTIVE) (\% PER AN- } \\
\text { NUM,NSA) }\end{array}$ \\
\hline 83 & Commpaper & CP90 & Cmmercial Paper Rate (AC) \\
\hline 84 & 3 mo T-bill & FYGM3 & $\begin{array}{l}\text { INTEREST RATE: U.S.TREASURY BILLS,SEC MKT,3-MO.(\% PER } \\
\text { ANN,NSA) }\end{array}$ \\
\hline 85 & 6 mo T-bill & FYGM6 & $\begin{array}{l}\text { INTEREST RATE: U.S.TREASURY BILLS,SEC MKT,6-MO.(\% PER } \\
\text { ANN,NSA) }\end{array}$ \\
\hline 86 & $1 \mathrm{yr} \mathrm{T}$-bond & FYGT1 & $\begin{array}{l}\text { INTEREST RATE: U.S.TREASURY CONST MATURITIES,1-YR.(\% } \\
\text { PER ANN,NSA) }\end{array}$ \\
\hline 87 & 5 yr T-bond & FYGT5 & $\begin{array}{l}\text { INTEREST RÁTE: U.S.TREASURY CONST MATURITIES,5-YR.(\% } \\
\text { PER ANN,NSA) }\end{array}$ \\
\hline 88 & $10 \mathrm{yr}$ T-bond & FYGT10 & $\begin{array}{l}\text { INTEREST RATE: U.S.TREASURY CONST MATURITIES,10-YR.(\% } \\
\text { PER ANN,NSA) }\end{array}$ \\
\hline 89 & Aaabond & FYAAAC & BOND YIELD: MOODY'S AAA CORPORATE (\% PER ANNUM) \\
\hline 90 & Baa bond & FYBAAC & BOND YIELD: MOODY'S BAA CORPORATE (\% PER ANNUM) \\
\hline 91 & CP-FF spread & $\operatorname{scp} 90$ & cp90-fyff \\
\hline 92 & $\begin{array}{ll}3 & \text { mo-FF } \\
\text { spread } & \end{array}$ & sfygm3 & fygm 3 -fyff \\
\hline 93 & $\begin{array}{ll}6 & \text { mo-FF } \\
\text { spread } & \end{array}$ & sFYGM6 & fygm6-fyff \\
\hline 94 & 1 yr-FF spread & sFYGT1 & fygt1-fyff \\
\hline 95 & 5 yr-FFspread & sFYGT5 & fygt5-fyff \\
\hline 96 & $10 y r-F F$ spread & SFYGT10 & fygt 10 -fyff \\
\hline 97 & Aaa-FF spread & & fyaaac-fyff \\
\hline 98 & Baa-FF spread & sFYBAAC & fybaac-fyff \\
\hline 99 & Ex rate: major & $\begin{array}{l}\text { Ex rate: } \\
\text { major }\end{array}$ & $\begin{array}{l}\text { FRB Nominal Major Currencies Dollar Index (Linked to EXRUS in } \\
\text { 1973:1) }\end{array}$ \\
\hline 100 & Ex rate: Switz & EXRSW & $\begin{array}{l}\text { FOREIGN EXCHANGE RATE: SWITZERLAND (SWISS FRANC PER } \\
\text { U.S.\$) }\end{array}$ \\
\hline 101 & Ex rate: Japan & EXRJAN & FOREIGN EXCHANGE RATE: JAPAN (YEN PER U.S.\$) \\
\hline 102 & Ex rate: UK & EXRUK & $\begin{array}{l}\text { FOREIGN EXCHANGE RATE: UNITED KINGDOM (CENTS PER } \\
\text { POUND) }\end{array}$ \\
\hline 103 & $\begin{array}{ll}\text { EX } & \text { rate: } \\
\text { Canada } & \end{array}$ & EXRCAN & FOREIGN EXCHANGE RATE: CANADA (CANADIAN \$ PER U.S.\$) \\
\hline 104 & PPI: fin gds & PWFSA & PRODUCER PRICE INDEX: FINISHED GOODS $(82=100, \mathrm{SA})$ \\
\hline 105 & PPI: cons gds & PWFCSA & $\begin{array}{l}\text { PRODUCER PRICE INDEX:FINISHED CONSUMER GOODS } \\
(82=100, \mathrm{SA})\end{array}$ \\
\hline 106 & PPI: int matls & PWIMSA & $\begin{array}{l}\text { PRODUCER PRICE INDEX:INTERMED MAT.SUPPLIES \& COMPO- } \\
\text { NENTS }(82=100, \text { SA })\end{array}$ \\
\hline 107 & $\begin{array}{l}\text { PPI: } \quad \text { crude } \\
\text { matls }\end{array}$ & PWCMSA & PRODUCER PRICE INDEX:CRUDE MATERIALS $(82=100, \mathrm{SA})$ \\
\hline 108 & $\begin{array}{l}\text { NAPM } \quad \text { com } \\
\text { price }\end{array}$ & $\mathrm{PMCP}$ & NAPM COMMODITY PRICES INDEX (PERCENT) \\
\hline 109 & CPI-U: all & PUNEW & CPI-U: ALL ITEMS $(82-84=100, \mathrm{SA})$ \\
\hline 110 & CPI-U: apparel & U83 & CPI-U: APPAREL \& UPKEEP $(82-84=100, \mathrm{SA})$ \\
\hline 111 & CPI-U: transp & PU 84 & CPI-U: TRANSPORTATION $(82-84=100, \mathrm{SA})$ \\
\hline 112 & $\begin{array}{l}\text { CPI-U: medi- } \\
\text { cal }\end{array}$ & PU85 & CPI-U: MEDICAL CARE $(82-84=100, \mathrm{SA})$ \\
\hline 113 & CPI-U: comm. & PUC & CPI-U: COMMODITIES $(82-84=100, \mathrm{SA})$ \\
\hline 114 & CPI-U: dbles & PUCD & CPI-U: DURABLES $(82-84=100, \mathrm{SA})$ \\
\hline 115 & $\begin{array}{l}\text { CPI-U: ser- } \\
\text { vices }\end{array}$ & PUS & CPI-U: SERVICES $(82-84=100, \mathrm{SA})$ \\
\hline 116 & CPI-U: ex food & PUXF & CPI-U: ALL ITEMS LESS FOOD $(82-84=100, \mathrm{SA})$ \\
\hline 117 & $\begin{array}{l}\text { CPI-U: ex shel- } \\
\text { ter }\end{array}$ & PUXHS & CPI-U: ALL ITEMS LESS SHELTER $(82-84=100$, SA $)$ \\
\hline 118 & CPI-U: ex med & PUXM & CPI-U: ALL ITEMS LESS MEDICAL CARE $(82-84=100, \mathrm{SA})$ \\
\hline 119 & PCE defl & GMDC & PCE,IMPL PR DEFL:PCE $(2005=100)$ \\
\hline 120 & $\begin{array}{l}\text { PCE defl: } \\
\text { dlbes }\end{array}$ & GMDCD & PCE,IMPL PR DEFL:PCE; DURABLES $(2005=100)$ \\
\hline 121 & $\begin{array}{l}\text { PCE } \\
\text { nondble }\end{array}$ & GMDCN & PCE,IMPL PR DEFL:PCE; NONDURABLES $(2005=100)$ \\
\hline 122 & $\begin{array}{l}\text { PCE defl: ser- } \\
\text { vices }\end{array}$ & GMDCS & PCE,IMPL PR DEFL:PCE; SERVICES $(2005=100)$ \\
\hline 123 & AHE: goods & CES 275 & $\begin{array}{l}\text { AVERAGE HOURLY EARNINGS OF PRODUCTION OR NONSUPER- } \\
\text { VISORY WORKERS ON PRIVATE NO }\end{array}$ \\
\hline 124 & AHE: const & $\mathrm{CES} 277$ & $\begin{array}{l}\text { AVERAGE HOURLY EARNINGS OF PRODUCTION OR NONSUPER- } \\
\text { VISORY WORKERS ON PRIVATE NO }\end{array}$ \\
\hline 125 & AHE: $\mathrm{mfg}$ & CES 278 & $\begin{array}{l}\text { AVERAGE HOURLY EARNINGS OF PRODUCTION OR NONSUPER- } \\
\text { VISORY WORKERS ON PRIVATE NO }\end{array}$ \\
\hline 126 & $\begin{array}{l}\text { Consumer ex- } \\
\text { pect }\end{array}$ & HHSNTN & U. OF MICH. INDEX OF CONSUMER EXPECTATIONS(BCD-83) \\
\hline
\end{tabular}

B.2. Tables 
TABLE II

Share of Variance Explained by Common Factors.

\begin{tabular}{|c|c|c|c|c|c|}
\hline Variable & $R^{2}$ & Variable & $R^{2}$ & Variable & $R^{2}$ \\
\hline FedFunds & 1 & Emp: mfg & 0.76 & S\&P PE ratio & 0.39 \\
\hline CPI-U: all & 1 & PCE defl: nondble & 0.74 & IP:nondble mats & 0.39 \\
\hline 1 yr T-bond & 1 & Emp: gds prod & 0.74 & Unf orders: dble & 0.38 \\
\hline 6 mo T-bill & 1 & IP: dble mats & 0.73 & Avg hrs: mfg & 0.37 \\
\hline Aaabond & 1 & IP: matls & 0.72 & PCE defl: dlbes & 0.34 \\
\hline 5 yr T-bond & 0.99 & CP-FF spread & 0.71 & Emp: retail & 0.32 \\
\hline 3 mo T-bill & 0.99 & Emp: dble gds & 0.7 & M\&T sales & 0.31 \\
\hline 10 yr T-bond & 0.99 & Emp: total & 0.69 & Avg hrs & 0.3 \\
\hline Aaa-FF spread & 0.99 & NAPM Inventories & 0.67 & Orders: cons gds & 0.3 \\
\hline Commpaper & 0.99 & IP: cons gds & 0.66 & $\mathrm{U} 15+\mathrm{wks}$ & 0.28 \\
\hline Baa bond & 0.99 & IP: cons dble & 0.62 & Emp: FIRE & 0.28 \\
\hline 10yr-FF spread & 0.99 & NAPM vendor del & 0.6 & Emp CPS nonag & 0.24 \\
\hline Baa-FF spread & 0.98 & Emp: wholesale & 0.6 & PI less transfers & 0.23 \\
\hline 1 yr-FF spread & 0.98 & CPI-U: transp & 0.59 & iIP:cons nondble & 0.23 \\
\hline 6 mo-FF spread & 0.98 & IP:bus eqpt & 0.58 & UI claims & 0.22 \\
\hline 5 yr-FFspread & 0.98 & $\mathrm{U}:$ all & 0.57 & Emp: const & 0.22 \\
\hline IP: $\mathrm{mfg}$ & 0.97 & PCED_lfe & 0.57 & Emp CPS total & 0.21 \\
\hline Cap util & 0.96 & S\&P div yield & 0.56 & PPI: crude matls & 0.2 \\
\hline PMI & 0.94 & CPI-U: services & 0.56 & $\mathrm{U} 27+$ wks & 0.2 \\
\hline IP: total & 0.93 & NAPM com price & 0.55 & CPI-U: apparel & 0.17 \\
\hline CPI-U: ex med & 0.92 & PPI: int matls & 0.55 & Overtime: mfg & 0.17 \\
\hline 3 mo-FF spread & 0.92 & PCE defl: services & 0.54 & Cons credit & 0.16 \\
\hline NAPM empl & 0.89 & PPI: fin gds & 0.53 & PI & 0.16 \\
\hline IP: products & 0.86 & Emp: nondbles & 0.5 & LoansRealEst & 0.16 \\
\hline NAPM prodn & 0.85 & Emp: TTU & 0.5 & AHE: goods & 0.16 \\
\hline CPI-U: ex shelter & 0.85 & PPI: cons gds & 0.49 & AHE: $\mathrm{mfg}$ & 0.15 \\
\hline NAPM new ordrs & 0.83 & Consumer expect & 0.49 & Orders: dble gds & 0.14 \\
\hline CPI-U: ex food & 0.83 & Emp: services & 0.45 & $\mathrm{MB}$ & 0.13 \\
\hline PCE Def & 0.82 & M\&T invent & 0.41 & BP: total & 0.13 \\
\hline PCE defl & 0.82 & C\&I loans & 0.4 & U $15-26$ wks & 0.12 \\
\hline CPI-U: comm. & 0.81 & CPI-U: dbles & 0.39 & Reserves tot & 0.11 \\
\hline IP: final prod & 0.8 & CPI-U: medical & 0.39 & $\mathrm{U}$ : mean duration & 0.1 \\
\hline BP: South & 0.1 & HStarts: South & 0.05 & IP: fuels & 0.03 \\
\hline RealGDP & 0.1 & Emp: mining & 0.05 & DJIA & 0.03 \\
\hline U 5-14 wks & 0.09 & BP: $\mathrm{MW}$ & 0.05 & $\mathrm{U}$; 5 wks & 0.03 \\
\hline M1 & 0.09 & Ex rate: Japan & 0.05 & HStarts: West & 0.02 \\
\hline Emp: Govt & 0.09 & BP: West & 0.05 & Orders: cap gds & 0.02 \\
\hline Retail sales & 0.08 & M2 & 0.04 & Reserves nonbor & 0.02 \\
\hline AHE: const & 0.08 & Ex rate: UK & 0.04 & S\&P 500 & 0.02 \\
\hline Inst cred/PI & 0.08 & $\mathrm{BP}: \mathrm{NE}$ & 0.04 & HStarts: MW & 0.02 \\
\hline HStarts: Total & 0.06 & EX rate: Canada & 0.03 & HStarts: NE & 0.02 \\
\hline Ex rate: major & 0.05 & Ex rate: Switz & 0.03 & IP: res util & 0.01 \\
\hline
\end{tabular}


BFAVAR WITH SIGN RESTRICTION

B.3. Figures: Benchmark Model 
FiguRE 8.- Output Responses: Benchmark Model

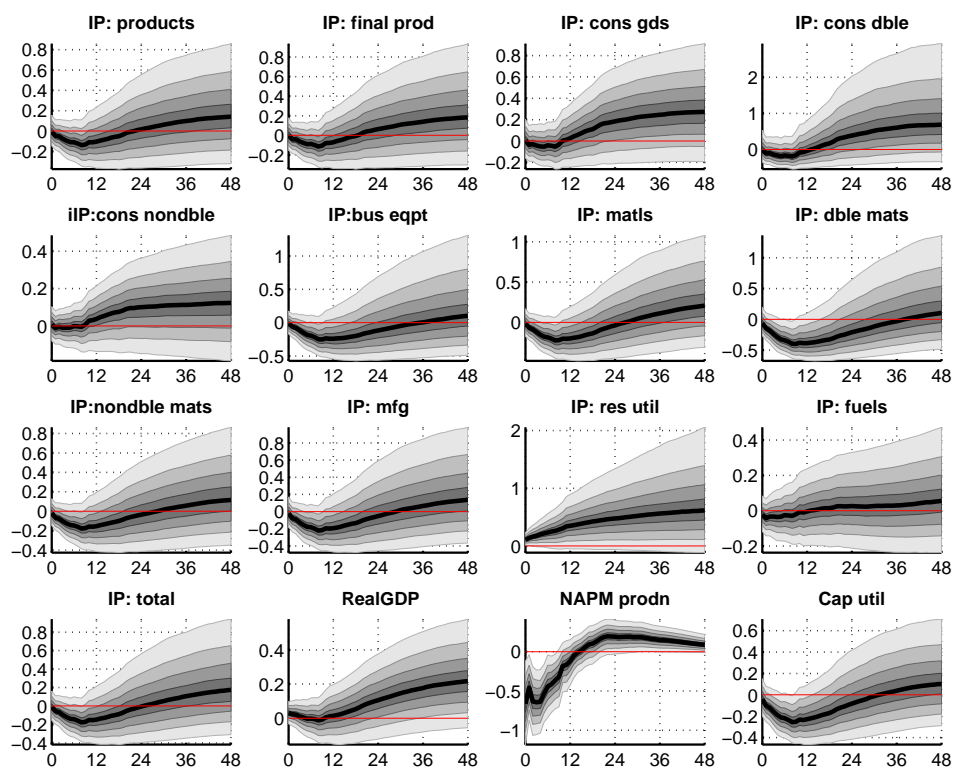

This figure provides plots of posterior IRFs for a selection of many output indicators for the benchmark model. 


\section{Figure 9.- Price Responses: Benchmark Model}
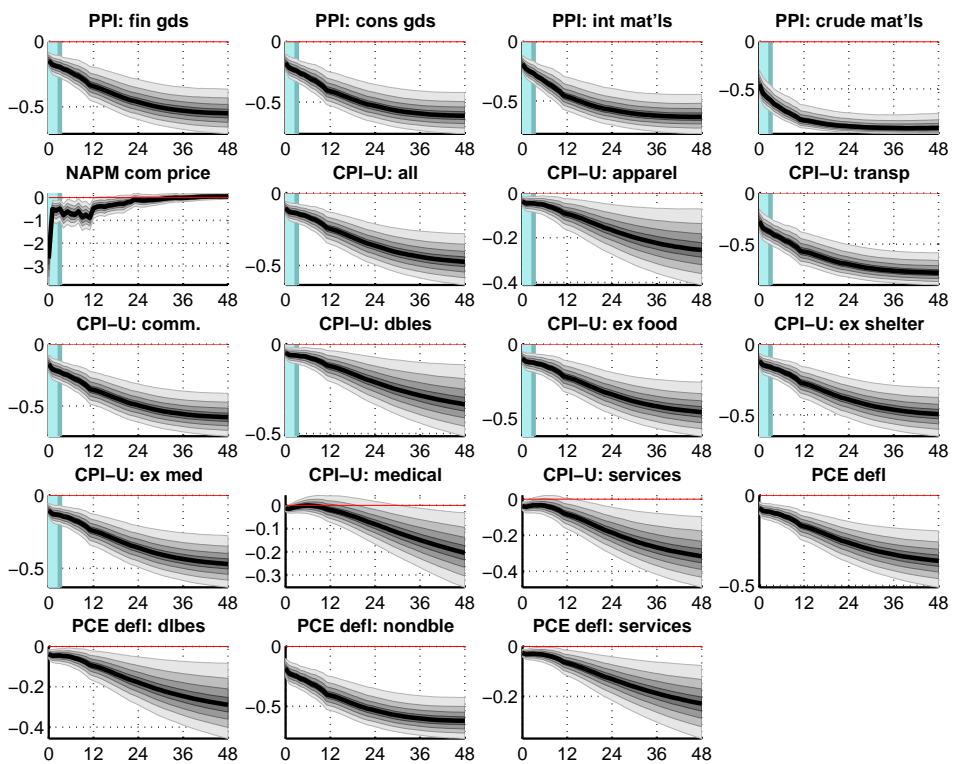

This figure provides plots of posterior IRFs for a selection of many price indicators for the benchmark model. 
Figure 10.- Unemployment Responses: Benchmark Model for the benchmark model.
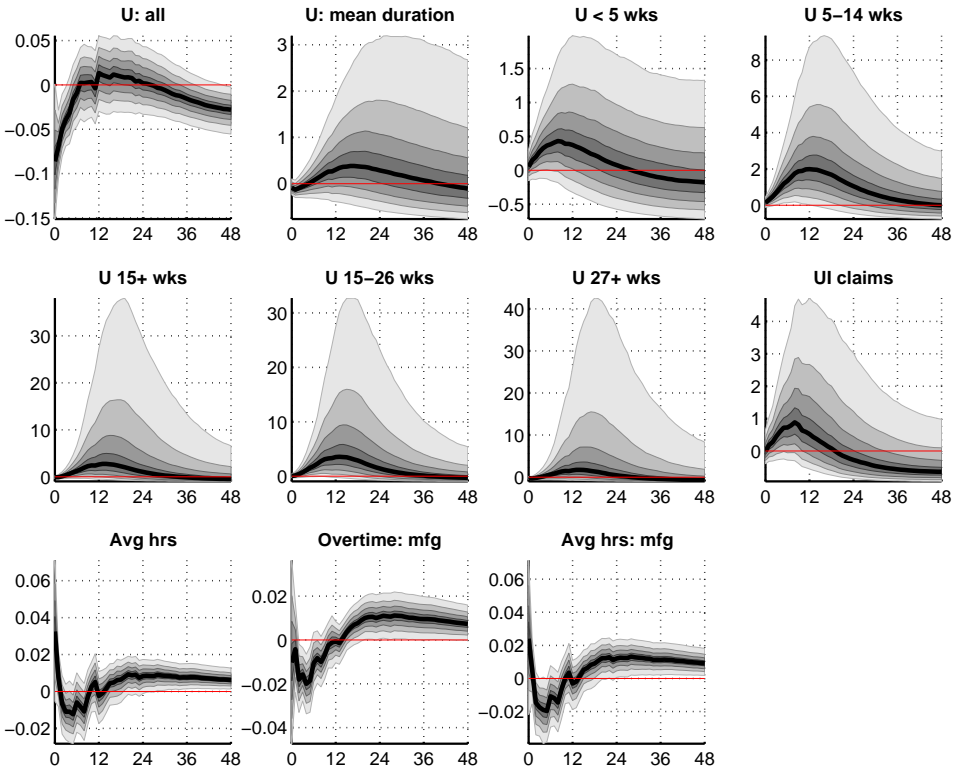

This figure provides plots of posterior IRFs for a selection of many unemployment indicators 
Figure 11.- Employment Responses: Benchmark Model
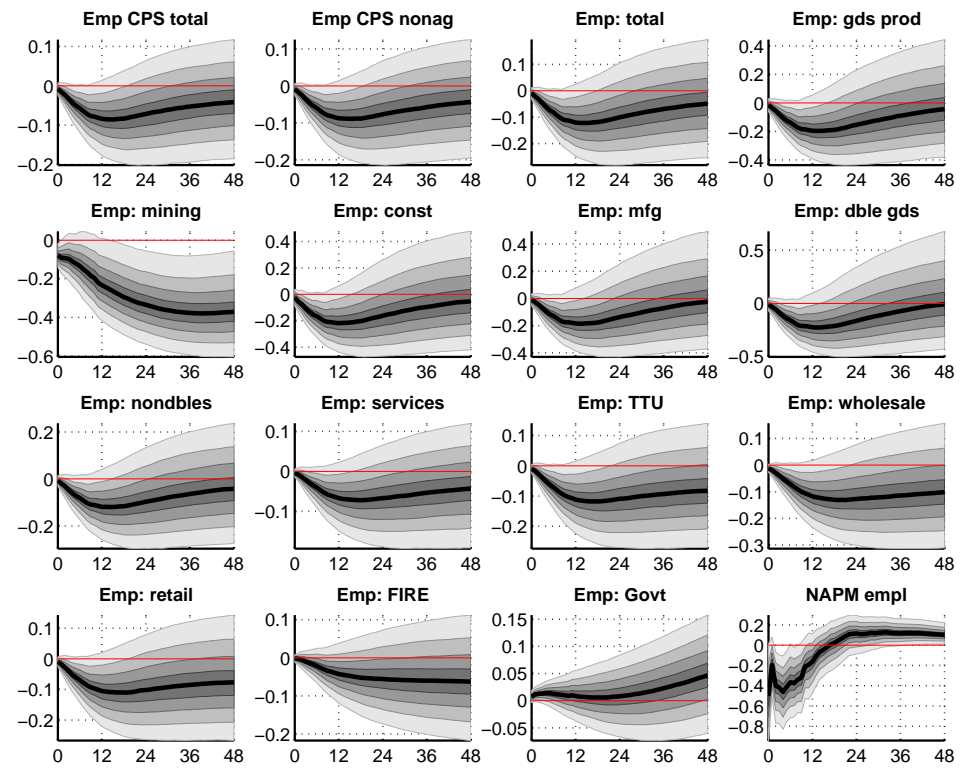

This figure provides plots of posterior IRFs for a selection of many employment indicators for the benchmark model. 


\section{Figure 12.- Loan Responses: Benchmark Model}
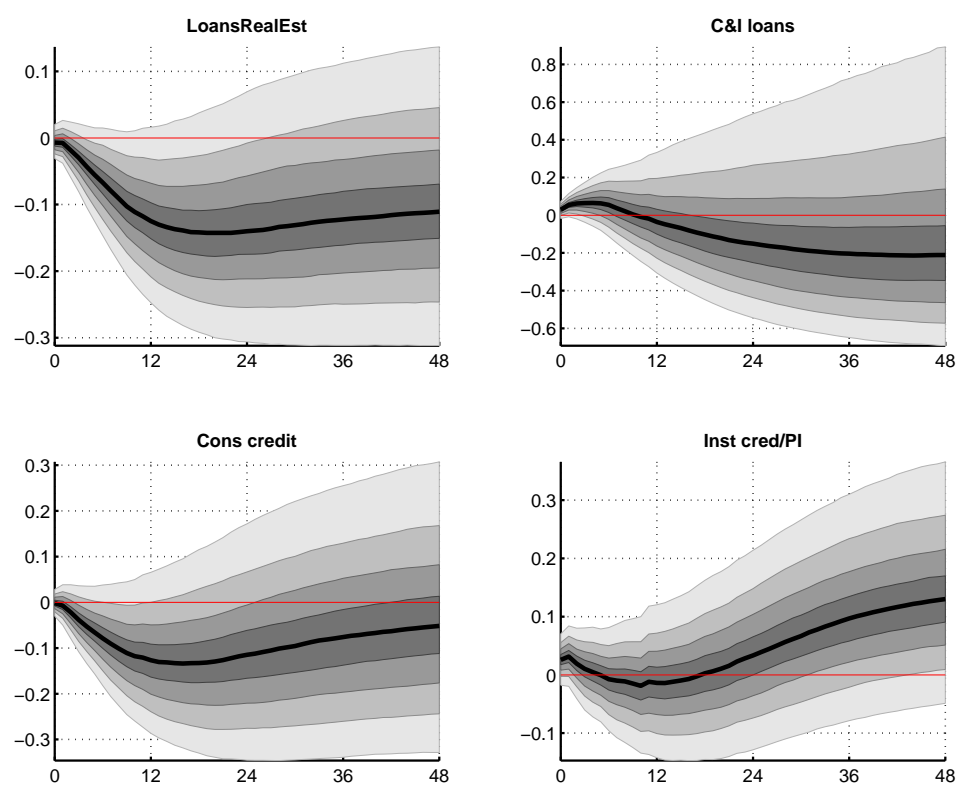

This figure provides plots of posterior IRFs for a selection of many loan indicators for the benchmark model. 


\section{FiguRE 13.- Spread Responses: Benchmark Model}
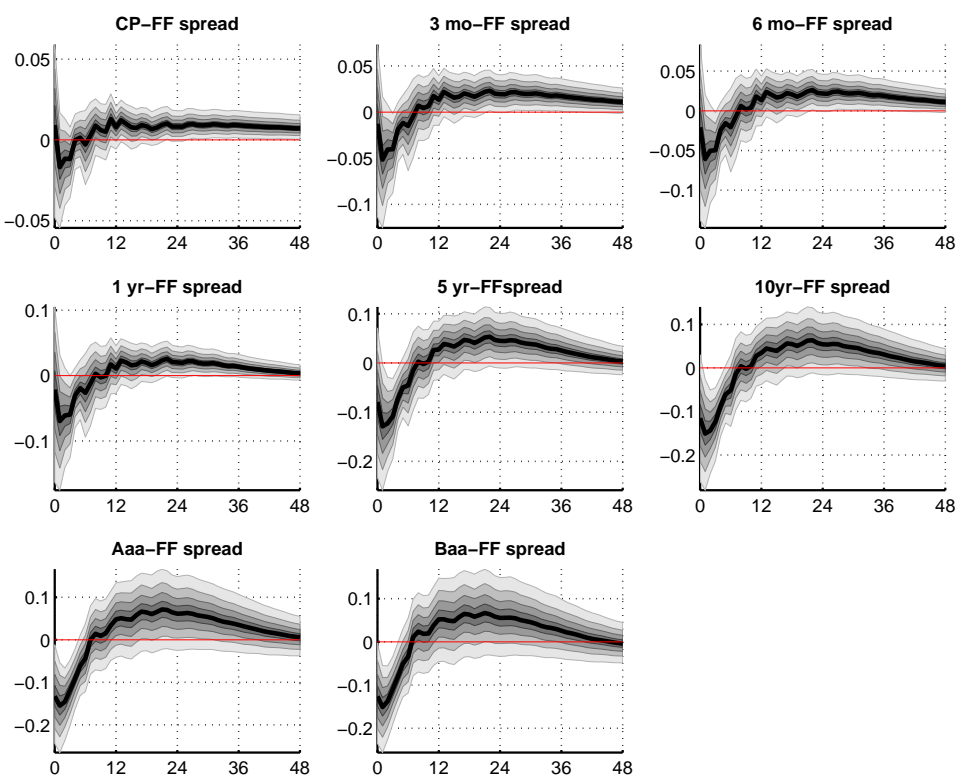

This figure provides plots of posterior IRFs for a selection of many spread indicators for the benchmark model. 


\section{REFERENCES}

[1] Amir-Ahmadi, Pooyan (2009), "Credit Shocks, Monetary Policy and Business Cycles"; working paper Goethe University Frankfurt

[2] Amir-Ahmadi, Pooyan and Albrecht Ritchl (2013), "Depression Econometrics: A FAVAR Model of Monetary Policy During the Great Depression"; CEPR Discussion Papers 7546, C.E.P.R. Discussion Papers.

[3] Arias, Jonas E., Rubio-Ramirez, Juan F. and Daniel F. Waggoner (2014), "Inference Based on SVARs Identified with Sign and Zero Restrictions: Theory and Applications", unpublished Working Paper

[4] Auerbach, Alan J., and Yuriy Gorodnichenko (2012), "Measuring the Output Responses to Fiscal Policy." American Economic Journal: Economic Policy, 4(2): 1-27.

[5] Baumeister, C. and Hamilton, J. D. (2015), "Sign Restrictions, Structural Vector Autoregressions, and Useful Prior Information." Econometrica, 83: 19631999.

[6] Bernanke, Ben and Jean Boivin (2003), "Monetary Policy in a Data-Rich Environment"; Journal of Monetary Economics 50:3, pp. 525-546

[7] Bernanke, Ben, Jean Boivin and P. Eliasz (2005), "Measuring the effects of monetary policy: a factor-augmented vector autoregressive (FAVAR) approach"; Quarterly Journal of Economics 120, pp. 387-422

[8] Bernanke, Ben and Illian Mihov (1998a), "Measuring Monetary Policy"; Quarterly Journal of Economics 113, pp. 869-902

[9] Bernanke, Ben and Illian Mihov (1998b), "The Liquidity Effect and Long-run Neutrality: Identification by Inequality Constraints"; Carnegie-Rochster Conference Series on Public Policy; 49, pp. 149-94

[10] Blanchard, Oliver J. and Mark Watson (1986), "Are All Business Cycles Alike?"; in R. J. Gordon, ed., The American Business Cycle, Chicago: University Press

[11] Blanchard, Oliver J. and Danny Quah (1989), "The Dynamics Effects of Aggregate Demand and Supply Disturbances"; American Economic Review; 79, pp. 655-73

[12] Canova, Fabio and Gianni De Nicolo (2002), "Monetary Disturbances Matter for Business Cycle Fluctuations in the G-7"; Journal of Monetary Economics; 49, pp. 1131-59

[13] Carter, C.K. and P. Kohn (1994), "On Gibbs Sampling for State Space Models?"; Biometrika 81, pp. 541-53

[14] Christiano, Lawrence, Martin Eichenbaum and Charles Evans (1999), "Monetary Policy Shocks: What Have We Learned and to What End"; ch.2 in J. B. Taylor and M. Woodford (eds.), The Handbook of Macroeconomics, v. 1a:65-148

[15] Christiano, Lawrence, Martin Eichenbaum and Charles Evans (2005), "Nominal Rigidities and the Dynamic Effects of a Shock to Monetary Policy"; Journal of Political Economy, vol. 113

[16] Timothy Cogley and Thomas J. Sargent, (2005), "Drifts and volatilities: Monetary policies and outcomes in the post WWII U.S"; Review of Economic Dynamics, Elsevier for the Society for Economic Dynamics, vol. 8(2), pages 262-302, April.

[17] J. Cochrane (1994), "Shocks"; Carnegie Rochester Conference Series on Public Policy 41, pp. 295-364

[18] Eliasz, Piotr (2005), "Likelihood-Based Inference in Large Dynamic Factor Models Using Gibbs Sampling"; Princeton University, unpublished Working Paper

[19] Gelman, A. and D.B.Rubin, (1992), "A Single Sequence from the Gibbs Sampler Gives a False Sense of Security"; in J.M. Bernardo, J. O. Berger, A. P. Dawid, and A.F.M. Smith, eds., Bayesian Statistics, Oxford: University Press

[20] Geman, S. and D. Geman, (1984), "Stochastic Relaxation, Gibbs Distribution and the Bayesian Restoration of Images"; IEEE Transactions of Pattern Analysis and Machine Intelligence 6, pp. 721-41

[21] Giacomini, Raffaella and Toru Kitagawa, T. and , (2015) "Robust inference about nonidentified SVARs"; unpublished Working Paper

[22] Gordon, David and Eric Leeper, (1994) "The Dynamic Impacts of Monetary Policy: An Exercise in Tentative Identification"; Journal of Political Economy 102, pp. 1228-47 
[23] Granziera, Eleonora, Moon, Hyungsik Roger and Frank Schorfheide (2013), "Inference for VARs Identified with Sign Restrictions"; NBER Working Paper 17140

[24] Kadiyala, Rao and Sune Karlsson, (1997) "Numerical Methods for Estimation and Inference Bayesian VAR-Models"; Journal of Applied Econometrics, Vol. 12, pp. 99-132

[25] Kilian, Lutz and Daniel P. Murphy, (2012) "Why Agnostic Sign Restrictions Are Not Enough: Understanding the Dynamics of Oil Market VAR Models"; Journal of the European Economic Association, 10(5), October 2012, 1166-1188.

[26] Leeper, Eric, Christopher Sims, and Tao Zha, (1996) "What does Monetary Policy Do?"; Brookings Papers on Economic Activity 2, 1-63

[27] Moon, Hyungsik Roger and Frank Schorfheide (2012), "Bayesian and Frequentist Inference in Partially Identified Models"; Econometrica, 80(2), 2012, 755-782.

[28] Mountford, Andrew and Harald Uhlig (2005), "What are the effects of fiscal policy shocks?"; draft, Humboldt University

[29] Mumtaz, Haroon and Paolo Surico (2009), "The Transmission of International Shocks: A Factor-Augmented VAR Approach"; Journal of Money, Credit and Banking, Blackwell Publishing, vol. 41(s1), pages 71-100, 02

[30] Primiceri, Giorgio (2005), "Time Varying Structural Vector Autoregressions and Monetary Policy", The Review of Economic Studies, 72, July 2005, pp. 821-852

[31] Quah, D. and T. J. Sargent (1993), "A Dynamic Index Model for Large Cross Sections"; in J. H. Stock and M. W. Watson, eds., Business Cycles, Indicators, and Forecasting (University of Chicago Press for the NBER, Chicago) CH.7

[32] Rubio-Ramirez, Juan F., Daniel F. Waggoner and Tao Zha (2010), "Structural Vector Autoregressions: Theory of Identification and Algorithms for Inference", Review of Economic Studies, Wiley Blackwell, vol. 77(2), pages 665-696, 04.

[33] Sargent, Thomas, Noah Williams and Tao Zha (2006), "Shocks and Government Beliefs: The Rise and Fall of American Inflation,", American Economic Review, American Economic Association, vol. 96(4), pages 1193-1224, September.

[34] Sims, Christopher (1980), "Macroeconomics and Reality", Econometrica, vol. 48, pp. 1-48

[35] Sims, Christopher (1986), "Are Forecasting Models Usable for Policy Analysis", Minneapolis Federal Reserve Bank Quarterly Review, Winter 1986, pp. 2-16

[36] Sims, Christopher (1992), "Interpreting the Macroeconomic Time Series Facts: The Effects of Monetary Policy", European Economic Review, vol. 36, pp. 975-1011

[37] Sims, Christopher and Uhlig Harald (1991) "Understanding unit rooters: a helicopter tour", Econometrica, vol. 59, pp. 1591-1600

[38] Sims, Christopher, Daniel F. Waggoner and Tao Zha (2008), "Methods for inference in large multiple-equation Markov-switching models,", Journal of Econometrics, Elsevier, vol. 146(2), pages 255-274, October.

[39] Sims, Christopher and Tao Zha (1998), "Bayesian Methods for Dynamic Multivariate Models", International Economic Review, vol. 39(4), pp. 649-68

[40] Sims, Christopher and Tao Zha (1999), "Error Bands for Impulse Responses", Econometrica, vol. 67(5), pp. 1113-55

[41] Sims, Christopher and Tao Zha (2006), "”Were There Regime Switches in U.S. Monetary Policy?", American Economic Review, American Economic Association, vol. 96(1), pages 54-81, March.

[42] Stock, J. H. and M. W. Watson (1989), "New Indexes of coincident and leading economic indicators",NBER Macroeconomics Annual, 351-393

[43] Stock, J. H. and M. W. Watson (1991), "A probability model of the coincident economic indicators",in G. Moore and K. Lahiri, eds. The leading Economic Indicators:New Approaches and Forecasting Records (Cambridge University Press) 63-90

[44] Stock, J. H. and M. W. Watson (2005), "Implications of Dynamic Factor Models for VAR Analysis", unpublished Working Paper

[45] Stock, J. H. and M. W. Watson (2011), "Dynamic Factor Models", in Oxford Handbook of Forecasting, Michael P. Clements and David F. Hendry (eds), 2011, Oxford: Oxford University Press.

[46] Stock, J. H. and M. W. Watson (2015), "Factor Models and Structural Vector Autore- 
gressions in Macroeconomics", unpublished manuscript

[47] Uhlig, Harald (1994) "What macroeconomists should know about unit roots: a Bayesian perspective", Econometric Theory, vol. 10, pp. 645-71

[48] Uhlig, Harald (1998) "The robustness of identified VAR conclusion about money. A Comment.", Carnegie-Rochester Series in Public Economics, vol. 49, pp. 245-63

[49] Uhlig, Harald (2005) "What are the effects of a shock to monetary policy? Results from an agnostic identification procedure", Journal of Monetary Economics, vol. 52, pp. 381-419 


\section{TECHNICAL APPENDIX — NOT FOR PUBLICATION}

\section{A.4. Figures: Convergence Diagnostics}

Following Primiceri(2005), we assess the convergence of the Markov chain by inspecting the autocorrelation properties of the ergodic distributions draws. Specifically, in what follows, we consider the draws inefficiency factors (henceforth, IFs), defined as the inverse of the relative numerical efficiency measure of Geweke (1992),

(A.1) $\quad R N E=(2 \pi)^{-1} \frac{1}{S(0)} \int_{-\pi}^{\pi} S(\omega) d \omega$

is the spectral density of the sequence of draws from the Gibbs sampler for the quantity of interest at the frequency $\omega$. We estimate the spectral densities by smoothing the periodograms in the frequency domain by means of a Bartlett spectral window. Following Berkowitz and Diebold (1998), we select the bandwidth parameter automatically via the procedure introduced by Beltrao and Bloomfield (1987). Figures (XXX) show, the draws IFs for the models hyperparametersi.e. the free elements of the matrices $B, Q, \Lambda, R, F$. As the figures show, the autocorrelation of the draws is uniformly very low, being in the vast majority of cases around or below 2, thus suggesting that the Markov chains have indeed converged ${ }^{11}$.

\section{FIGURE 14.- Inefficiency Factors for all parameters}

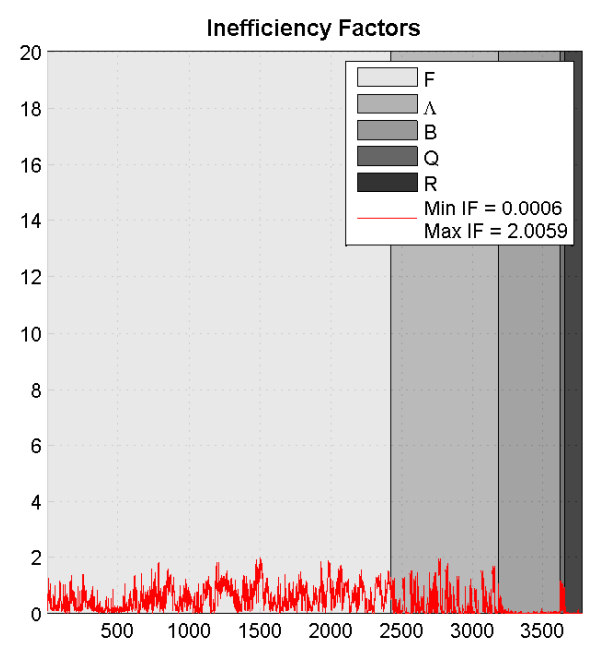

This figure reports the inefficiency factors (IFs) for the posterior estimates of the parameters. The IF is the inverse of the relative numerical efficiency measure of Gewekes (1992), i.e. the

IF is an estimate of $\left(1+2 \sum_{k=1}^{\infty} \rho_{k}\right)$, where $\rho_{k}$ is the k-th autocorrelation of the chain. Following Primiceri (2005) our estimates estimate are performed using a 4 percent tapered window for the estimation of the spectral density at frequency zero. Values of the IFs below or around twenty are regarded as satisfactory. All parameters are clearly below with the highest IF of 2.

\footnotetext{
${ }^{11}$ As stressed by Primiceri (2005, Appendix B), values of the IFs below or around twenty are generally regarded as satisfactory.
} 
FiguRE 15.- Convergence of Factors
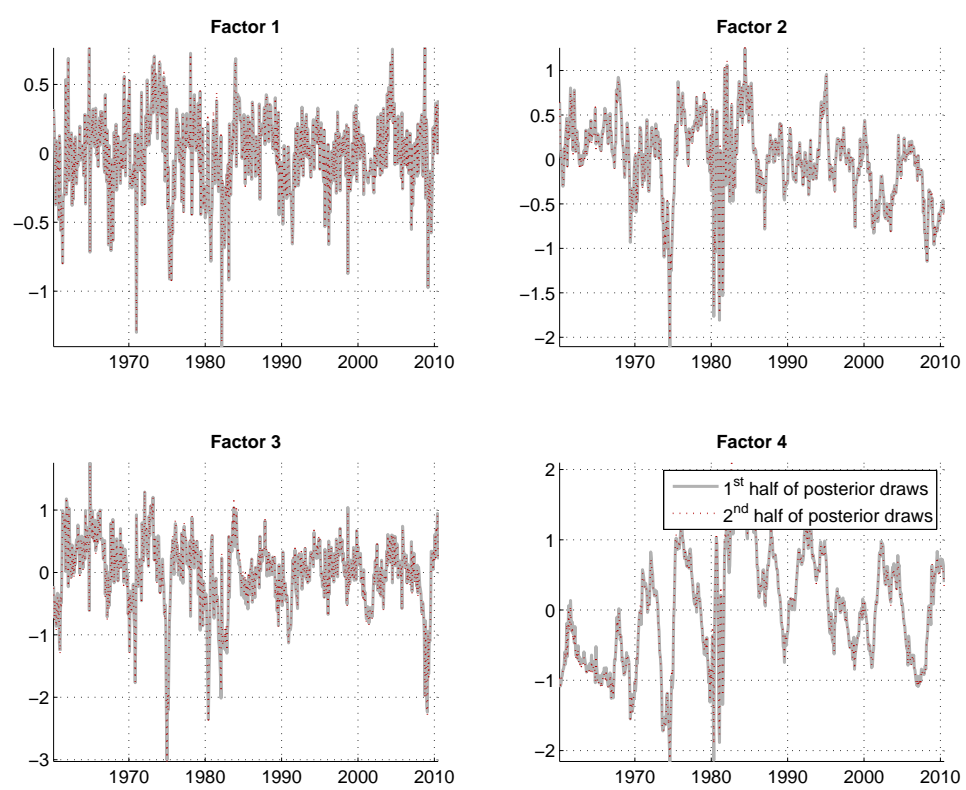
Figure 16.- Convergence of Coefficients
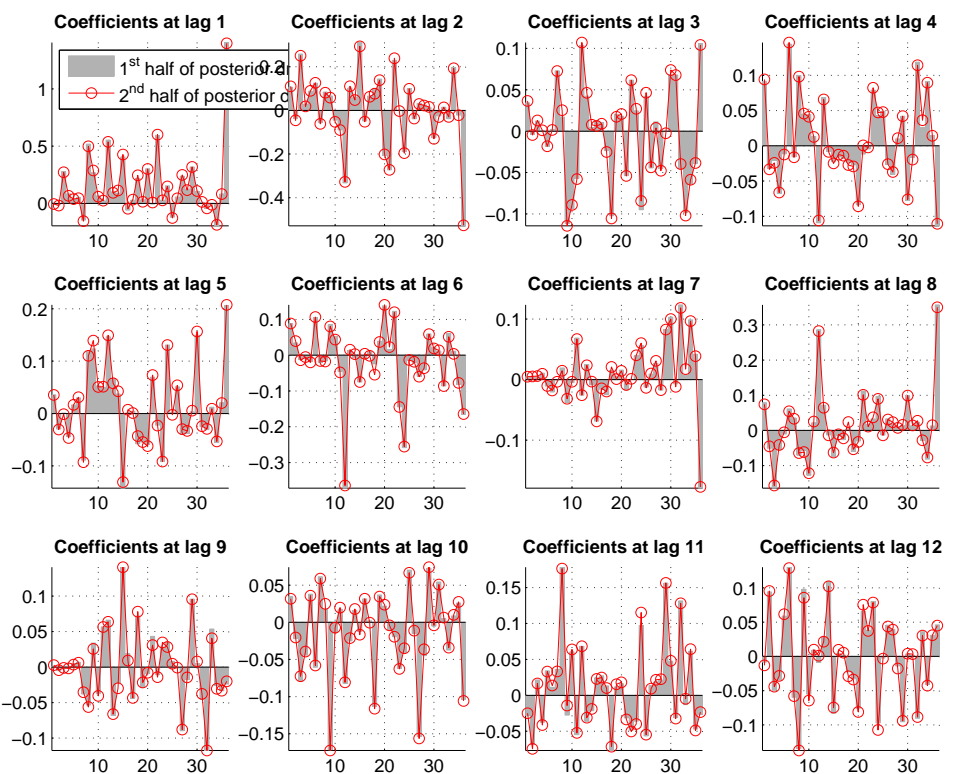
FigURE 17.- Convergence of state error covariance matrix

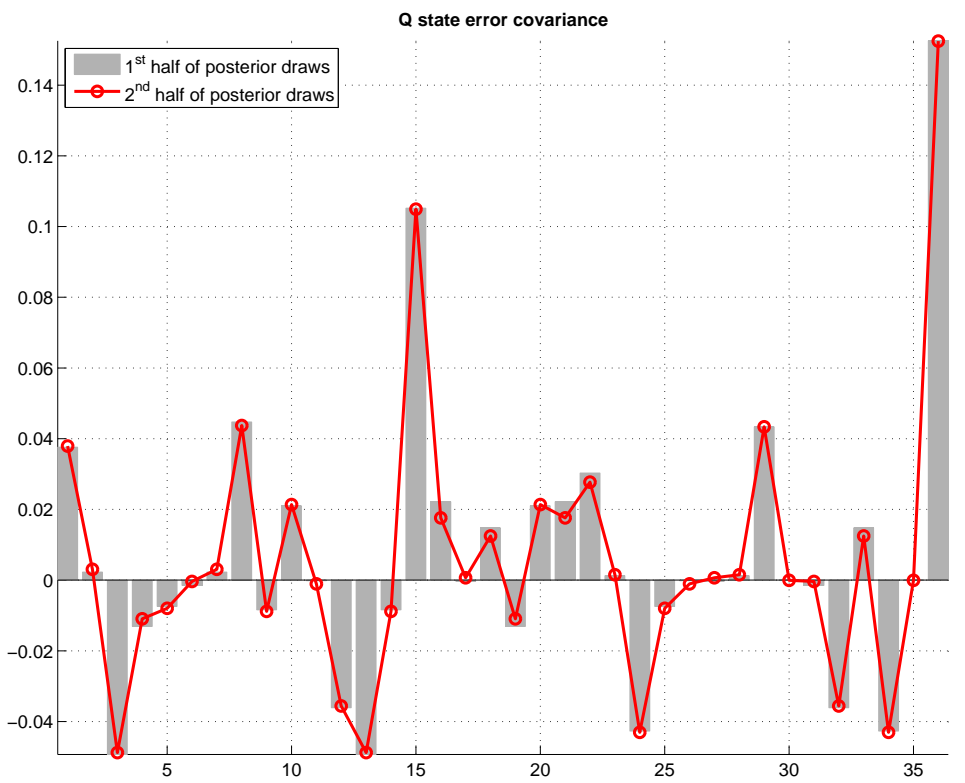


FIGURE 18.- Convergence of idiosyncratic covariance matrix

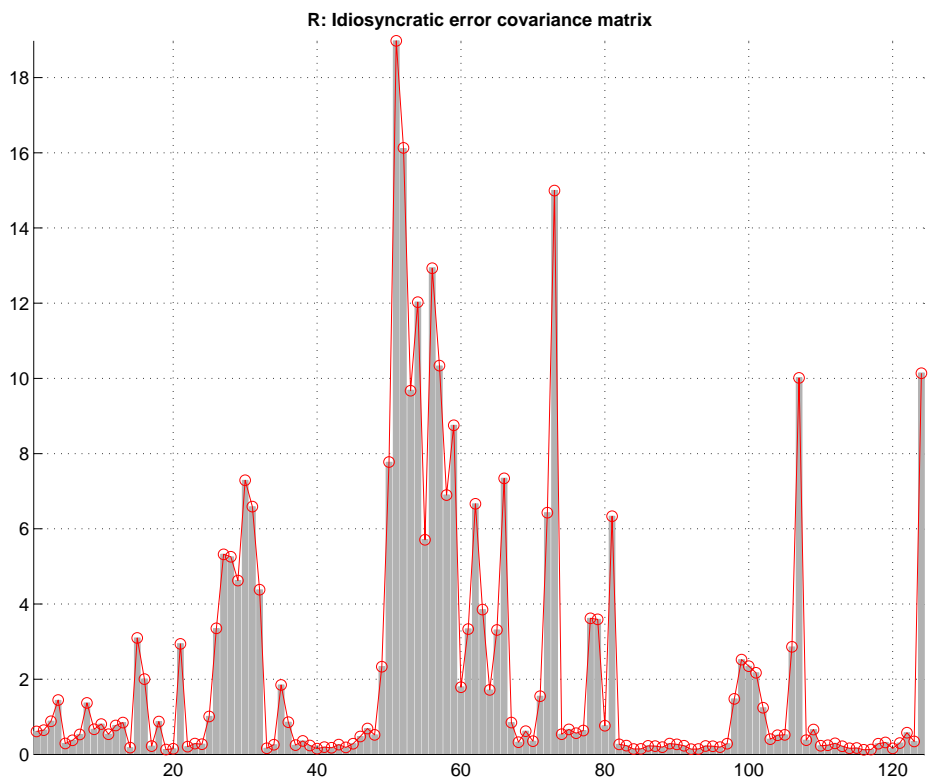




\section{FIGURE 19.- Convergence of factor loadings}
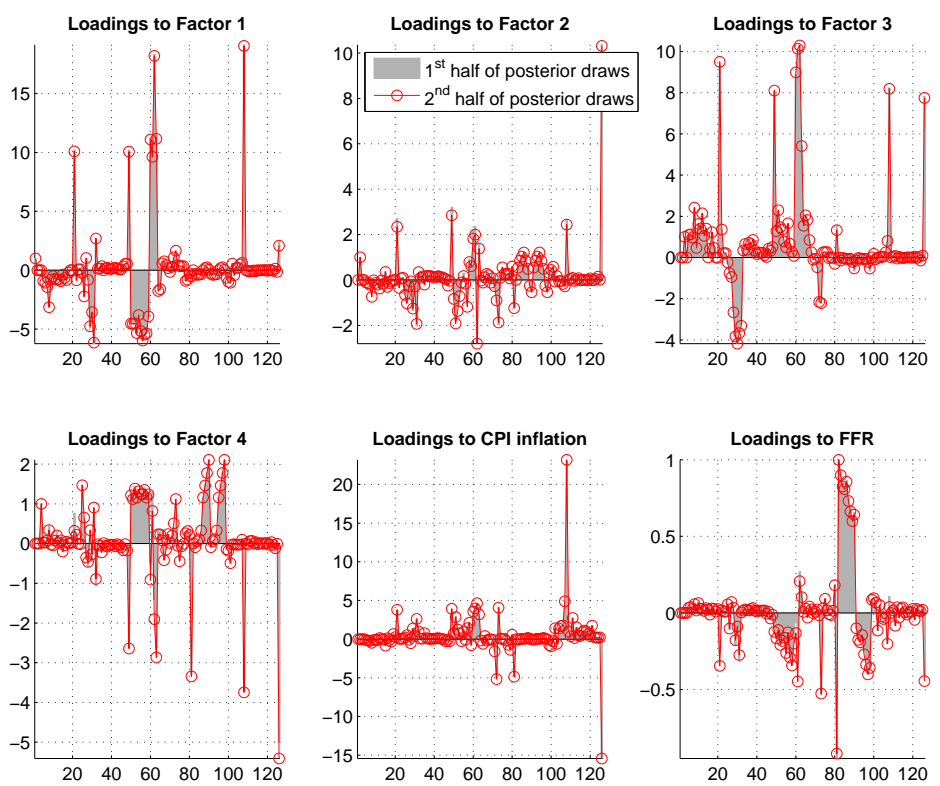
A.5. Figures: Comparisons

Figure 20.- Recursive Cholesky identification: full sample
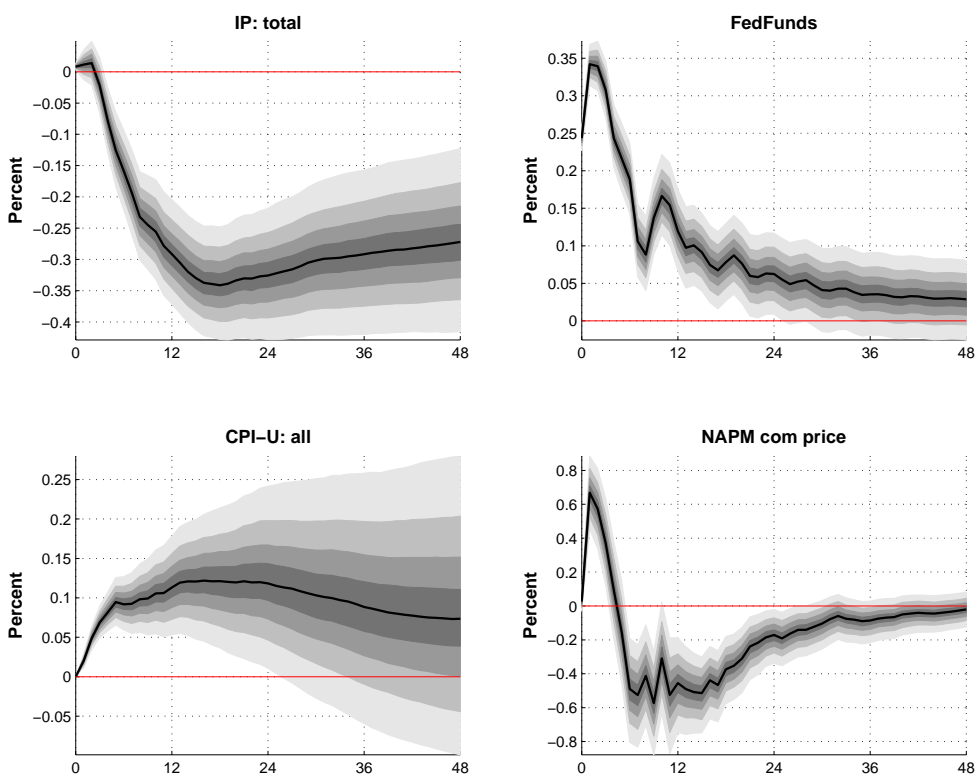
In the Figure (21)-(26) we compare the results for the output-restricted specification to the results from the benchmark specification. While it may not be surprising that we find a more pronounced decline in industrial production as a result, we also find considerably tighter confidence bands, indicating that this particular identification restriction has considerable "bite". We do not recommend imposing it, however, unless one already "believes" in the continuous, contractionary impact of a monetary policy shock, and wishes to examine its quantitative consequences, given this additional assumption.

FiguRE 21.- Selected output IRFs comparing two different sets of sign restrictions: baseline restrictions (grey) and the additional output resteiction (red) for the full sample model.
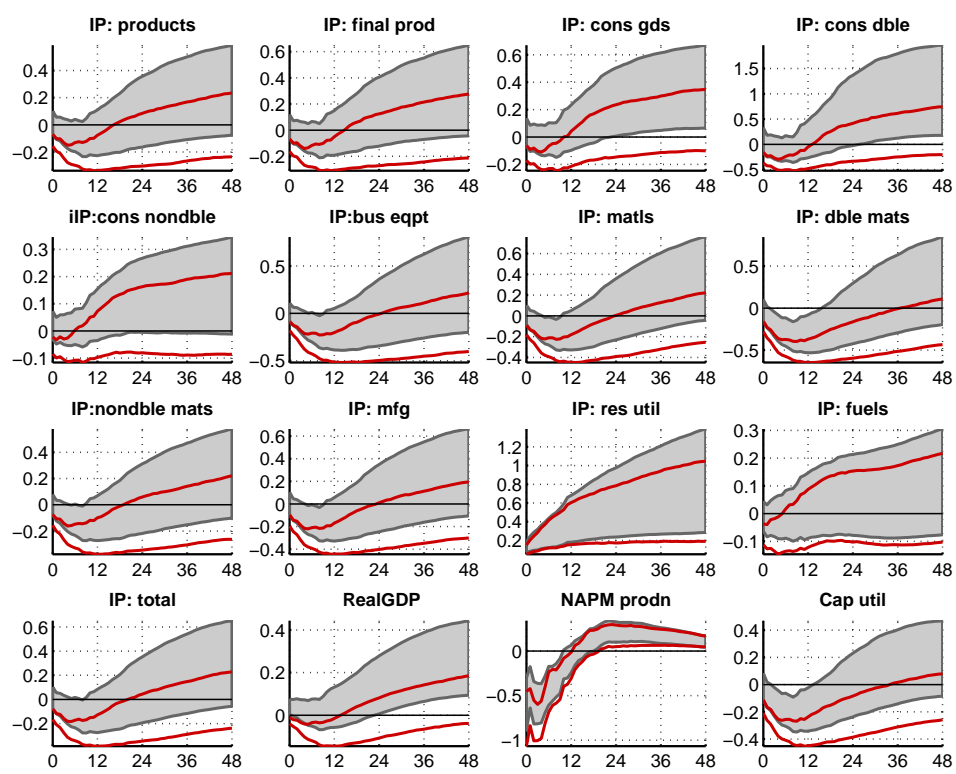
FIGURE 22.- Selected price IRFs comparing two different sets of sign restrictions: baseline restrictions (grey) and the additional output resteiction (red) for the full sample model.
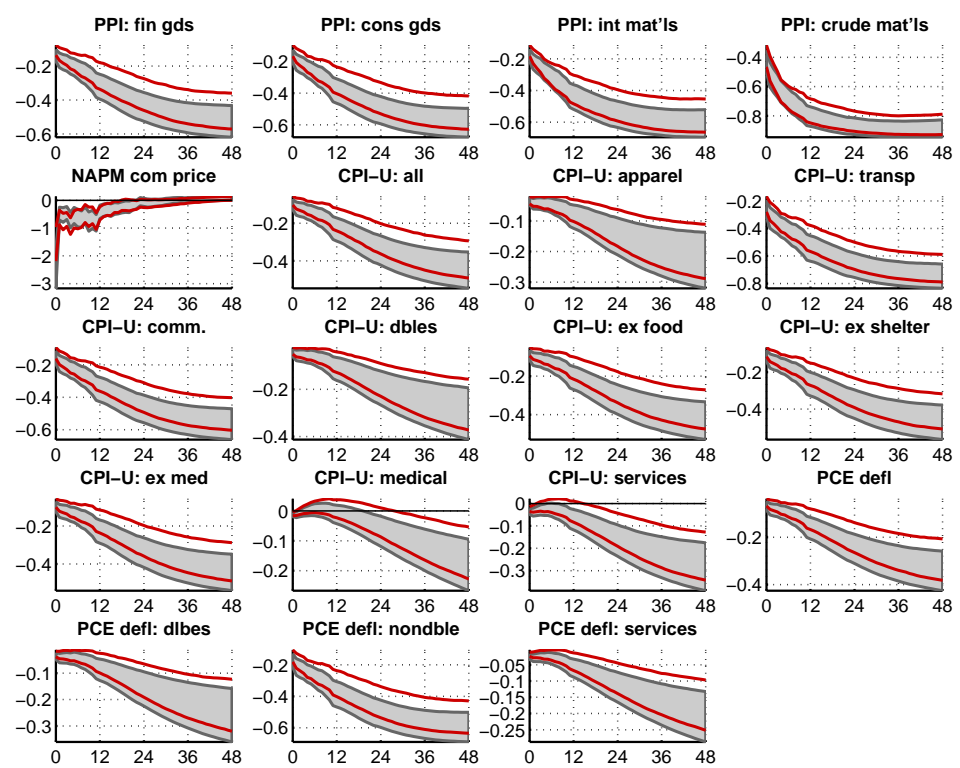
FIGURE 23.- Selected unemployment IRFs comparing two different sets of sign restrictions: baseline restrictions (grey) and the additional output resteiction (red) for the full sample model.
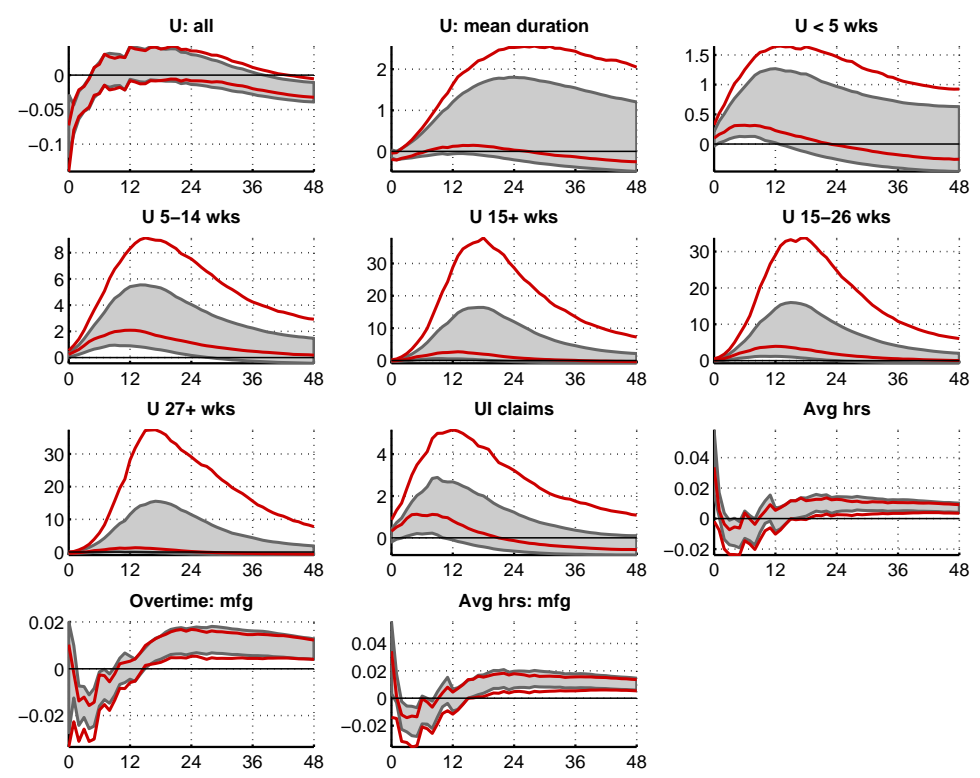
FiguRE 24.- - Selected employment IRFs comparing two different sets of sign restrictions: baseline restrictions (grey) and the additional output resteiction (red) for the full sample model.
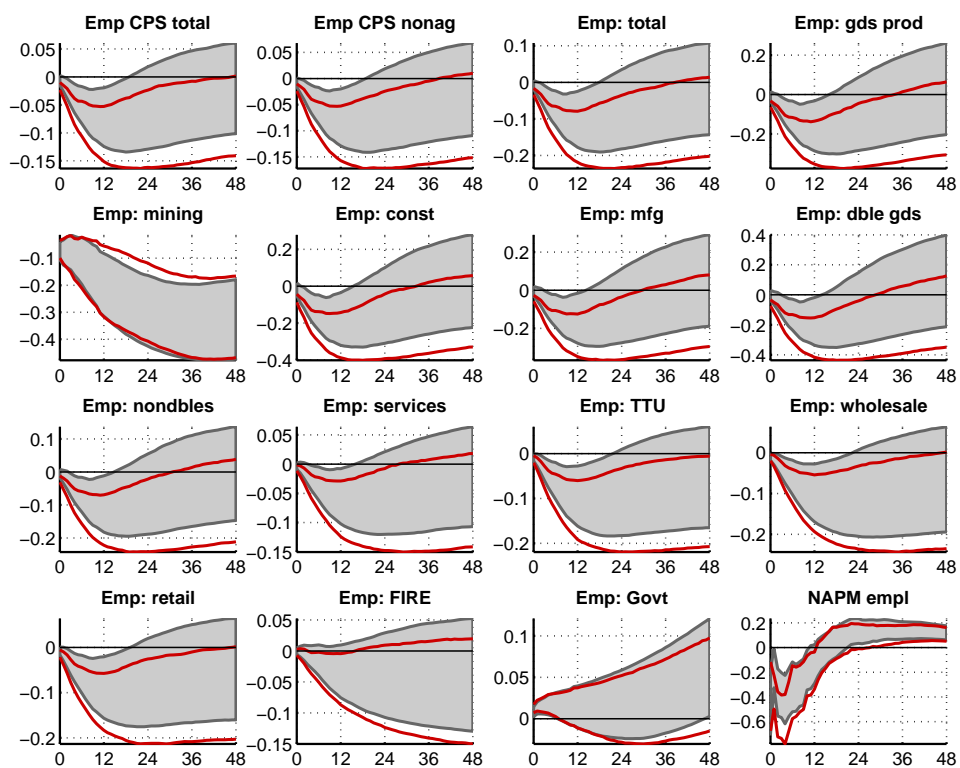
FIGURE 25.- Selected spread IRFs comparing two different sets of sign restrictions: baseline restrictions (grey) and the additional output resteiction (red) for the full sample model.
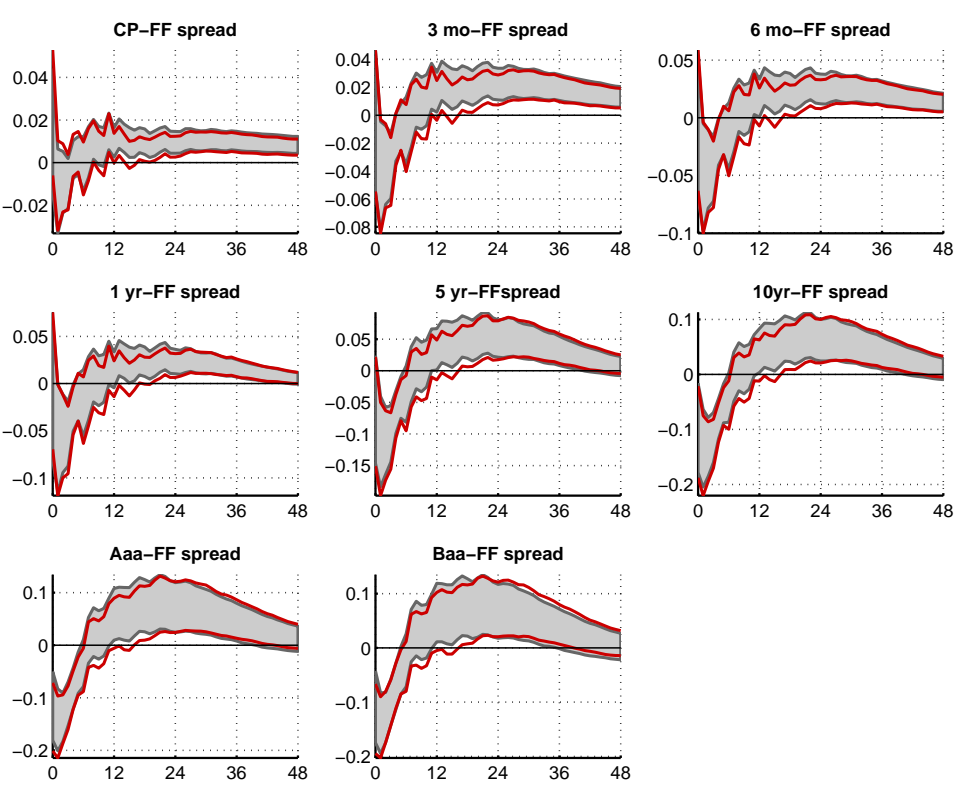
FIGURE 26. - Selected loan IRFs comparing two different sets of sign restrictions: baseline restrictions (grey) and the additional output resteiction (red) for the full sample model.
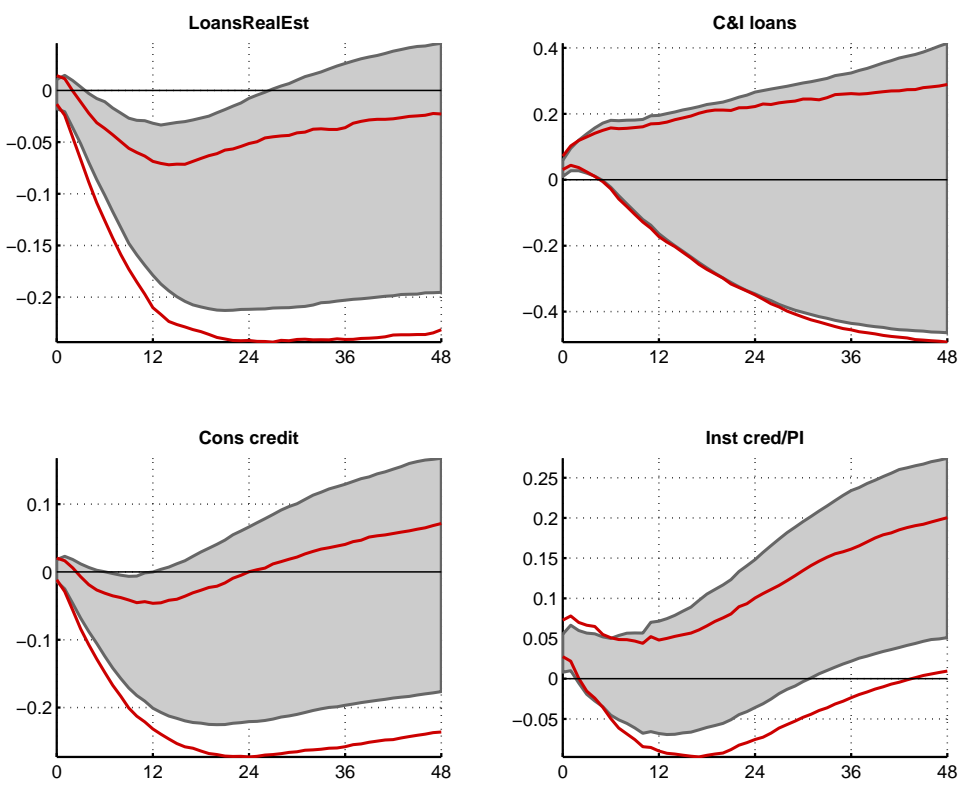


\section{APPENDIX B: VARIATIONS}

In this section, we explore and document variations on our model specification and subsamples to cover potential model and parameter instabilities. The table below summarizes all variations we considered in the paper.

TABLE III

Model VARiation.

\begin{tabular}{lll}
\hline \hline Model Version & Core VAR $\left(f_{t}^{y}\right)$ & Time Span \\
\hline \hline Baseline Model & {$[\mathrm{CPI}, \mathrm{FFR}]$} & $1960: 02-2010: 06$ \\
Variation 1 & {$[\mathrm{FFR}]$} & $1960: 02-2010: 06$ \\
Variation 2 & {$[\mathrm{CPI}, \mathrm{FFR}]$} & $1960: 02-1979: 09$ \\
Variation 3 & {$[\mathrm{FFR}]$} & $1960: 02-1979: 09$ \\
Variation 4 & {$[\mathrm{CPI}, \mathrm{FFR}]$} & $1984: 02-2010: 06$ \\
Variation 5 & {$[\mathrm{FFR}]$} & $1984: 02-2010: 06$ \\
Variation 6 & {$[\mathrm{CPI}, \mathrm{FFR}]$} & $1984: 02-2007: 01$ \\
Variation 7 & {$[\mathrm{FFR}]$} & $1984: 02-2003: 12$ \\
Variation 8 & {$[\mathrm{FFR}]$} & $1981: 09-2010: 06$ \\
\hline \hline
\end{tabular}


B.1. Figures: Variation 2

In this subsection we analyze the data for the pre Volcker period covering 1960:02-1979:09 including CPI inflation and the federal funds rate in the core VAR for the FAVAR model.

\section{FiguRE 27.- Output Responses: Benchmark Model}
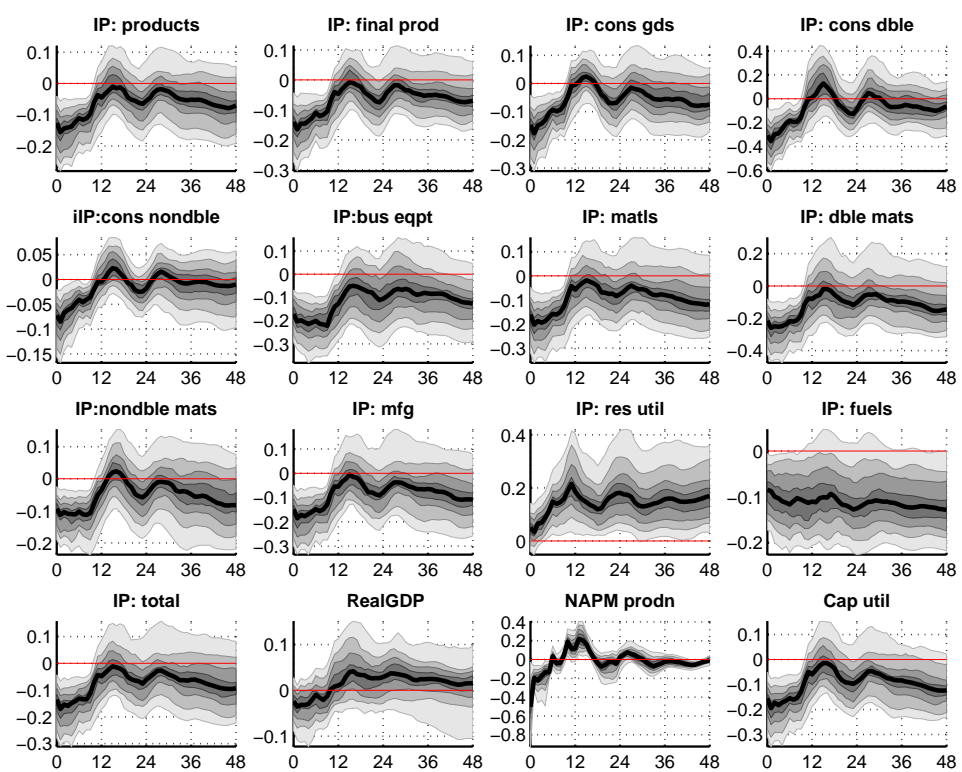

This figure provides plots of posterior IRFs for a selection of many output indicators for the benchmark model. 
Figure 28.- Price Responses: Benchmark Model
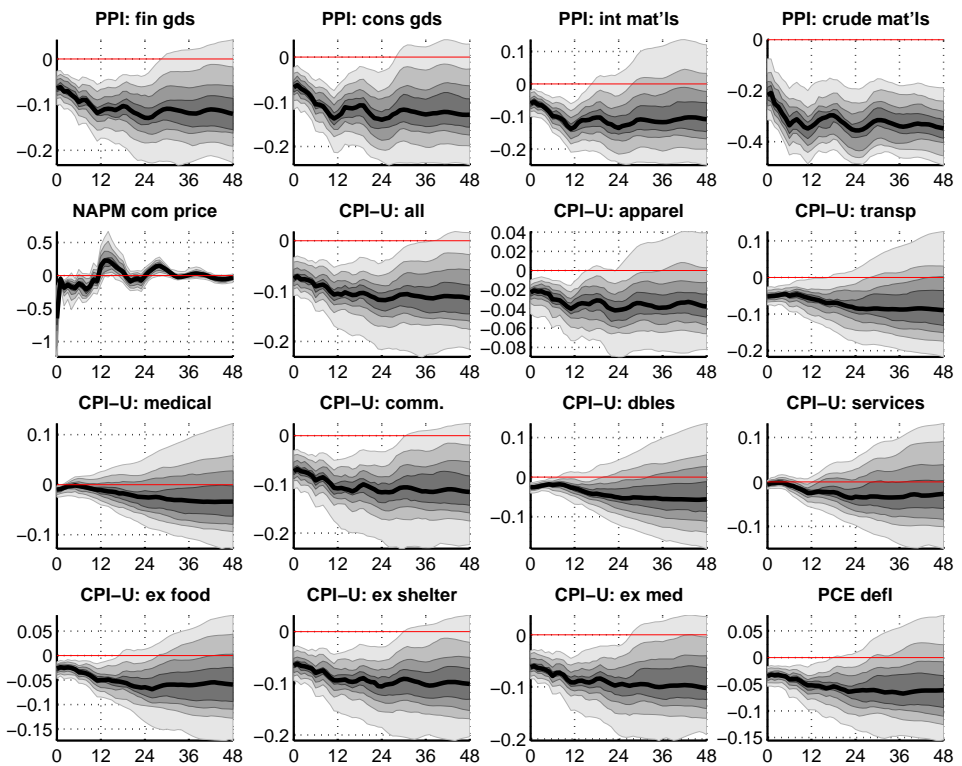

This figure provides plots of posterior IRFs for a selection of many price indicators for the benchmark model. 
Figure 29.- Unemployment Responses: Benchmark Model for the benchmark model.
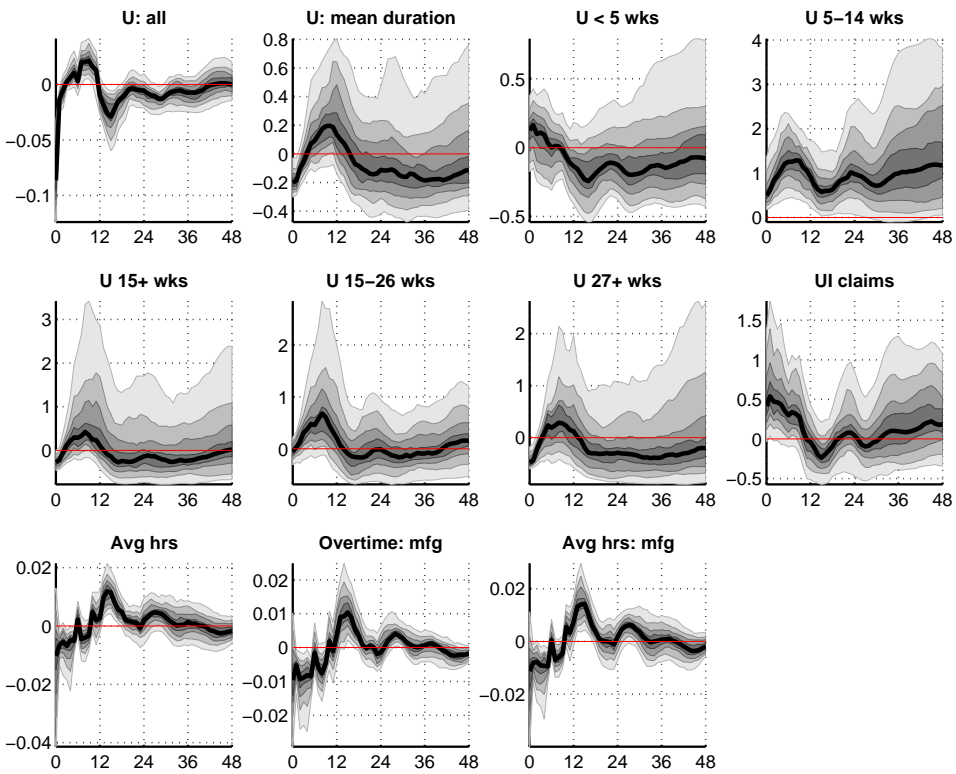

This figure provides plots of posterior IRFs for a selection of many unemployment indicators 
Figure 30.- Employment Responses: Benchmark Model
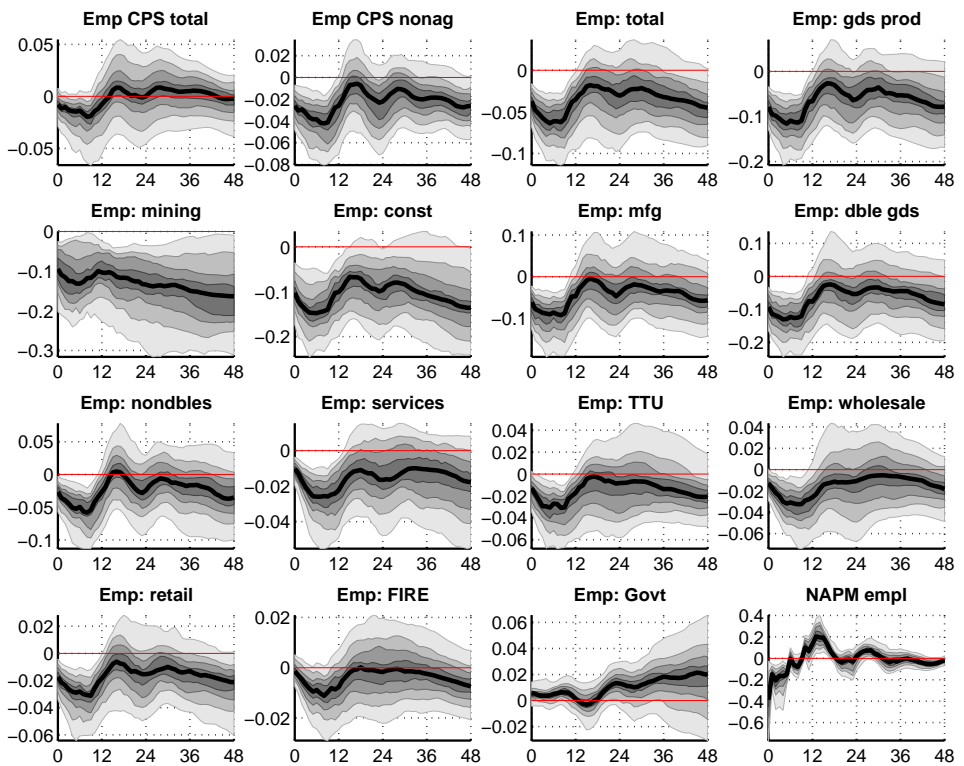

This figure provides plots of posterior IRFs for a selection of many employment indicators for the benchmark model. 
Figure 31.- Loan Responses: Benchmark Model
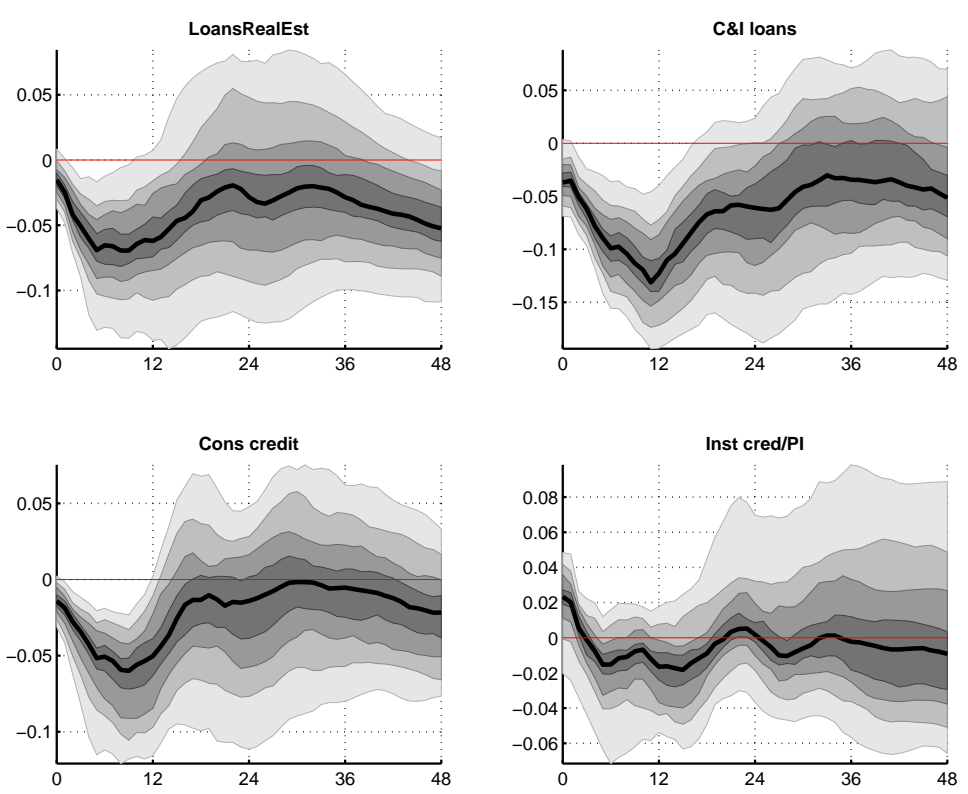

This figure provides plots of posterior IRFs for a selection of many loan indicators for the benchmark model. 


\section{FiguRE 32.- Spread Responses: Benchmark Model}
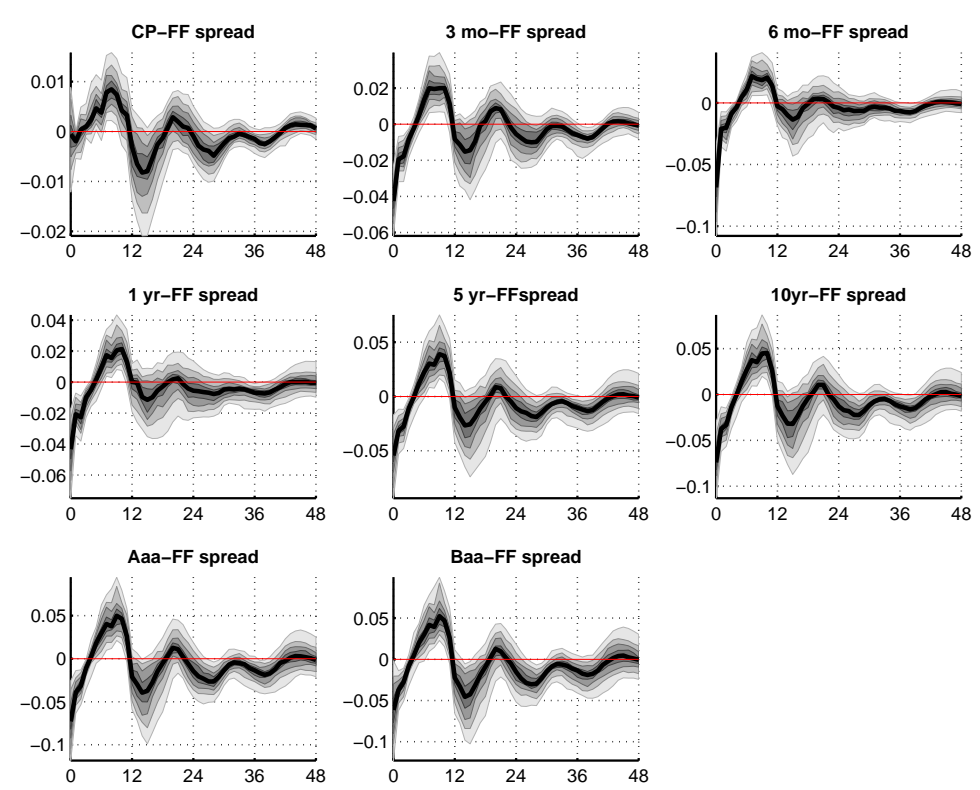

This figure provides plots of posterior IRFs for a selection of many spread indicators for the benchmark model. 


\section{B.2. Figures: Variation 3}

In this subsection we analyze the data for the pre Volcker period covering $1960: 02-1979: 09$ including only the federal funds rate in the core VAR for the FAVAR model.

\section{FiguRE 33.- Output Responses: Benchmark Model}
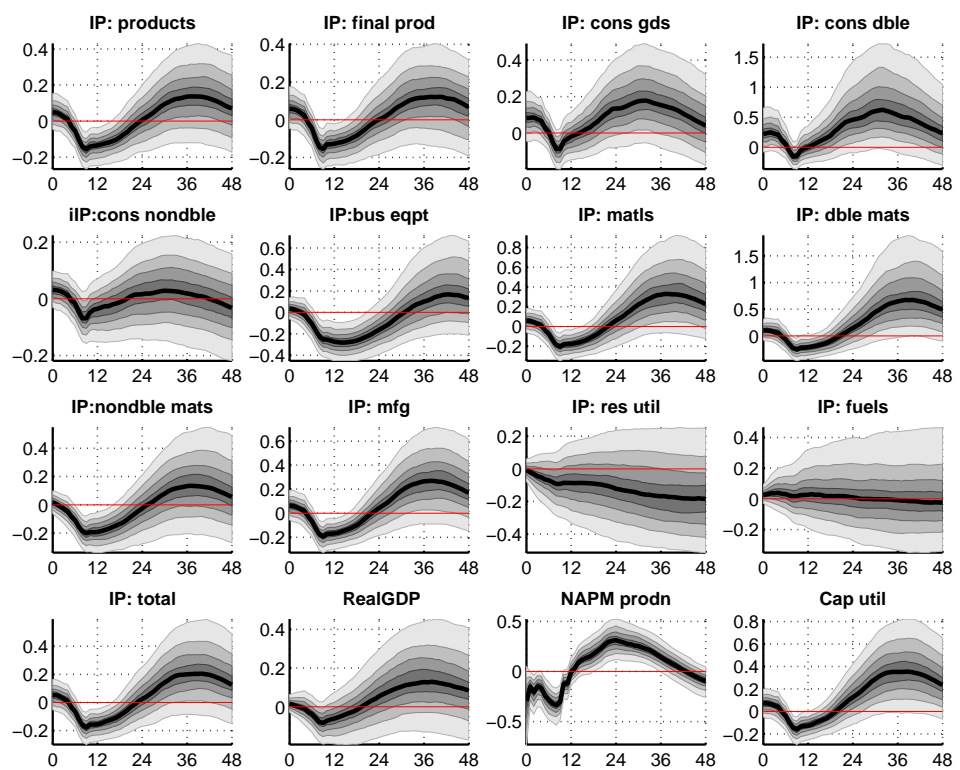

This figure provides plots of posterior IRFs for a selection of many output indicators for the benchmark model. 
FiguRE 34.- Price Responses: Benchmark Model
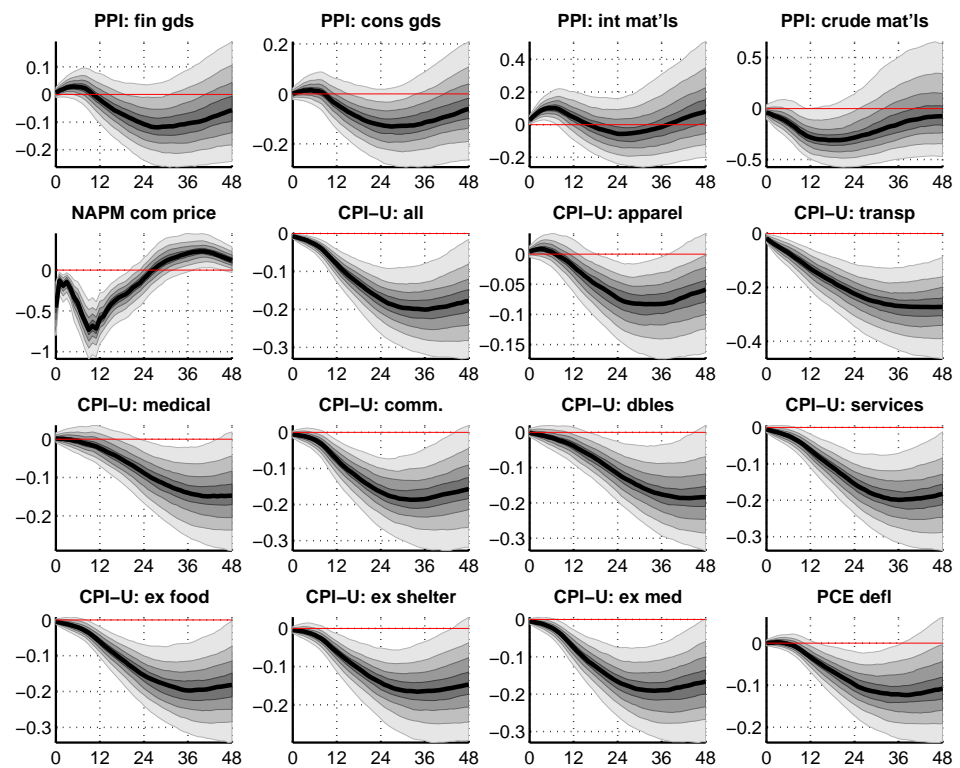

This figure provides plots of posterior IRFs for a selection of many price indicators for the benchmark model. 
Figure 35.- Unemployment Responses: Benchmark Model for the benchmark model.
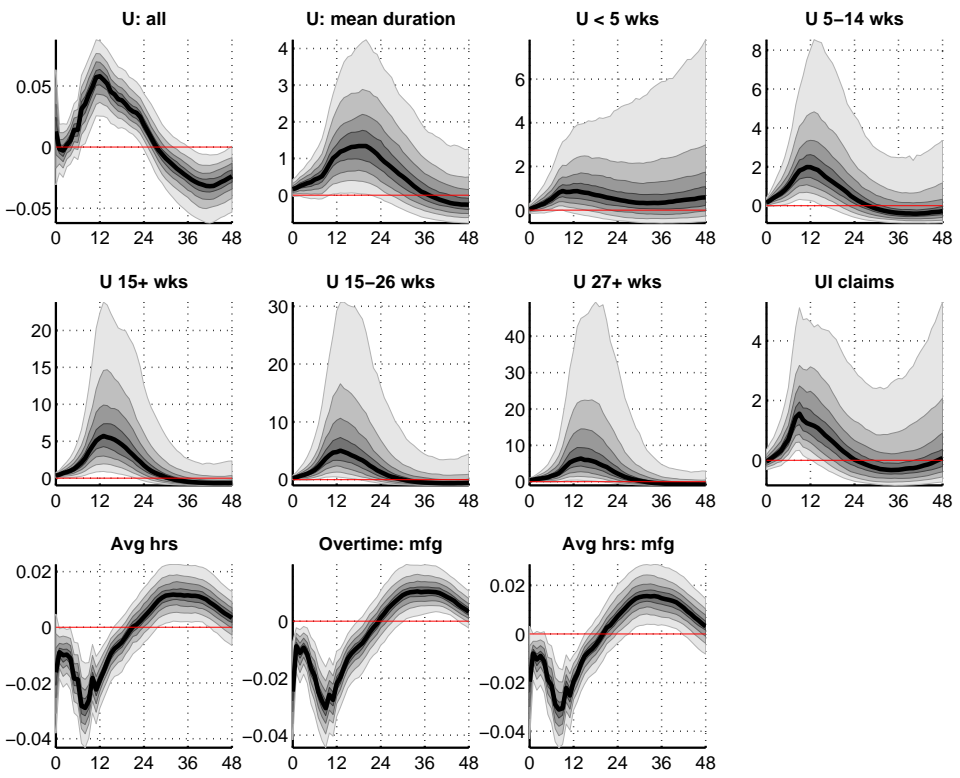

This figure provides plots of posterior IRFs for a selection of many unemployment indicators 
Figure 36.- Employment Responses: Benchmark Model
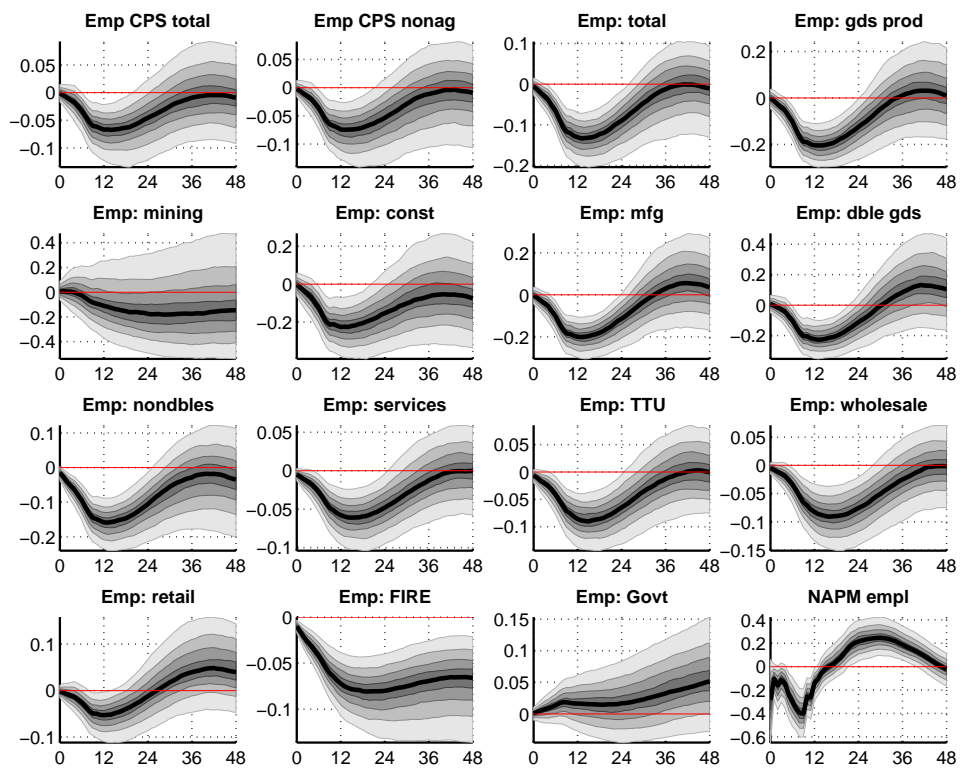

This figure provides plots of posterior IRFs for a selection of many employment indicators for the benchmark model. 


\section{Figure 37.- Loan Responses: Benchmark Model}
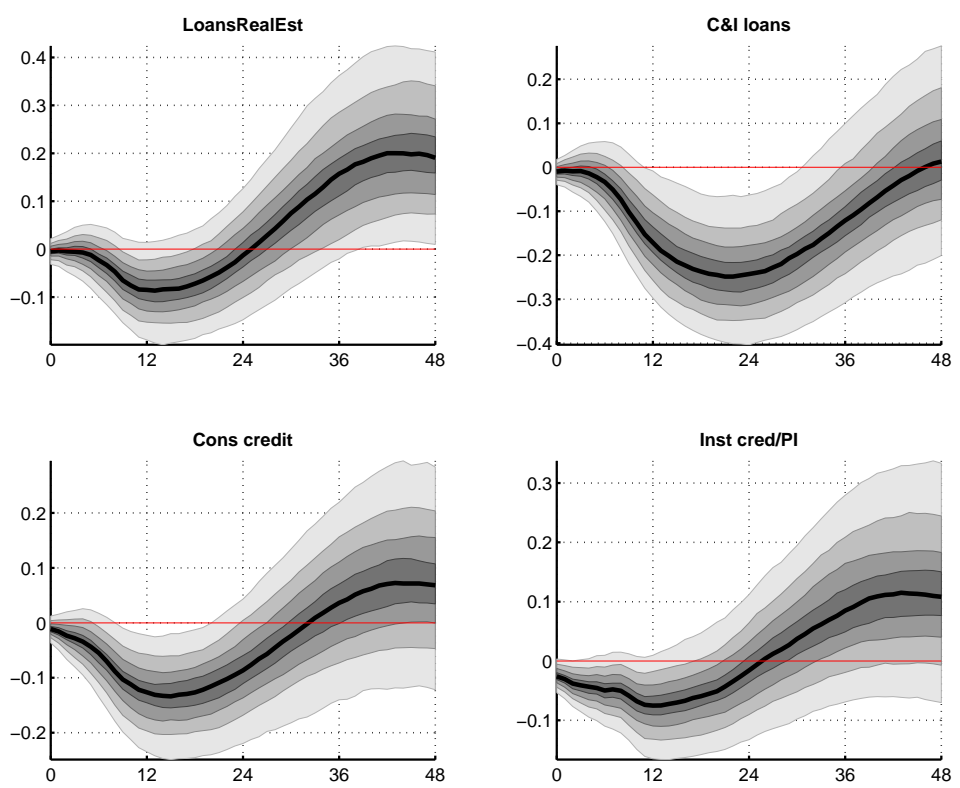

This figure provides plots of posterior IRFs for a selection of many loan indicators for the benchmark model. 


\section{FiguRE 38.- Spread Responses: Benchmark Model}
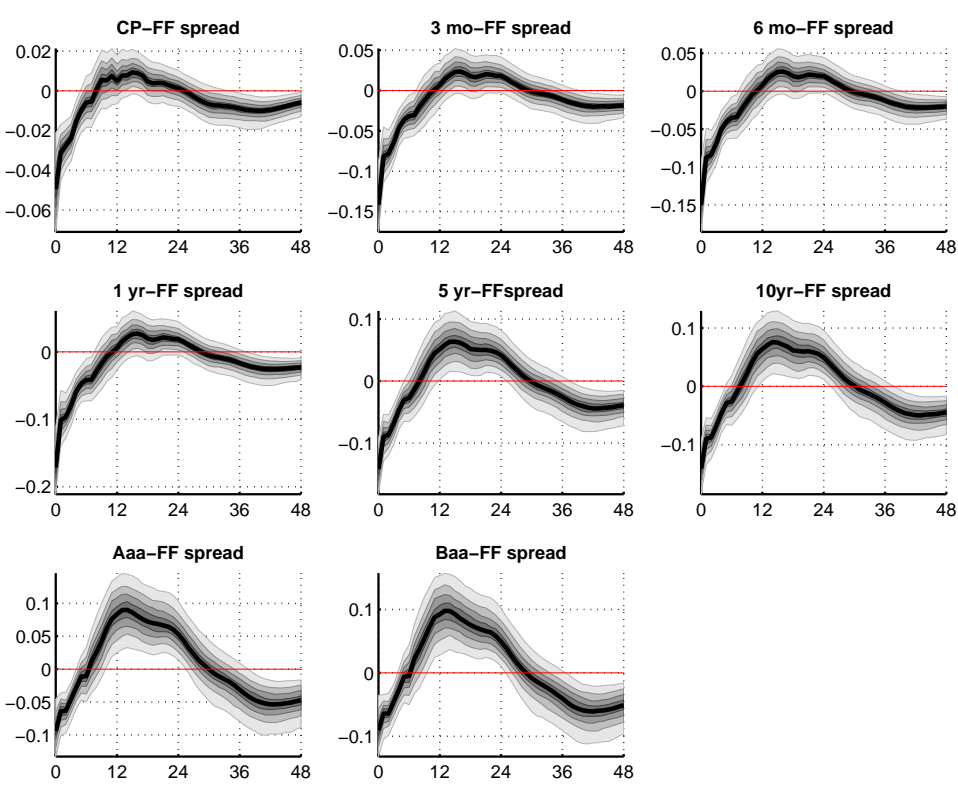

This figure provides plots of posterior IRFs for a selection of many spread indicators for the benchmark model. 


\section{B.3. Figures: Variation 4}

In this subsection we analyze the data for the post Volcker period covering $1984: 02-2010$ : 06 including the recent financial crisis with CPI inflation and the federal funds rate in the core VAR of the FAVAR model. 
Figure 39.- Output Responses: Benchmark Model
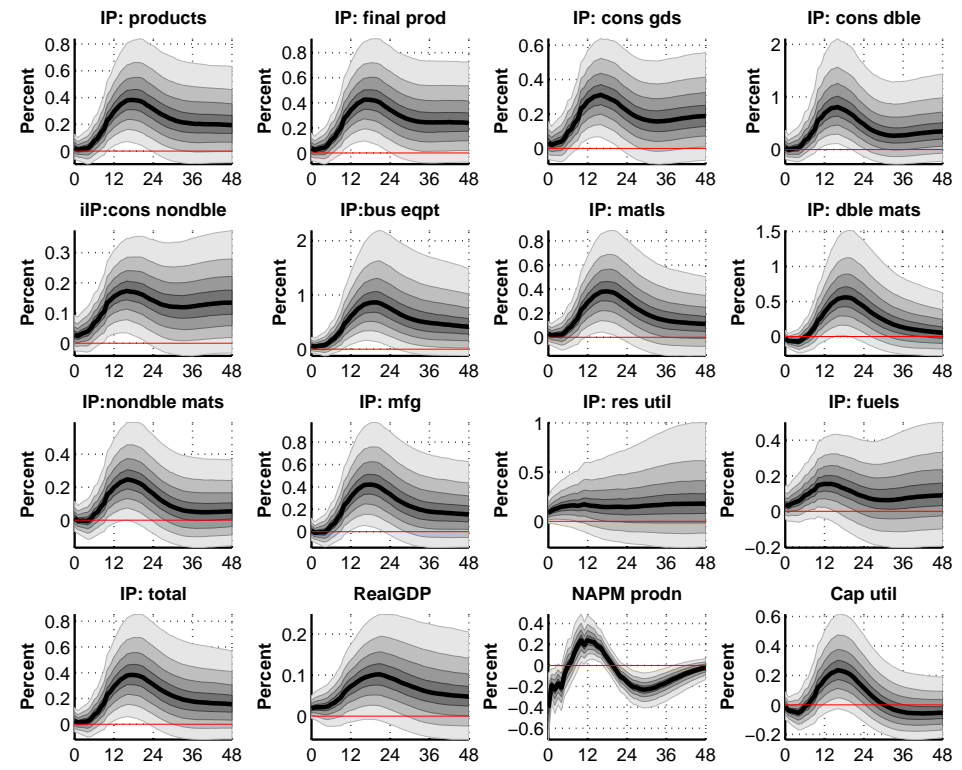

This figure provides plots of posterior IRFs for a selection of many output indicators for the benchmark model. 
Figure 40.- Price Responses: Benchmark Model
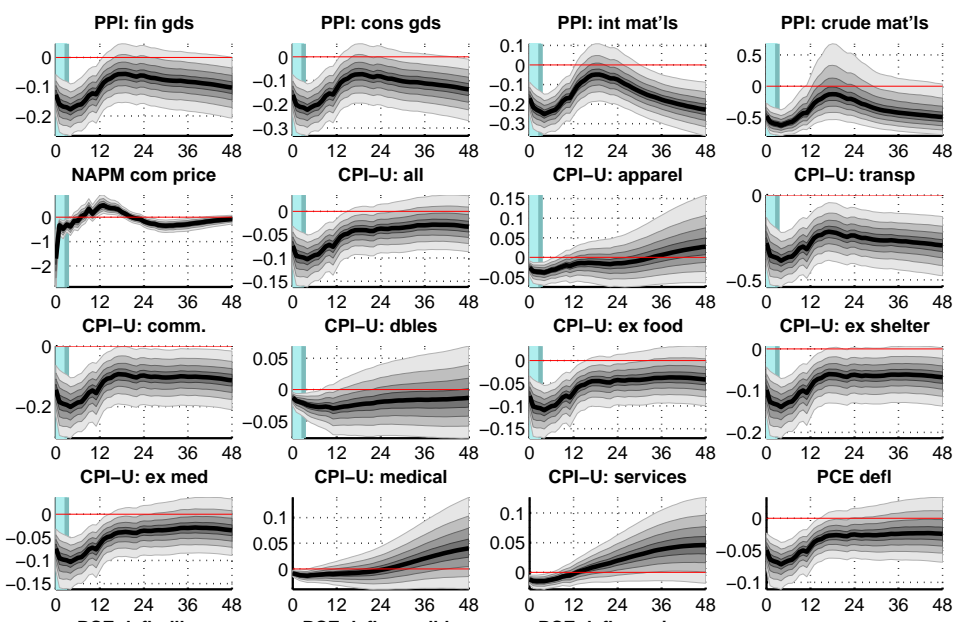

CPI-U: services
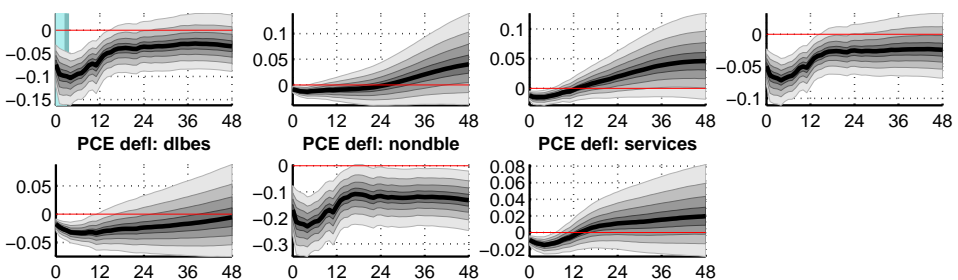

This figure provides plots of posterior IRFs for a selection of many price indicators for the benchmark model. 
Figure 41.- Unemployment Responses: Benchmark Model
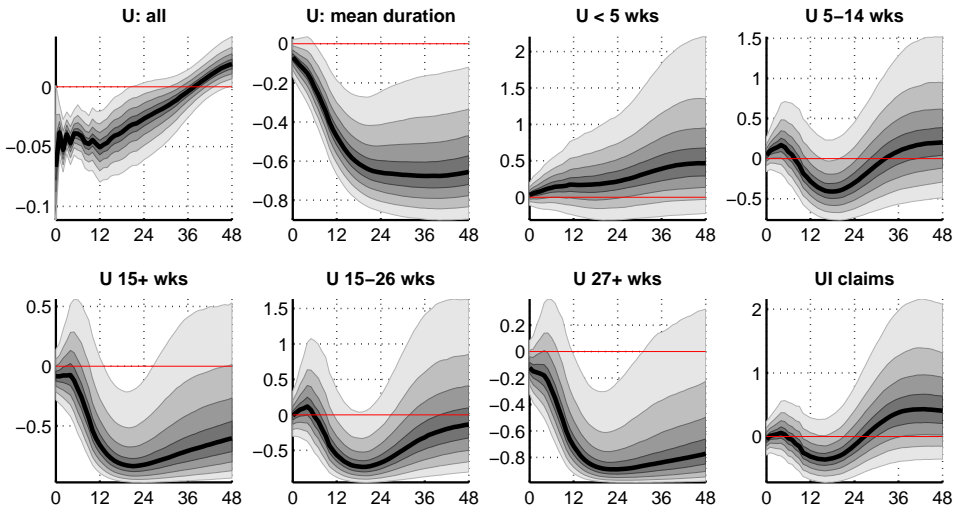

U 27+ wks
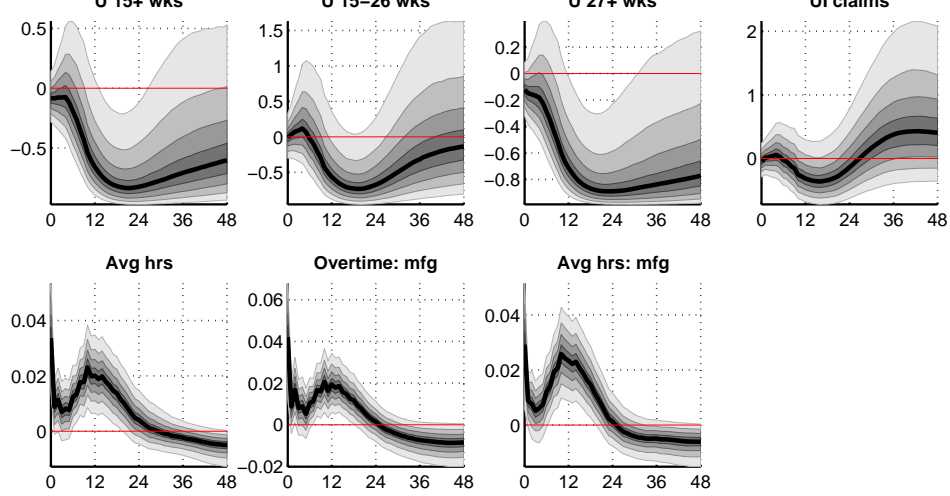

This figure provides plots of posterior IRFs for a selection of many unemployment indicators 
Figure 42.- Employment Responses: Benchmark Model
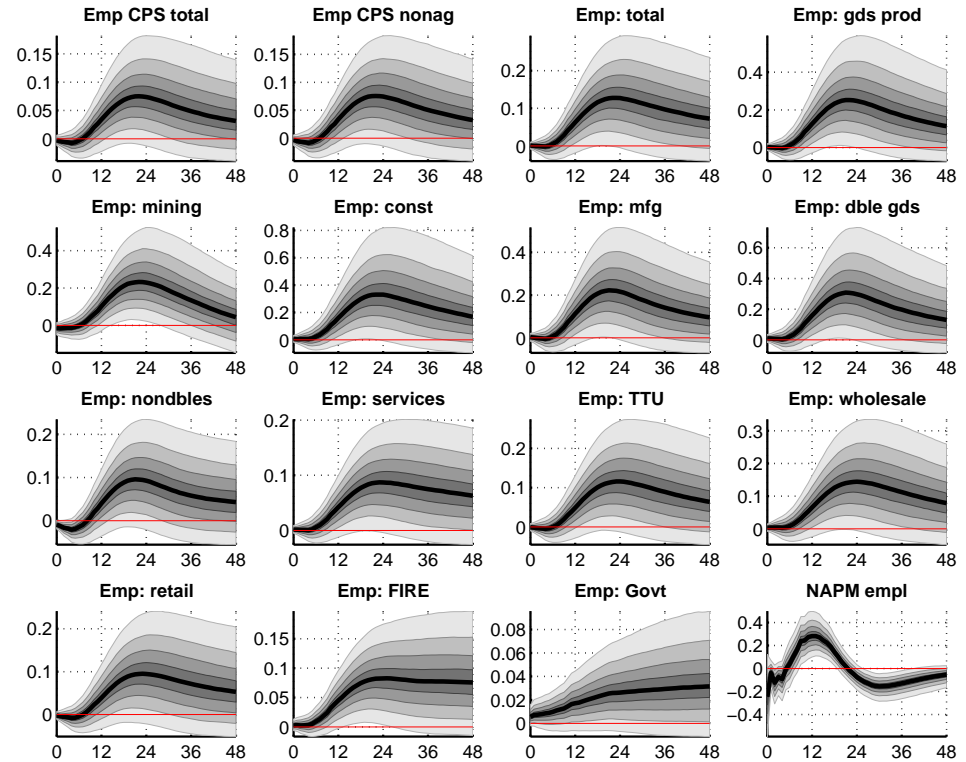

This figure provides plots of posterior IRFs for a selection of many employment indicators for the benchmark model. 


\section{Figure 43.- Loan Responses: Benchmark Model}
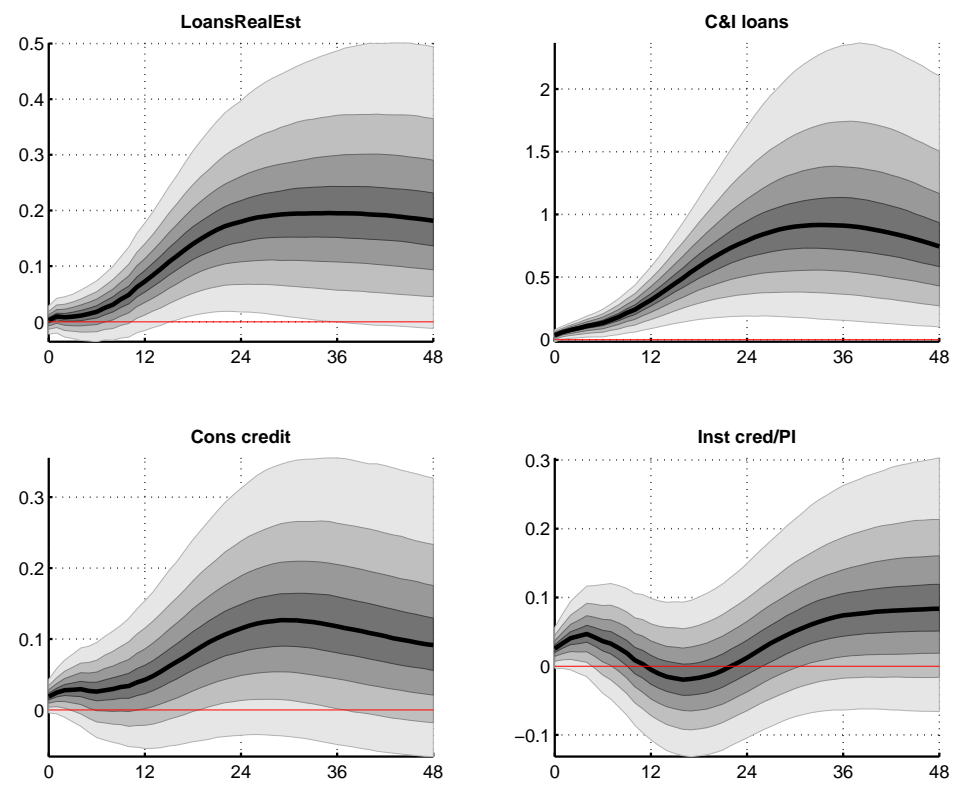

This figure provides plots of posterior IRFs for a selection of many loan indicators for the benchmark model. 


\section{FiguRE 44.- Spread Responses: Benchmark Model}
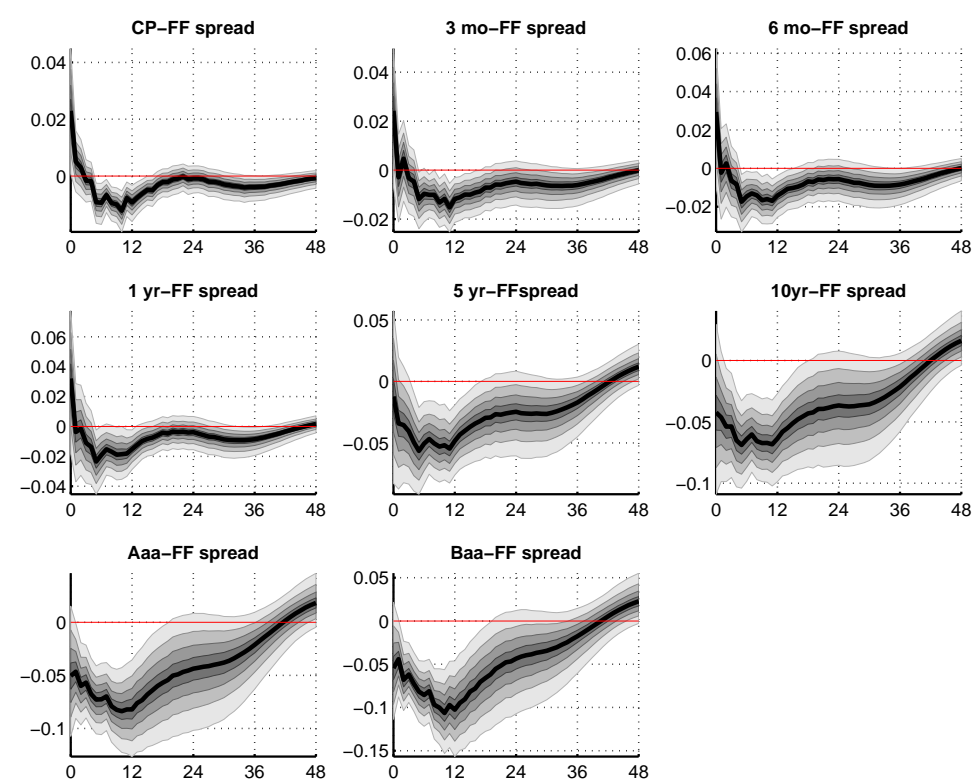

This figure provides plots of posterior IRFs for a selection of many spread indicators for the benchmark model. 


\section{B.4. Figures: Variation 5}

In this subsection we analyze the data for the post Volcker period covering 1984: 02-2010: 06 including the recent financial crisis with the federal funds rate in the core VAR of the FAVAR model. 
FiguRe 45.- Output Responses: Benchmark Model
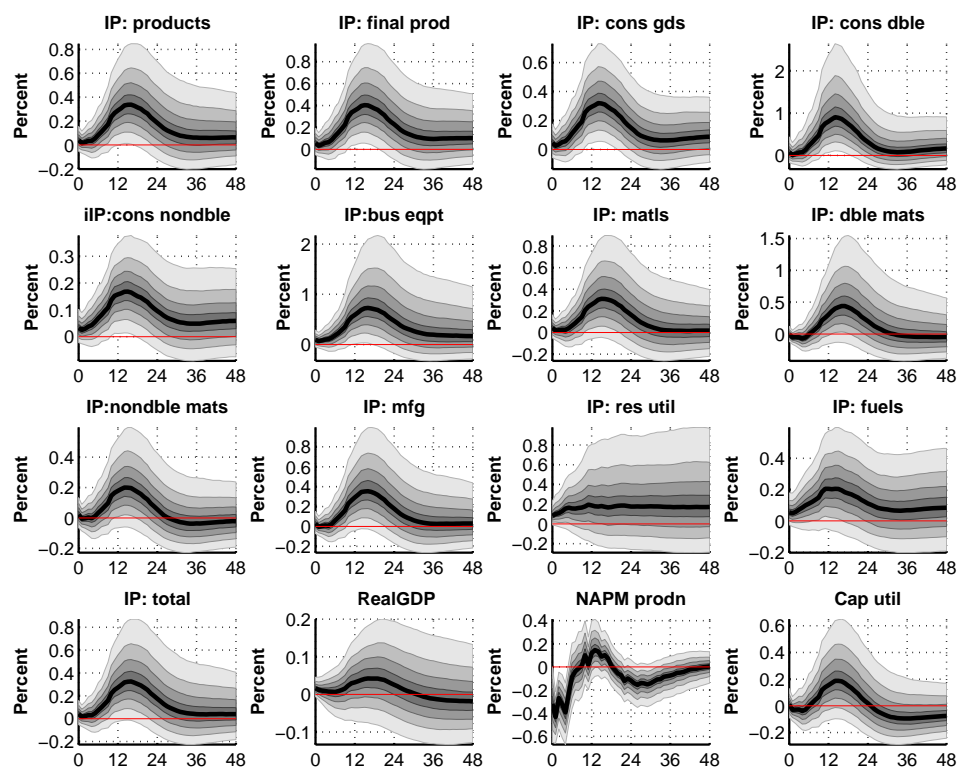

This figure provides plots of posterior IRFs for a selection of many output indicators for the benchmark model. 
Figure 46.- Price Responses: Benchmark Model

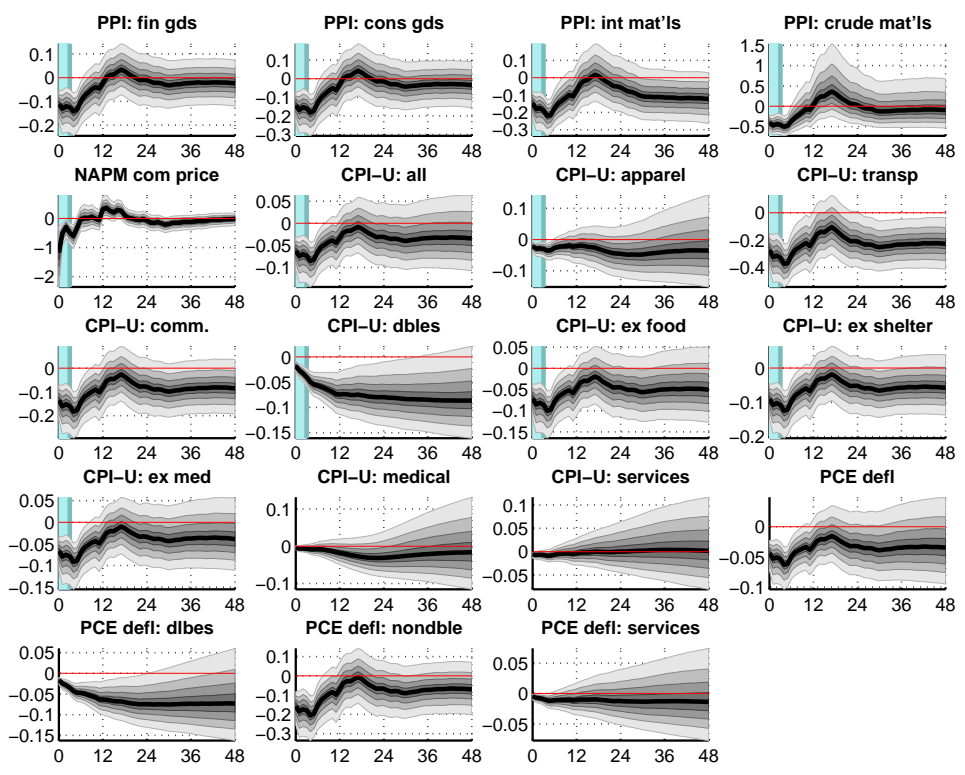

This figure provides plots of posterior IRFs for a selection of many price indicators for the benchmark model. 
Figure 47.- Unemployment Responses: Benchmark Model for the benchmark model.
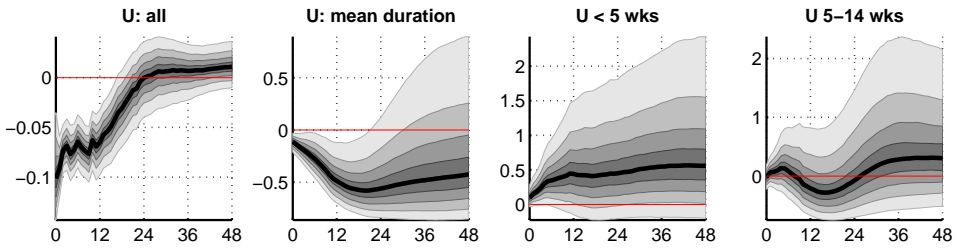

U 15+ wks

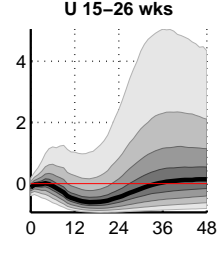

U 27+ wks
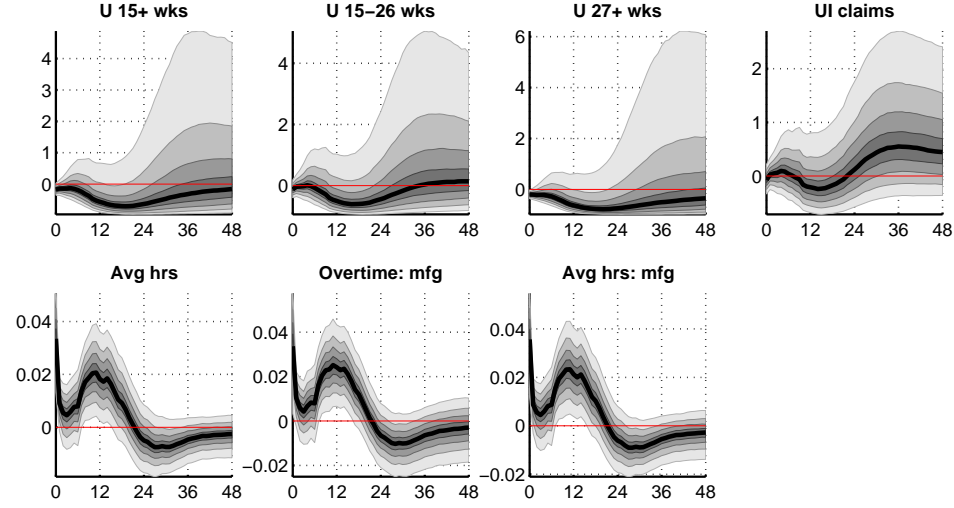

This figure provides plots of posterior IRFs for a selection of many unemployment indicators 
Figure 48.- Employment Responses: Benchmark Model
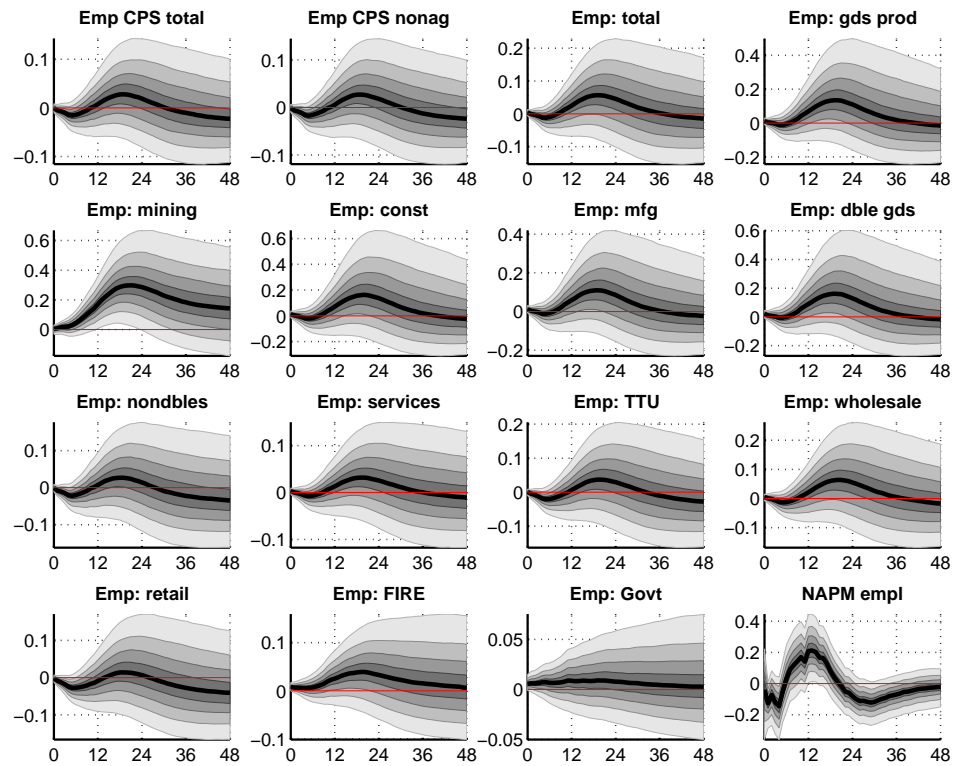

This figure provides plots of posterior IRFs for a selection of many employment indicators for the benchmark model. 
Figure 49.- Loan Responses: Benchmark Model
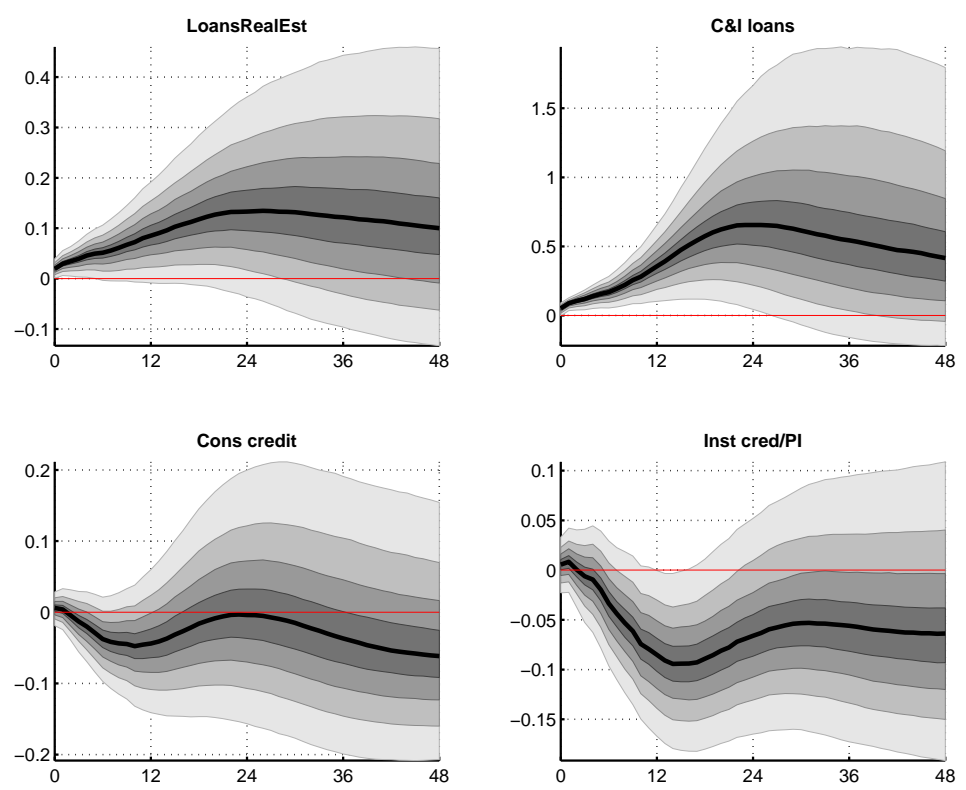

This figure provides plots of posterior IRFs for a selection of many loan indicators for the benchmark model. 


\section{FiguRE 50.- Spread Responses: Benchmark Model}
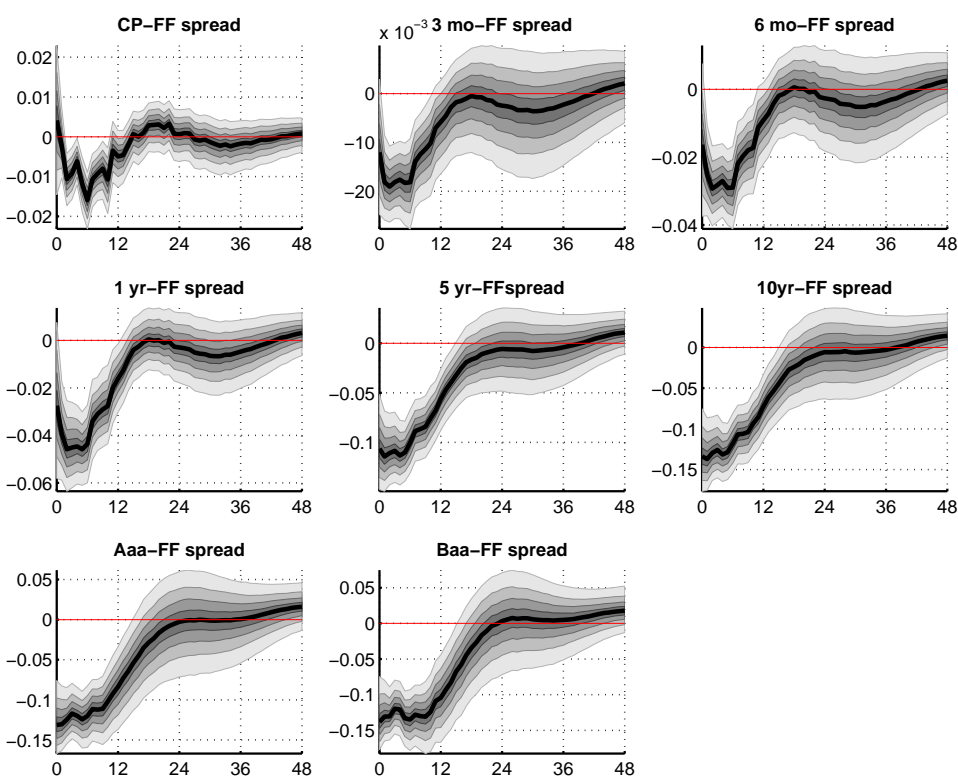

This figure provides plots of posterior IRFs for a selection of many spread indicators for the benchmark model. 


\section{B.5. Figures: Variation 6}

In this subsection we analyze the data for the post Volcker period covering 1984:02-2007: 01 including the recent financial crisis with CPI inflation and the federal funds rate in the core VAR of the FAVAR model. 


\section{Figure 51.- Output Responses: Benchmark Model}
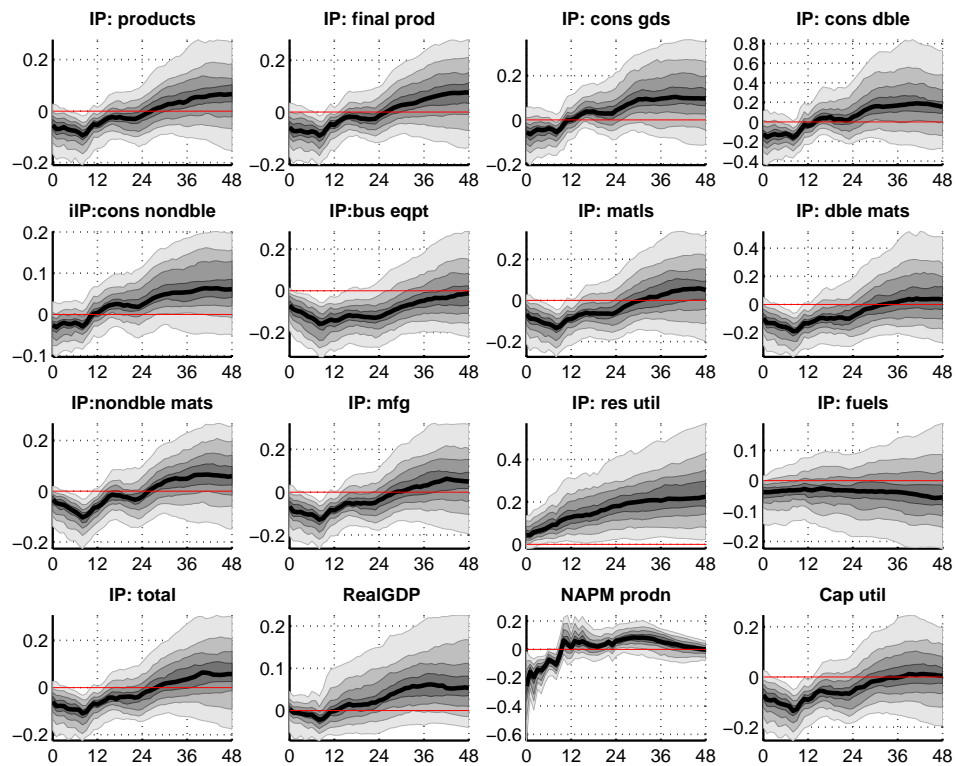

This figure provides plots of posterior IRFs for a selection of many output indicators for the benchmark model. 


\section{FiguRE 52.- Price Responses: Benchmark Model}
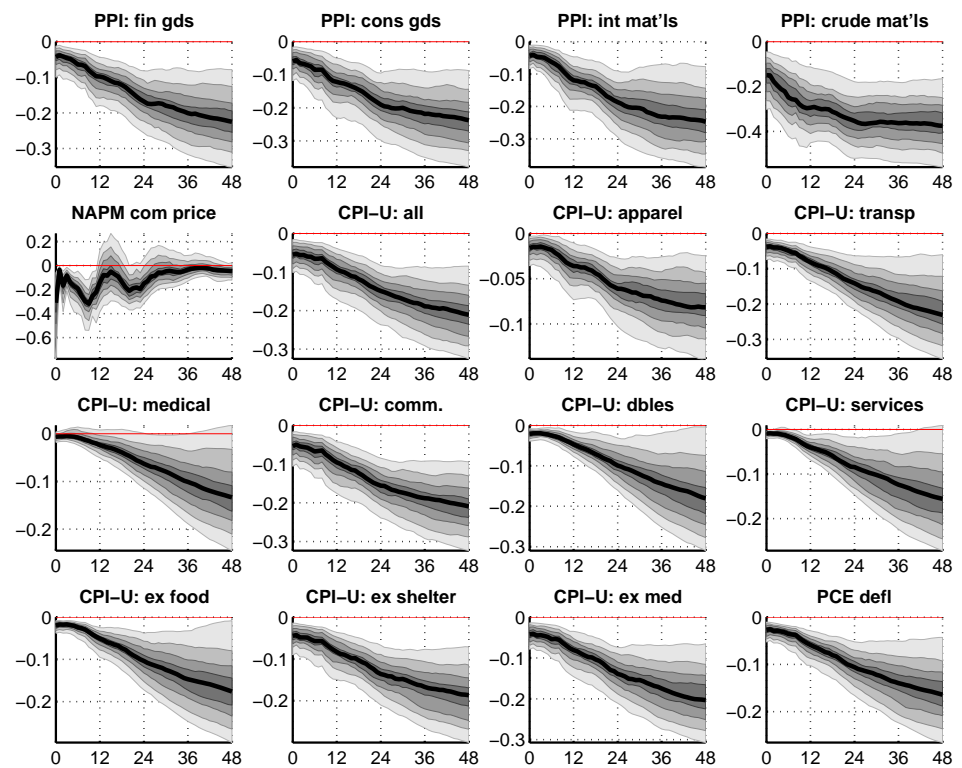

This figure provides plots of posterior IRFs for a selection of many price indicators for the benchmark model. 
Figure 53.- Unemployment Responses: Benchmark Model for the benchmark model.
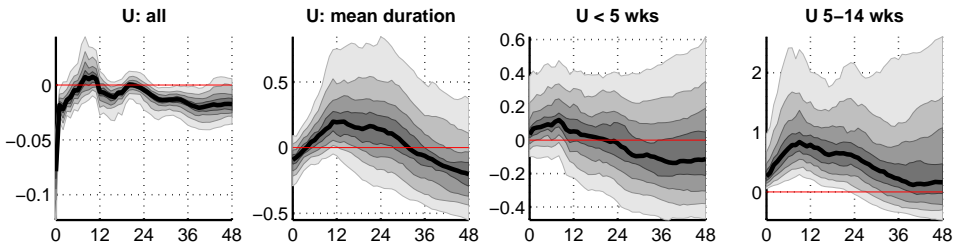

U 15+ wks

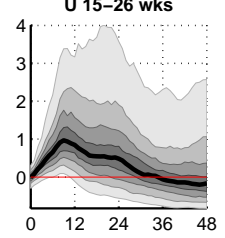

U 27+ wks
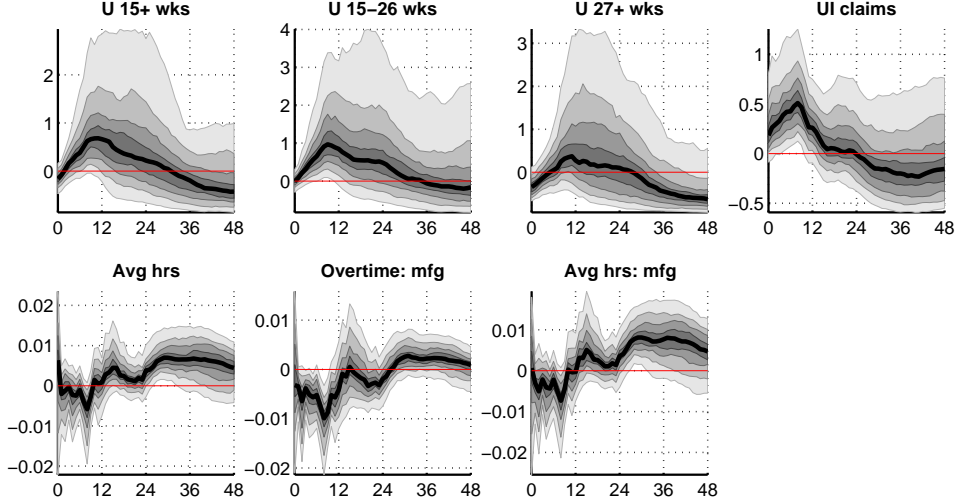

This figure provides plots of posterior IRFs for a selection of many unemployment indicators 
Figure 54.- Employment Responses: Benchmark Model
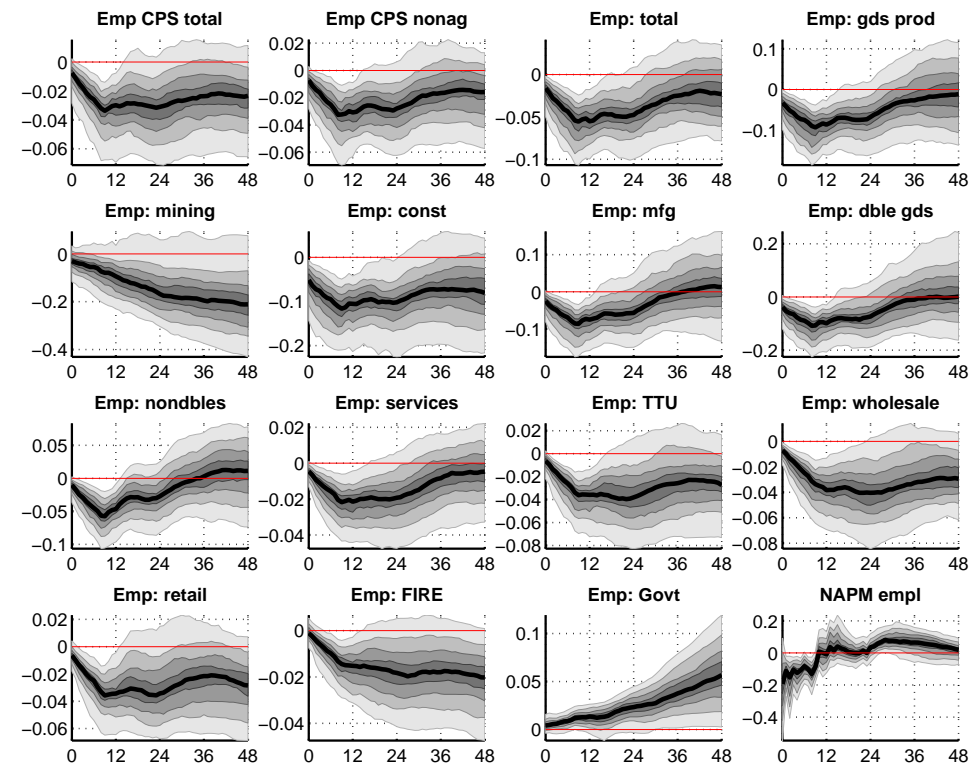

This figure provides plots of posterior IRFs for a selection of many employment indicators for the benchmark model. 


\section{Figure 55.- Loan Responses: Benchmark Model}
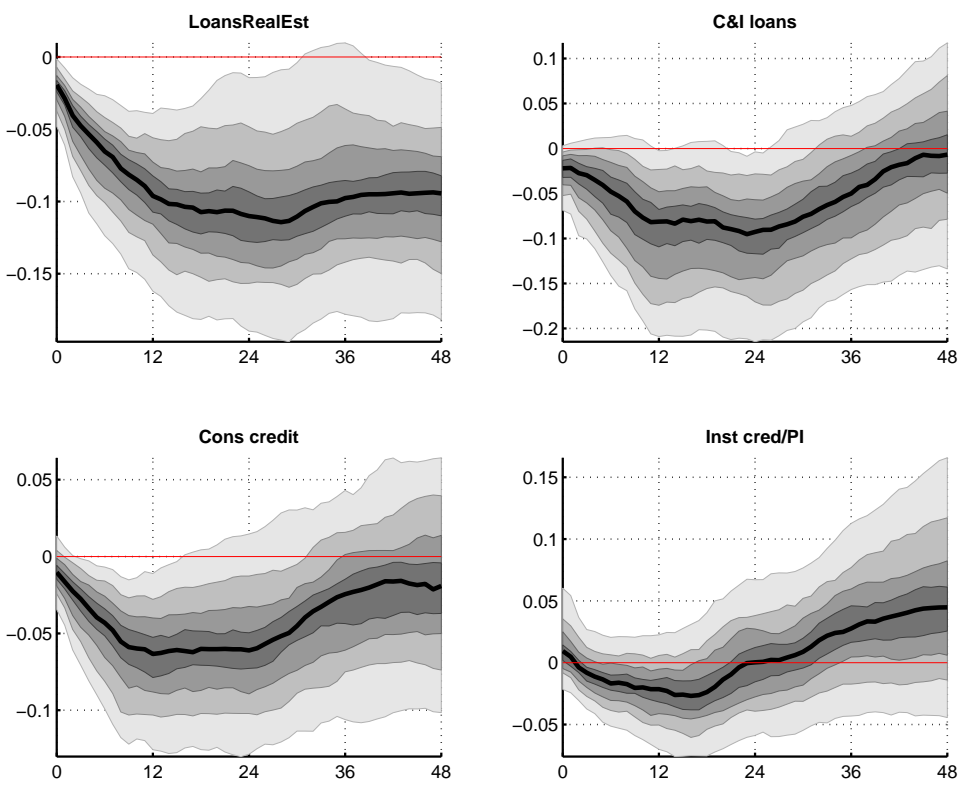

This figure provides plots of posterior IRFs for a selection of many loan indicators for the benchmark model. 


\section{FiguRE 56.- Spread Responses: Benchmark Model}
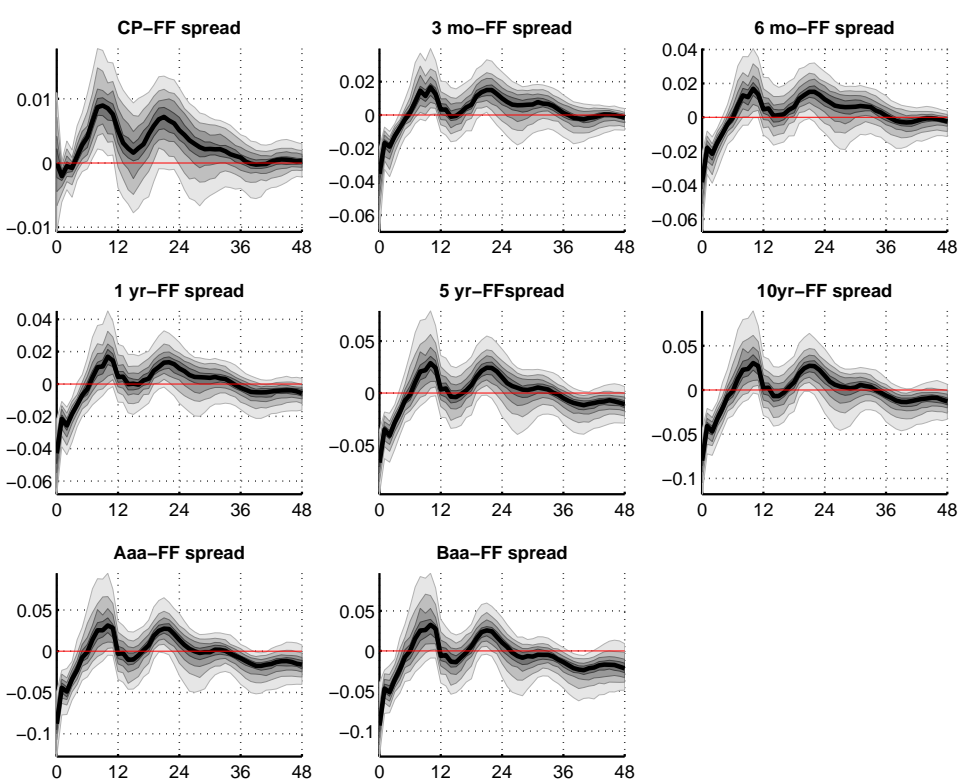

This figure provides plots of posterior IRFs for a selection of many spread indicators for the benchmark model. 


\section{B.6. Figures: Variation 7}

In this subsection we analyze the data for the post Volcker period covering 1984: 02-2003: $12^{12}$ including the recent financial crisis with CPI inflation and the federal funds rate in the core VAR of the FAVAR model.

${ }^{12}$ The end period of the sample is consistent with Stock and Watson (2005). 
FiguRe 57.- Output Responses: Benchmark Model
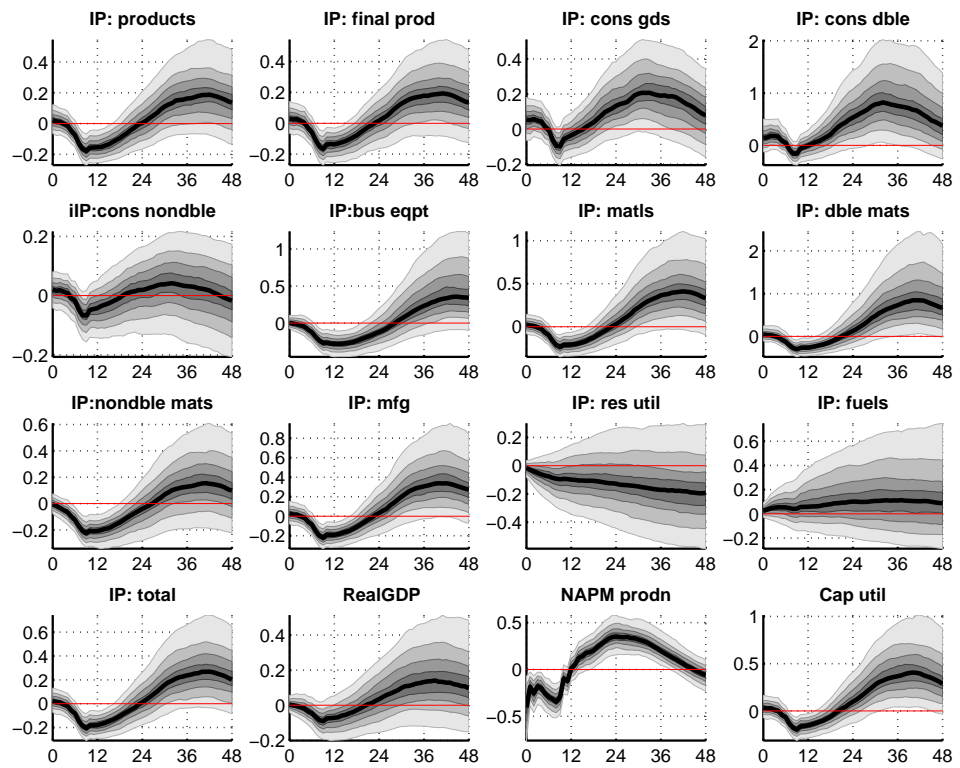

This figure provides plots of posterior IRFs for a selection of many output indicators for the benchmark model. 
Figure 58.- Price Responses: Benchmark Model
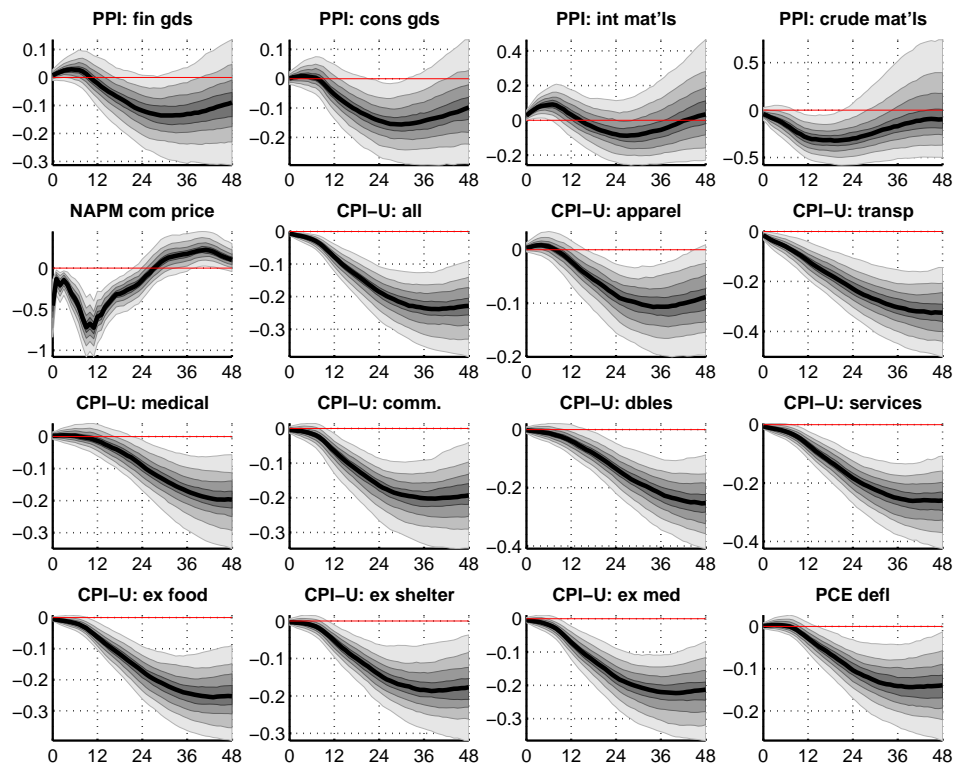

This figure provides plots of posterior IRFs for a selection of many price indicators for the benchmark model. 
Figure 59.- Unemployment Responses: Benchmark Model for the benchmark model.
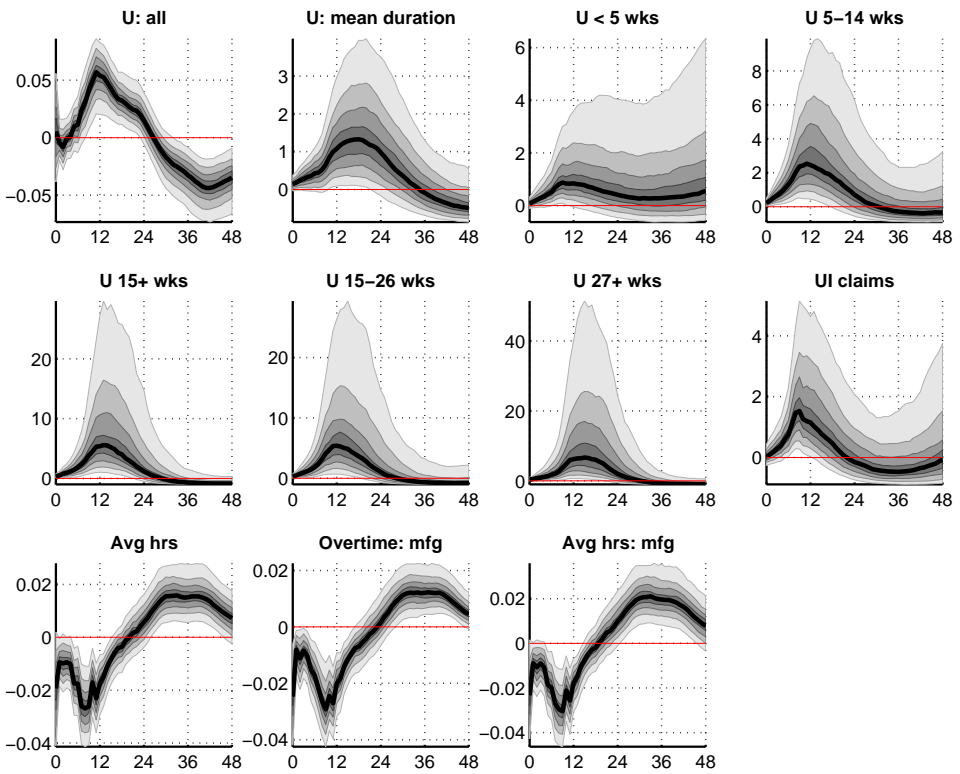

This figure provides plots of posterior IRFs for a selection of many unemployment indicators 
Figure 60.- Employment Responses: Benchmark Model
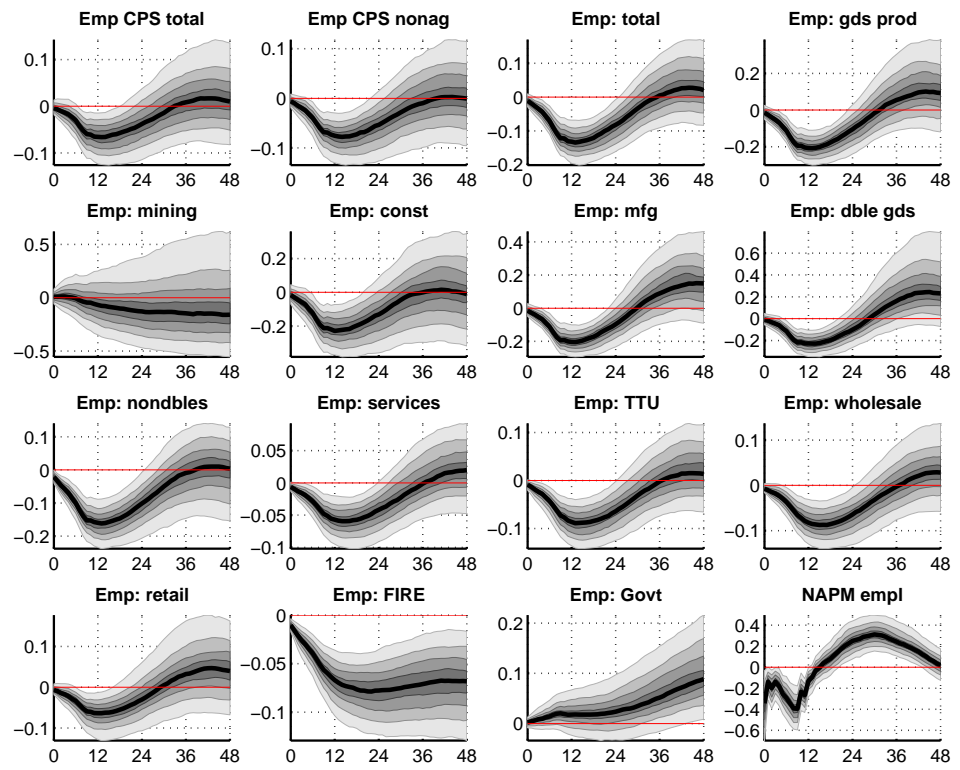

This figure provides plots of posterior IRFs for a selection of many employment indicators for the benchmark model. 


\section{Figure 61.- Loan Responses: Benchmark Model}
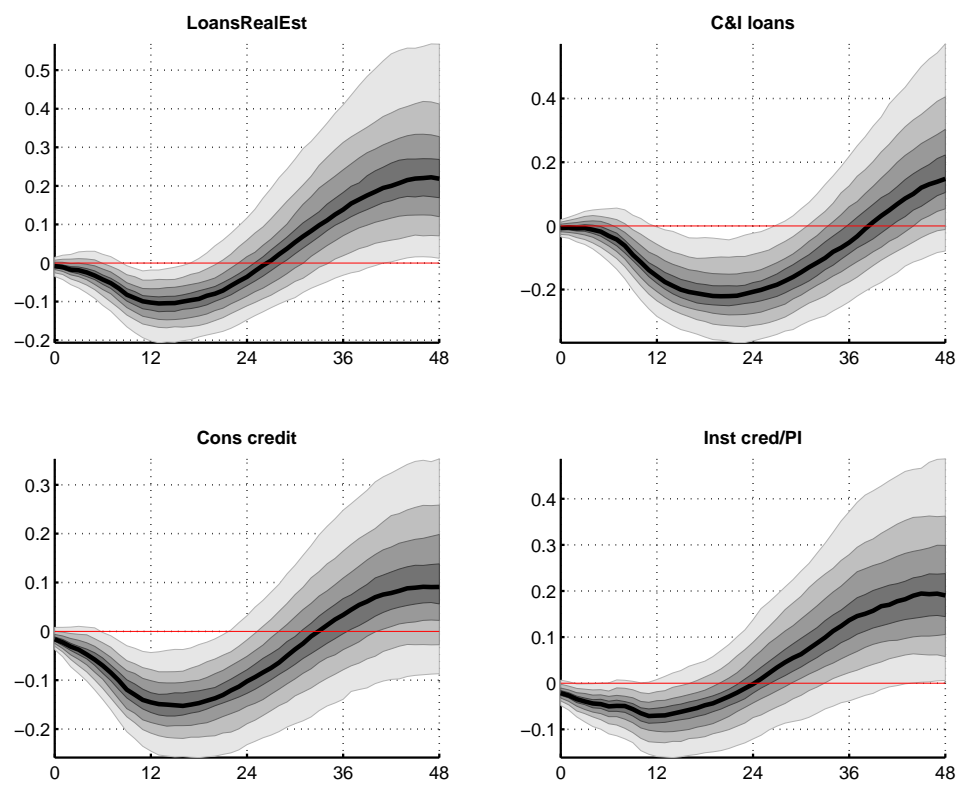

This figure provides plots of posterior IRFs for a selection of many loan indicators for the benchmark model. 


\section{FiguRE 62.- Spread Responses: Benchmark Model}
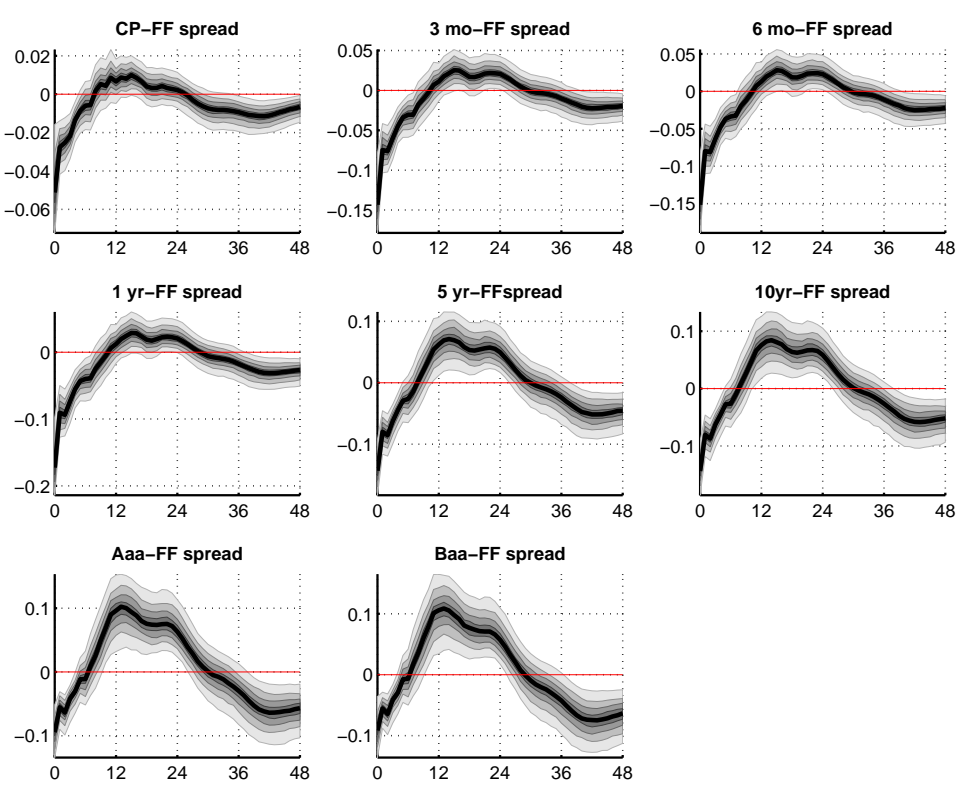

This figure provides plots of posterior IRFs for a selection of many spread indicators for the benchmark model. 